\title{
An Investment-and-Marriage Model with Differential Fecundity
}

\author{
Hanzhe Zhang*
}

September 19, 2019

\begin{abstract}
I build an equilibrium investment-and-marriage model to explain stylized facts about education, income, and marriage for Americans born in the twentieth century that had not been explained in a unified way. The most novel finding is a theoretical explanation for why women attend college at a higher rate and earn a lower average income than men. Differential fecundity and an equilibrium marriage market form the basis of my explanation. The model also accounts for gender-specific relationships between age at marriage and income, as well as the evolving relationship between age at marriage and spousal income for women. I provide evidence to support my theory and calibrate the model to conduct counterfactual analyses.
\end{abstract}

Keywords: college gender gap, earnings gender gap, marriage age, nonassortative matching JEL: C78, D1

\footnotetext{
*Department of Economics, Michigan State University; hanzhe@ msu.edu. This paper subsumes the previously circulated papers "A Marriage-Market Perspective of the College Gender Gap" and "Courtship as an Investing Game: Labor-Market and Marriage-Market Outcomes by Age at Marriage." I especially thank Phil Reny for advice throughout the project. I thank the editor, James Heckman, and the referees for their excellent suggestions. I also thank Martha Bailey, Gary Becker, Pierre-André Chiappori, Amanda Chuan, Stacy Dickert-Conlin, Jon Eguia, Scott Kominers, Corinne Low, Maria Porter, Larry Samuelson, Aloysius Siow, Hugo Sonnenschein, Mallika Thomas, Richard van Weelden, Alessandra Voena, and Ben Zou, as well as seminar participants at Chicago, Queen's, Michigan State, Drexel, University of Michigan H2D2 Research Day, Boston College, Cornell, Oregon, Venice CESIfo Summer Institute, and Texas for useful comments.
} 


\section{Introduction}

Three sets of stylized facts about education, income, and marriage for Americans born in the twentieth century have not, until now, been explained in a unified way. First, although the college gender gap reversed, the earnings gender gap persists: More women than men are going to college, but women continue to earn less than men on average. Second, the relationship between age at marriage and midlife income has been positive for women and hump-shaped for men: (i) the later a woman marries, the more she earns on average, and (ii) men who married in their mid-twenties have a higher average income than those who married earlier or later. Third, the relationship between age at marriage and spousal income for women has been hump-shaped and changing: (i) women who married in their mid-twenties have a higher average spousal income than those who married earlier or later, and (ii) women who married in their thirties have a lower average spousal income than those who married at around 20 in the pre-1960 birth cohorts, but a higher one in the post-1960 birth cohorts.

I build an investment-and-marriage model to explain these facts in a unified way. The key gender difference in the model is fecundity: Women remain fertile for a shorter period than men. In particular, I provide a new explanation for the opposite college and earnings gender gaps. It is natural to think that women's shorter fertility span deters them from making income-improving investments, but I highlight an equilibrium marriage-market effect that results in more women than men going to college.

The model proceeds as follows. A new generation of men and women enters the economy at the beginning of each of the infinitely many discrete periods. Individuals differ in their abilities to realize a high lifetime income from an investment. They make investments over three periods, as illustrated in Figure 1. Individuals with sufficiently low abilities forgo college and marry immedi-

\section{Figure 1: Investment and marriage decisions}

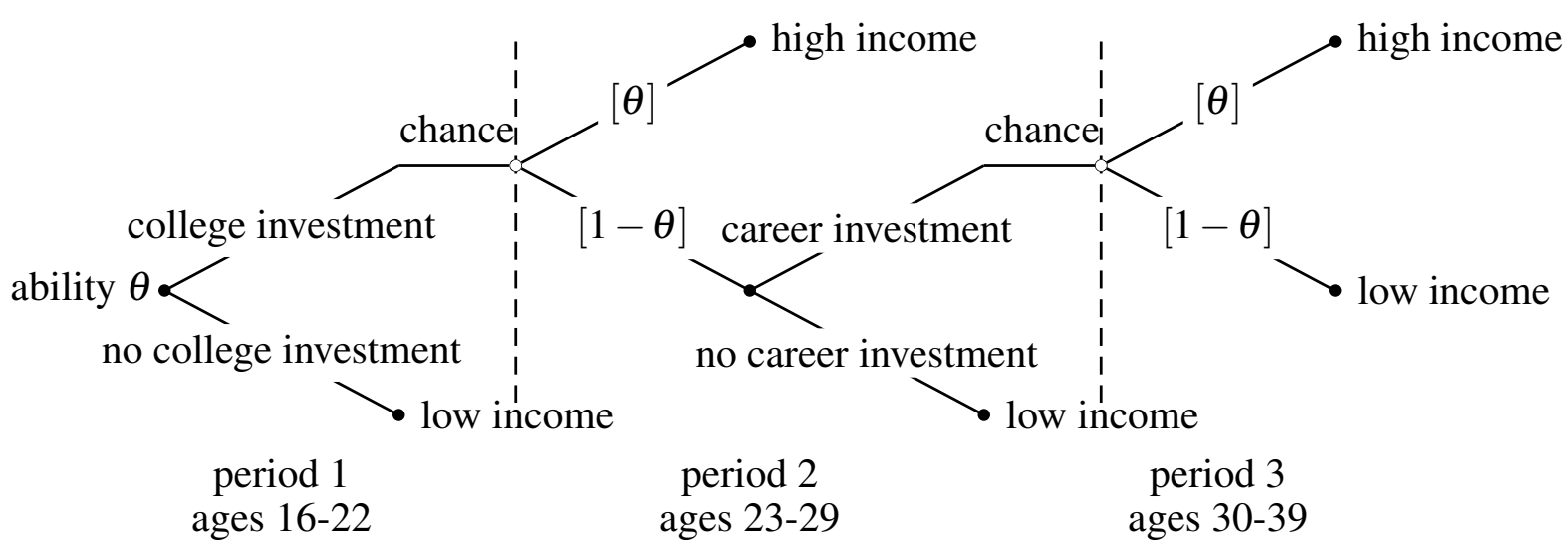

ately. Those with sufficiently high abilities go to college and realize an uncertain income return. Those who realize a high income marry. Those who realize a low income can take another income 
draw by making what I call a career investment (obtaining additional education, receiving additional training, or searching for a new job). However, this career investment is costlier for women, because it delays fertility to a less fertile period of life. Once the returns to this investment realize, all men and women marry.

Because career investment is costlier for women, only the highest-ability women who realized a low income after college will make a career investment, while all men who realized a low income after college will make a career investment. Therefore, (i) the lowest-ability individuals marry in the first period and earn the lowest incomes, (ii) all of the women who realized a high income after college and intermediate-ability women who realized a low income after college marry in the second period, while all of the men who realized a high income after college marry in the second period because all of those who realized a low income after college choose to make a career investment, and (iii) the highest-ability women who realized a low return after college make a career investment and marry in the third period with a high income realized with high probabilities, while all of the men who made a career investment marry in the third period with a high income realized with relatively lower probabilities. Hence, there is a positive relationship between age at marriage and income for women and a hump-shaped relationship for men.

Turning to the marriage market, we can produce the hump-shaped relationship between age at marriage and spousal income for women. Even though women who marry in the third period have a higher average income than those who marry in the second period, they are less fertile. Lower fertility may hurt the marriage prospects of those who marry in the third period. If the effect is sufficiently large, the average spousal income for women who marry in the third period is the lowest, matching the pattern in the pre-1960 birth cohorts; if the effect is sufficiently small, the average spousal income for them is higher than that for women who marry in the first period, matching the pattern in the post-1960 birth cohorts.

Most surprisingly, in the unique equilibrium of the model more women than men go to college and fewer women than men earn a high income. The reason more women than men go to college is subtle, and operates through an equilibrium marriage-market channel. As pointed out above, because of differential fecundity, college women are less likely than college men to make career investments. Consequently, high-income women are scarcer than high-income men in the marriage market. High-income women are then more "valuable" than high-income men in the marriage market, thus providing an endogenously higher marriage-market incentive for women to go to college. Therefore, in summary, more women than men go to college because of an endogenously higher marriage-market incentive, while fewer women than men end up with high incomes because of their shorter fertility span.

I use a simple theory to match a large number of stylized facts, and make three contributions. First, I provide the first explanation of college and earnings gender gaps using only one gender 
difference (differential fecundity), which contributes to the line of research that studies these two gender gaps, especially the effects of the marriage market on them (Iyigun and Walsh, 2007; Chiappori et al., 2009; Ge, 2011; Lafortune, 2013; Bruze, 2015; Greenwood et al., 2016; Chiappori et al., 2017). ${ }^{1}$ Second, I provide a detailed account and unified explanation of the relationships between age at marriage and midlife income, based on labor-market shocks (i.e., uncertain returns) and differential fecundity, which complements explanations based on search frictions (Becker, 1974) and information frictions in the marriage market (Bergstrom and Bagnoli, 1993). ${ }^{2}$ Third, I provide a theory consistent with a previous fertility-based explanation of the relationship between age at marriage and spousal income for women (Low, 2017; Gershoni and Low, 2017), and show that differential fecundity is able to explain even more gender differences in economic and marital outcomes than the literature suggests (Siow, 1998; Greenwood et al., 2003; Coles and Francesconi, 2011; Díaz-Giménez and Giolito, 2013). ${ }^{3}$

To distinguish my theoretical explanations from others', I provide three key pieces of empirical evidence. First, I verify the key implication of my explanation of the college gender gap: Marriage-market returns to college are higher for women than for men. Second, I show lifecycle income paths that can be explained by labor-market shocks in the model but cannot be explained by alternative theories based on marriage frictions. Third, I show that mandated coverage of infertility treatments by insurance improved the marital outcomes of women who married in their thirties, which supports my explanation of the average spousal income for women based on fertility and income tradeoffs.

Finally, I calibrate my model to (i) validate its quantitative fit, (ii) quantify the relative importance of marriage-market frictions and labor-market shocks on marriage timing, (iii) quantify the counterfactual effects of infertility treatment insurance mandates on labor and marital outcomes, and (iv) conduct several counterfactual analyses of how gender equality would affect labor and marital outcomes.

The rest of the paper is organized as follows. Section 2 discusses the three sets of stylized facts in detail. Section 3 includes the model, characterization of its unique equilibrium, and explana-

\footnotetext{
${ }^{1}$ Other explanations for the college gender gap include gender differences in distributions of noncognitive skills (Buchmann and DiPrete, 2006; Goldin et al., 2006; Becker et al., 2010a,b), in labor-market returns to college (Dougherty, 2005; Mulligan and Rubinstein, 2008; Hubbard, 2011), in occupational choices (Charles and Luoh, 2003; Olivieri, 2014), and in opportunity costs of college (Chuan, 2018). Prior explanations for the earnings gender gap include gender differences in occupational choices (Bronson, 2015), in social roles (Goldin, 2014), and in career costs of children (Adda et al., 2017).

${ }^{2}$ The relationship between age at marriage and personal income has been documented for American men and women in the 1960 census (Keeley, 1974, 1977, 1979) and in the 1980 census (Bergstrom and Schoeni, 1996). It has also been documented for Taiwanese men in their 1989 census (Zhang, 1995) as well as for Canadians in their 1981 census and Brazilians in their 1991 census (Zhang, 2015). Relatedly, Oppenheimer (1988); Todd et al. (2005); Iyigun and Lafortune (2016) study age patterns at marriage.

${ }^{3}$ See also Siow and Zhu (2002), Schmidt (2005, 2007), Buckles (2007, 2008), Dessy and Djebbari (2010), Coles and Francesconi (2017, 2018), Bitler and Schmidt (2012), and Garcia-Moran (2018).
} 
tions for the stylized facts, with omitted proofs in Appendix A and justifications for assumptions in Appendix B. Section 4 summarizes empirical evidence and calibration results, with details in Appendices C and D, respectively. Section 5 concludes.

\section{Documenting the Stylized Facts}

Figure 2 summarizes the three sets of stylized facts to be explained by the model: (a) a reversed college gender gap and a persistent earnings gender gap, (b) a hump-shaped relationship between age at marriage and midlife income for men and a positive relationship for women, and (c) a hump-shaped and evolving relationship between age at marriage and spousal income for women.

I use the decennial censuses of 1960, 1970, and 1980, as well as five-year American Community Surveys (ACS) 2010 and 2015 in the Integrated Public Use Microdata Series (IPUMS) USA (Ruggles et al., 2017). Age at (first) marriage is either reported directly (as variable AGEMARR) in these three decennial censuses or imputed from the year entering current marriage (variable YRMARR) in ACS since 2008 for those who have married once and stayed married. The measure of income is the reported pre-tax wage and salary income in the previous calendar year, inflationadjusted to 1999 USD (i.e., INCWAGE $\times$ CPI99). ${ }^{4}$ Midlife income is measured by income between ages 41 and 50 whenever possible. ${ }^{5}$

\section{(a) College and earnings gender gaps}

The college-educated share of Americans aged 35-39 was higher for men before 2000 but higher for women after 2000 (the left panel of Figure 2a), while the average labor income has been consistently higher for men than for women (the right panel of Figure 2a). The coexistence of these two opposite gender gaps is not uniquely American, but rather a global phenomenon: In 2010, women went to college at higher rates than men in 67 countries across all inhabited continents, but earned less than men on average in each of these countries (Becker et al., 2010a). ${ }^{6}$

\section{(b) Relationships between age at marriage and midlife income}

Men who married in their mid-twenties have a higher average midlife income than men who married earlier or later (Figure 2b). To match the three periods in my model, I compare birthyear by birth-year the average incomes of early, middle, and late grooms-those who first married

\footnotetext{
${ }^{4}$ Similar relationships are obtained if total income (INCTOT) is used instead (Appendix E). Similar relationships are also obtained if labor income instead of log labor income is used.

${ }^{5}$ Since spousal income was not reported in the 1950 census, I use the income between ages 51 and 60 in the 1960 census for the 1900s birth cohort. Since age at marriage was not present in IPUMS USA between 1980 and 2008, age at marriage and income between ages 41 and 50 are not simultaneously available for the 1940s and 1950s birth cohorts; I use the income between ages 61 and 70 for the 1940s birth cohort and the income between ages 51 and 60 for the 1950s birth cohort.

${ }^{6}$ See Becker et al. (2010a,b) for the worldwide college gender gap since 1960, Goldin et al. (2006) for the American college gender gap in the twentieth century, and Goldin $(1990,2006,2014)$ for the American earnings gender gap in the twentieth century.
} 
Figure 2: Stylized facts

(a) Reversed college gender gap and persistent earnings gender gap
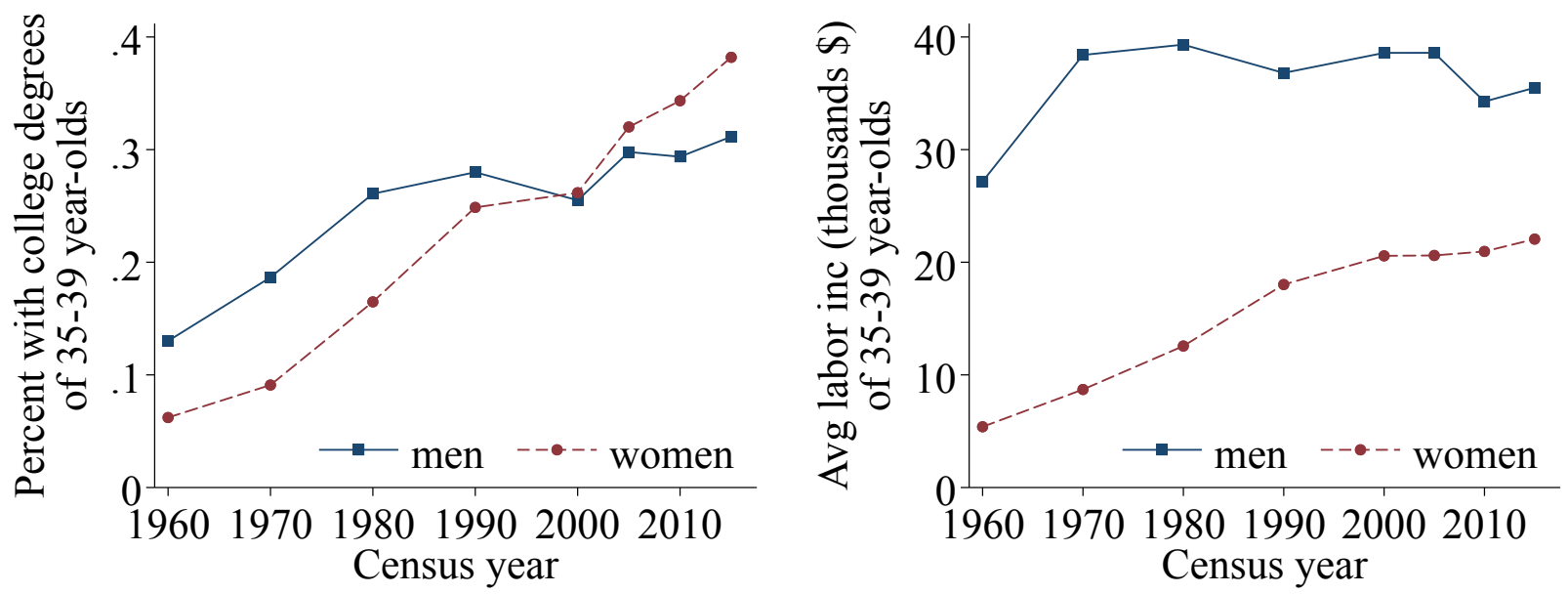

(b) Relationships between marriage age and labor income for men and women, by birth cohort

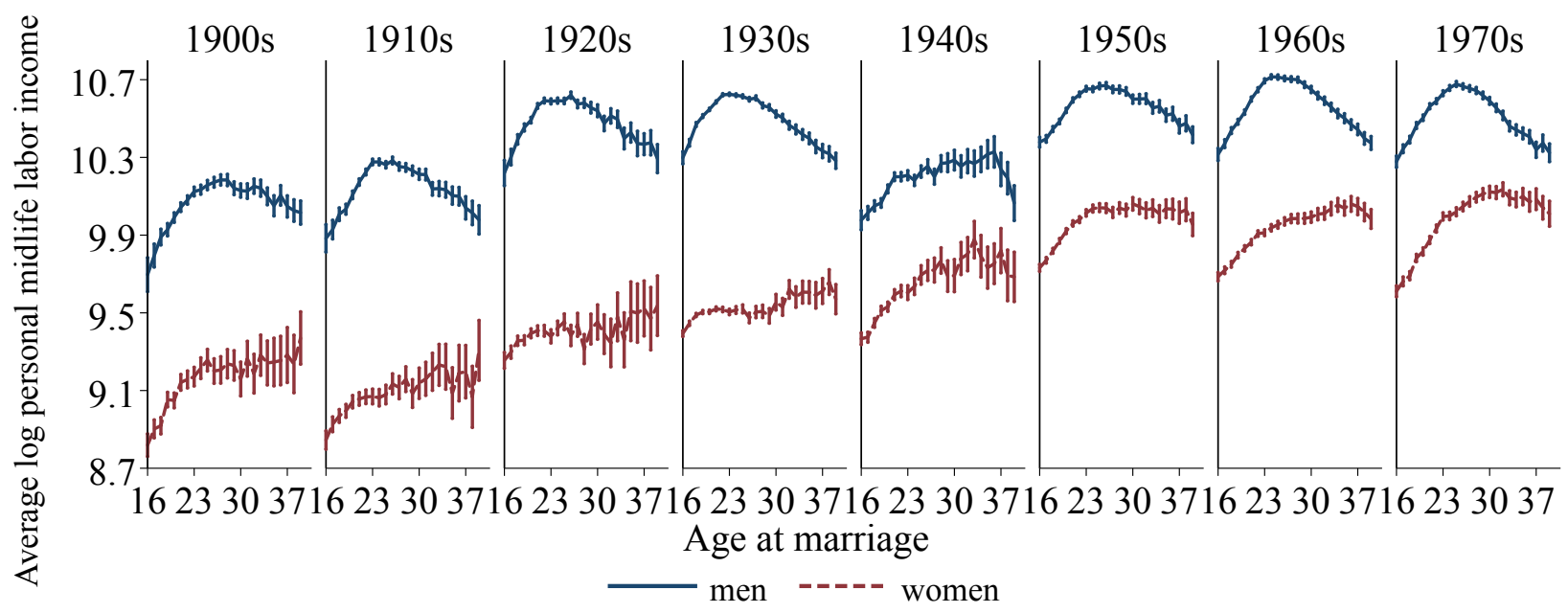

(c) Relationship between marriage age and spousal labor income for women, by birth cohort

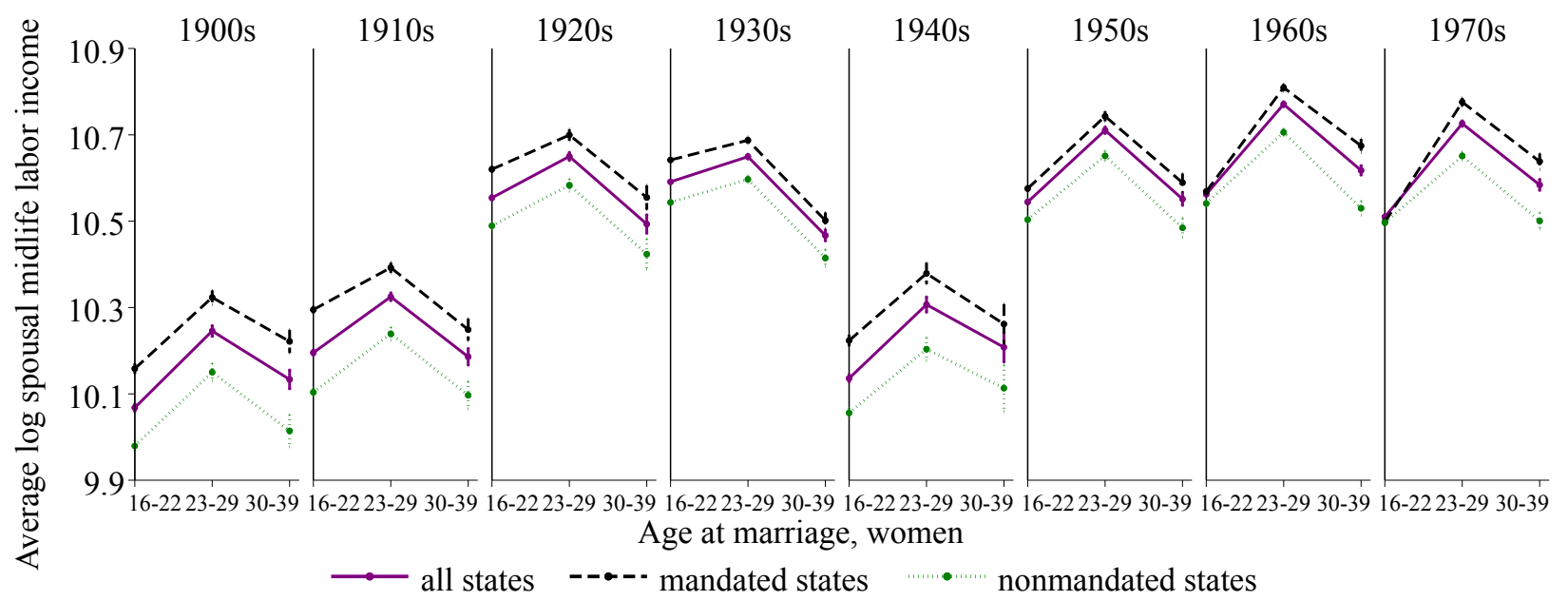


between ages 16 and 22, between ages 23 and 29, and between ages 30 and 39, respectively. Middle grooms born in almost every year between 1900 and 1979 earned a statistically and economically significantly higher average midlife income than early and late grooms born in the same year; compared to middle grooms, on average, early grooms earned 11.8 percent less and late grooms earned 12.9 percent less (Figure A1a in Appendix A).

In contrast, the later a woman married, the more she earned on average (Figure 2b). Early brides had on average 13.6 percent less midlife income than middle brides born in the same year, and middle brides had on average 4.2 percent less midlife income than late brides born in the same year (Figure A1b). The observed gender difference in the relationships between age at marriage and personal income suggests that there is a fundamental gender asymmetry that results in genderdifferential marriage timing and labor decisions.

\section{(c) Relationship between age at marriage and spousal income for women}

The husbands of the women who married in their mid-twenties earned a higher average midlife income than the husbands of those who married earlier or later (Figure 2c). More precisely, the husbands of early brides and of late brides earned, respectively, 14.7 percent and 14.0 percent less midlife income on average than the husbands of middle brides (Figure A1c).

Furthermore, the relationship changed over time. Early brides in the pre-1950 birth cohorts had higher-income husbands than late brides (the first five panels of Figure 2c), but the pattern was reversed for post-1950 birth cohorts (the last three panels of Figure 2c). This change was more pronounced in the 13 states that passed laws between 1985 and 1995 requiring that infertility treatments be covered or offered by insurance (dashed lines versus dotted lines in the last three panels of Figure 2c). ${ }^{7}$ Because infertility treatment was (and still is) quite expensive, the laws reduced the costs for women and effectively extended the biological clocks of women in these states. We should expect that the marital outcome of early brides would have dropped more and the marital outcome of late brides would have improved more in these 13 states after the laws were passed. Indeed, the average spousal income of late brides statistically significantly surpassed that of early brides born after 1960 in the mandated states but not in the nonmandated states (Figure A1d). This observation suggests that gender-differential fertility span can help explain the observed relationship between age at marriage and spousal income for women.

\section{Explaining the Stylized Facts}

In this section I set up the model, characterize its unique equilibrium, and show how the model's predictions are consistent with the stylized facts documented above.

\footnotetext{
${ }^{7}$ The 13 mandated states are Maryland (1985); Arkansas, Hawaii, Massachusetts, Montana, Texas (1987); California, Connecticut, Rhode Island (1989); New York (1990); Illinois, Ohio (1991); and West Virginia (1995). See Table 1 of Buckles (2007). See also Schmidt (2005, 2007); Bitler and Schmidt (2012).
} 


\subsection{Model}

Consider an economy over an infinite number of discrete periods. At the beginning of each period, a unit mass of men and a unit mass of women enter the economy. Each agent is endowed with a heterogeneous ability $\theta \in[0,1]$. Let $F_{m}$ and $F_{w}$ denote the continuous and strictly increasing cumulative distribution of abilities for men and women, respectively. Men and women make investment and marriage decisions over the next three periods of their lives to maximize their lifetime utility. Think of the three periods as ages 16-22, 23-29, and 30-39. Each agent pays investment cost, and receives a reservation payoff $z$ from working and an additional endogenously determined marriage payoff $v$ if married. Each agent is risk-neutral and does not discount.

\subsubsection{Investments}

Figure 1 illustrates an agent's investment and marriage decisions over the three periods. In period 1, each agent decides whether to go to college. Anyone who decides not to go to college earns a low lifetime income and enters the marriage market immediately. Anyone who decides to go to college pays a cost, $c_{m}$ for a man and $c_{w}$ for a woman, and is assumed to delay marriage. ${ }^{8}$

In period 2 , an ability- $\theta$ agent who went to college gets on the path to a high lifetime income with probability $\theta$. Anyone who does not get on the path to a high lifetime income decides whether to make a career investment, which costs the same as a college investment. A career investment is (i) obtaining additional education beyond college, (ii) obtaining additional training, or (iii) finding a new job. ${ }^{9}$ Anyone who does not make a career investment earns a low lifetime income and enters the marriage market in the second period. Anyone who makes a career investment gets another chance to improve his/her lifetime income but delays marriage.

In period 3, an ability- $\theta$ agent who made a career investment enters the marriage market with either a high lifetime income with probability $\theta$ or a low lifetime income otherwise.

\subsubsection{Differential Fecundity}

For simplicity, a person can be either fertile or less fertile, with a high probability or a low probability of having a child. A man is fertile for all three periods, but a woman is fertile for only the first two periods and is less fertile in the third period. In the marriage market, men are distinguished by income only, but women are distinguished by income and fertility. Let $T_{m}=\{H, L\}$ and $T_{w}=\{H, L, h, l\}$ denote the sets of marital characteristics for men and women, respectively; letters $H$ and $h$ denote high-income types, letters $L$ and $l$ denote low-income types, uppercase letters denote fertile types, and lowercase letters denote less fertile types.

Income and fertility determine each agent's payoff as follows. Each income- $y$ agent can gen-

\footnotetext{
${ }^{8}$ The strategy of entering the marriage market while investing is assumed to be infeasible in the basic model. I provide in Appendix B.1 theoretical and empirical justifications for this assumption, and relax the assumption in the calibration exercises in Appendix D.

${ }^{9}$ I show in Appendix B that individuals with a lower income are indeed more likely to choose a career investment.
} 
erate a reservation utility of $z(y)$ without being married. An income- $y_{m}$ man and an income- $y_{w}$ fertility- $\phi_{w}$ woman would generate a total utility of $z\left(y_{m}, y_{w}, \phi_{w}\right)$ from marriage. Hence, the surplus due to marriage is $s\left(y_{m}, y_{w}, \phi_{w}\right)=z\left(y_{m}, y_{w}, \phi_{w}\right)-z\left(y_{m}\right)-z\left(y_{w}\right)$. Assume the marriage surplus is nonnegative, strictly increasing in income, and strictly increasing in fertility. Furthermore, assume the surplus is strictly supermodular in incomes and strictly supermodular in husband's income and wife's fertility level. Formally, let $s_{\tau_{m}} \tau_{w}=s\left(\tau_{m}, \tau_{w}\right)$ denote the surplus of a type- $\tau_{m}$ man and a type- $\tau_{w}$ woman and let $\delta_{\tau_{w}} \equiv s_{H \tau_{w}}-s_{L \tau_{w}}$ denote the marriage surplus difference between when a type- $\tau_{w}$ woman marries a high-income man and when she marries a low-income man. Strict supermodularity in incomes means $\delta_{H}>\delta_{L}$ and $\delta_{h}>\delta_{l}$, and strict supermodularity in husband's income and wife's fertility level means $\delta_{H}>\delta_{h}$ and $\delta_{L}>\delta_{l}$. The two assumptions together imply that $\delta_{H}$ is the largest and $\delta_{l}$ is the smallest, and $\delta_{h}$ can be larger, smaller, or equal to $\delta_{L}$. These supermodularity assumptions will help us pin down the stable matching patterns. ${ }^{10}$

\subsubsection{The Marriage Market}

Overlapping generations of men and women meet and bargain over the division of their marriage surplus until they reach a stable outcome in which no one can improve his or her payoff. Formally, a marriage market is described by distributions of marriage characteristics, $G_{m}=$ $\left\{G_{m} \tau_{m}\right\}_{\tau_{m} \in T_{m}}$ and $G_{w}=\left\{G_{w} \tau_{w}\right\}_{\tau_{w} \in T_{w}}$, where $G_{m \tau_{m}}$ is the mass of type- $\tau_{m}$ men and $G_{w \tau_{w}}$ is the mass of type- $\tau_{w}$ women. A stable outcome of the marriage market $\left(G_{m}, G_{w}\right)$ consists of stable matching $G=\left\{G_{\tau_{m} \tau_{w}}\right\}_{\left(\tau_{m}, \tau_{w}\right) \in T_{m} \times T_{w}}$ and stable marriage payoffs $v_{m}=\left\{v_{m} \tau_{m}\right\}_{\tau_{m} \in T_{m}}$ and $v_{w}=\left\{v_{w} \tau_{w}\right\}_{\tau_{w} \in T_{w}}$. Stable matching $G$ satisfies feasibility: $\sum_{\tau_{w}} G_{\tau_{m}} \tau_{w} \leq G_{m} \tau_{m}$ for any $\tau_{m} \in T_{m}$ and $\sum_{\tau_{m}} G_{\tau_{m}} \tau_{w} \leq G_{w} \tau_{w}$ for any $\tau_{w} \in T_{w}$. Stable marriage payoffs $v_{m}$ and $v_{w}$ satisfy (i) individual rationality: $v_{m} \tau_{m} \geq 0$ for any $\tau_{m} \in T_{m}$ and $v_{w} \tau_{w} \geq 0$ for any $\tau_{w} \in T_{w}$ (every person receives at least as much as they would have if they had remained single); (ii) pairwise efficiency: $v_{m} \tau_{m}+v_{w} \tau_{w}=s_{\tau_{m}} \tau_{w}$ if $G_{\tau_{m}} \tau_{w}>0$ (every married couple divides the entire marriage surplus); and (iii) Pareto efficiency: $v_{m} \tau_{m}+v_{w} \tau_{w} \geq s_{\tau_{m}} \tau_{w}$ for all $\tau_{m} \in T_{m}$ and $\tau_{w} \in T_{w}$ (no man-woman pair not married to each other can simultaneously improve their marriage payoffs by marrying each other). A stable outcome exists for any marriage market (Theorem 2 of Gretsky et al. (1992)).

\subsection{Unique Equilibrium}

Define $\sigma_{m 1}(\theta)$ and $\sigma_{m 2}(\theta)$ as the probability of an ability- $\theta$ man investing in the first and second period, respectively, and define $\sigma_{w 1}(\theta)$ and $\sigma_{w 2}(\theta)$ for an ability- $\theta$ woman similarly. Strategies are summarized by functions $\sigma_{m}=\left(\sigma_{m 1}, \sigma_{m 2}\right)$ and $\sigma_{w}=\left(\sigma_{w 1}, \sigma_{w 2}\right)$. We say that strategies $\sigma_{m}$ and $\sigma_{w}$ induce the marriage market $\left(G_{m}, G_{w}\right)$ if the distributions of men's and women's marriage characteristics in each period are $G_{m}$ and $G_{w}$, respectively, when men and women of every

\footnotetext{
${ }^{10}$ I provide in Appendix B.3 a microfoundation of the marriage surplus function that satisfies surplus monotonicity, surplus supermodularity, and transferable utility, based on intrahousehold allocation of private and public goods.
} 
generation respectively choose strategies $\sigma_{m}$ and $\sigma_{w}$.

Definition 1. A quadruple $\left(\sigma_{m}^{*}, \sigma_{w}^{*}, v_{m}^{*}, v_{w}^{*}\right)$ is an equilibrium if $(i) \sigma_{m}^{*}(\theta)$ and $\sigma_{w}^{*}(\theta)$ respectively maximize each ability- $\theta$ man's and each ability- $\theta$ woman's expected utility when the marriage payoffs are $v_{m}^{*}$ and $v_{w}^{*}$, and (ii) $v_{m}^{*}$ and $v_{w}^{*}$ are stable marriage payoffs of the marriage market $\left(G_{m}^{*}, G_{w}^{*}\right)$ induced by $\sigma_{m}^{*}$ and $\sigma_{w^{*}}^{*}$

\subsubsection{Equilibrium Investments}

Optimal investments differ by gender because of differential fecundity, and the difference in investments is crucial to explain all of the stylized facts regarding gender differences. Men's optimal investments can be solved by backward induction. If an ability- $\theta$ man who receives a low-income offer after college decides to make a career investment, then he incurs a cost $c_{m}$ and expects a lifetime income gain $\theta\left(z_{m H}-z_{m L}\right)$ and a lifetime marriage gain $\theta\left(v_{m H}-v_{m L}\right)$. An ability- $\theta$ man makes a career investment if and only if the expected gain outweighs the cost-that is, if and only if his ability is above

$$
\theta_{m}:=\frac{c_{m}}{z_{m H}-z_{m L}+v_{m H}-v_{m L}} .
$$

A man goes through the same cost-benefit analysis to decide on optimal college investment. Therefore, in any equilibrium, any man with an ability above $\theta_{m}$ makes a college investment, and makes a career investment if he receives a low-income offer after college, while any man with an ability below $\theta_{m}$ makes no investment. ${ }^{11}$

Women's optimal investments can also be solved by backward induction. If an ability- $\theta$ woman who receives a low-income offer after college makes a career investment, then her expected income gain is $\theta\left(z_{w H}-z_{w L}\right)$ and her expected marriage gain is $\theta\left(v_{w h}-v_{w l}\right)-\left(v_{w L}-v_{w l}\right)$, where the term $v_{w L}-v_{w l}$ represents her loss in marriage payoff due to fertility decline. Therefore, she makes a career investment if and only if her ability $\theta$ is above

$$
\theta_{w 2}:=\frac{c_{w}+v_{w L}-v_{w l}}{z_{w H}-z_{w L}+v_{w h}-v_{w l}} .
$$

In contrast, a woman who makes a college investment does not expect an immediate fertility decline. An ability- $\theta$ woman makes a college investment if and only if her ability is above

$$
\theta_{w 1}:=\frac{c_{w}}{z_{w H}-z_{w L}+v_{w H}-v_{w L}} .
$$

Note that $\theta_{w 1}<\theta_{w 2}$ : Some women would not make a career investment. In summary, any woman whose ability is above $\theta_{w 2}$ makes a college investment and, in case her college investment fails, makes a career investment; any woman whose ability is between $\theta_{w 1}$ and $\theta_{w 2}$ makes a college investment only; and any woman whose ability is below $\theta_{w 1}$ makes no investment.

\footnotetext{
${ }^{11}$ Ability $-\theta_{m}$ men are indifferent between investing and not investing. It is without loss of generality to assume that they invest whenever they are indifferent. It is without loss of generality because the distribution of abilities is atomless and there is measure 0 of ability- $\theta_{m}$ men. Hence the stable outcome of the marriage market is not affected by the investment decisions of ability- $\theta_{m}$ men.
} 
The induced distributions of marriage characteristics can be characterized straightforwardly from optimal investments. Namely, type- $H$ men are those with an ability above $\theta_{m}$ who receive a high-income offer either after a college investment or after a career investment, so $G_{m H}=\int_{\theta_{m}}^{1}[\theta+$ $(1-\theta) \theta] d F_{m}(\theta)$. Type- $L$ men consist of (i) all men with an ability below $\theta_{m}$ and (ii) men with an ability above $\theta_{m}$ who fail to receive a high income after college and career investments. Because there is a unit mass of men in each period's marriage market, the mass of low-income men is simply $G_{m L}=1-G_{m H}{ }^{12}$ Type- $H$ women are those with an ability above $\theta_{w 1}$ who succeed right after college: $G_{w H}=\int_{\theta_{w 1}}^{1} \theta d F_{w}(\theta)$. Type- $h$ women are those with an ability above $\theta_{w 2}$ who succeed only after their career investment: $G_{w h}=\int_{\theta_{w 2}}^{1}(1-\theta) \theta d F_{w}(\theta)$. Type- $L$ women consist of (i) all women with an ability below $\theta_{w 1}$ and (ii) women with an ability between $\theta_{w 1}$ and $\theta_{w 2}$ who fail after college and do not make a career investment: $G_{w L}=F_{w}\left(\theta_{w 1}\right)+\int_{\theta_{w 1}}^{\theta_{w 2}}(1-\theta) d F_{w}(\theta)$. Finally, type- $l$ women are those with an ability above $\theta_{w 2}$ who fail to receive a high income after college and career investments: $G_{w l}=1-G_{w H}-G_{w L}-G_{w h}$.

\subsubsection{Equilibrium Matching and Marriage Payoffs}

Equilibrium stable matching is characterized as follows. First, because the marriage surplus is assumed to be strictly supermodular in incomes, given two equally fertile women, a higher-income woman almost surely marries a higher-income man. ${ }^{13}$ Second, because the surplus is assumed to be strictly supermodular in husband's income and wife's fertility, given two women with the same income, a more fertile woman almost surely marries a higher-income man. The two results together imply that (i) type- $H$ women almost surely marry higher-income husbands than women of any other type, and (ii) type- $l$ women almost surely marry lower-income husbands than women of any other type. Whether a type- $h$ woman or a type- $L$ woman marries a higher-income husband depends on an additional condition. A type- $h$ woman almost surely marries a man with a higher income than a type- $L$ woman does if and only if the surplus difference $\delta_{h}>\delta_{L}$, and a type- $L$ woman almost surely marries a higher-income woman than a type- $H$ woman does if and only if $\delta_{h}<\delta_{L}$. In summary, stable matching is positive-assortative in men's income and women's type, provided that women's types are ranked according to (i) $H \succ h \succ L \succ l$ when $\delta_{h}>\delta_{L}$, (ii) $H \succ L \succ h \succ l$ when $\delta_{h}<\delta_{L}$, or (iii) $H \succ L \sim h \succ l$ when $\delta_{h}=\delta_{L}$.

Because there is an equal mass of men and women in the marriage market, there is a positive

\footnotetext{
${ }^{12}$ There is a unit mass of men and women in each period's marriage market because of the overlapping-generations nature of the model. The period- $t$ marriage market consists of (i) those who are born in period $t-2$ and enter the marriage market in the third period of their lives, (ii) those who are born in period $t-1$ and enter the marriage market in the second period of their lives, and (iii) those who are in period $t$ and enter the marriage market in the first period of their lives. Because the optimal investments are stationary, there is a unit mass of men and women in each period's marriage market.

${ }^{13}$ The modifier "almost surely" is needed because the marriage market consists of a continuum of men and women, rather than a finite number of agents, as in Shapley and Shubik (1972) and Becker (1973). It is a standard quantifier in the literature (Chiappori and Oreffice, 2008; Chiappori et al., 2012a,b).
} 
mass of marriages between the bottom-ranked type- $L$ men and type- $l$ women, so $v_{m L}+v_{w l}=s_{L l}$, but neither $v_{m L}$ nor $v_{w l}$ is determinate. Therefore, stable marriage payoffs can be determined only up to a constant. To determine the stable marriage payoffs, it suffices to determine the marriage payoff differences between two adjacently ranked marriage types, because the sums of these differences, coupled with $v_{m L}$ and $v_{m l}$, can represent any marriage payoff. ${ }^{14}$ I show the detailed steps to determine marriage payoff differences in Appendix A.2.

The key takeaway from the derivation is that the marriage payoff difference between any two adjacently ranked female types-and, as a consequence, the marriage payoff difference between any two female types-can be represented by men's marriage premium $\pi_{m}=v_{m H}-v_{m L}$. Furthermore, the three optimal investment thresholds in equations (1)-(3) are uniquely determined by payoff differences, and as a consequence, uniquely determined by $\pi_{m}$. Therefore, any equilibrium can be represented by $\pi_{m}$. This representation is crucial for the construction of the proof of equilibrium existence and uniqueness.

\subsubsection{Equilibrium Existence and Uniqueness}

Theorem 1. An equilibrium exists. Equilibrium investments are uniquely determined, and equilibrium marriage payoffs are uniquely determined up to a constant.

The proof, presented in Appendix A.3, follows three steps. First, I construct (i) a correspondence that represents the demand for high-income men in the marriage market and (ii) a function that represents the supply. Second, I argue that each intersection of the constructed demand and supply curves corresponds to an equilibrium. Third, I show that (i) the constructed demand and supply curves always intersect, proving equilibrium existence, and (ii) the demand curve is downward-sloping and the supply curve is upward-sloping, proving equilibrium uniqueness.

\subsection{Explanations}

\section{(a) College and earnings gender gaps}

Proposition 1. Suppose women are less fertile in the third period while all other primitives are gender-symmetric: investment costs $c_{m}=c_{w}$, labor-market opportunities $F_{m}=F_{w}$, income premiums $z_{m H}-z_{m L}=z_{w H}-z_{w L}$, and marriage surpluses $s_{H L}=s_{L H}$. Strictly more women than men go to college in equilibrium. Strictly fewer women than men earn a high lifetime income in equilibrium if $G_{m H}\left(\delta_{l}\right)>G_{w H}\left(\delta_{l}\right)+G_{w h}\left(\delta_{l}\right)$.

Previous papers (cited in the introduction) have explained the college gender gap using gender differences in the psychic and monetary costs of investments, labor-market opportunities, college income premiums, and marital roles. Proposition 1 states that even in a model that does not include any of these gender differences, it could be the case that more women than men attend college.

\footnotetext{
${ }^{14}$ For example, $v_{m H}$ can be represented as $v_{m L}+\left(v_{m H}-v_{m L}\right)$, and $v_{w H}$ can be represented as $\left(v_{w H}-v_{w h}\right)+\left(v_{w h}-\right.$ $\left.v_{w L}\right)+\left(v_{w L}-v_{w l}\right)+v_{w l}$ when $H \succ h \succ L \succ l$.
} 
Adding any of these gender differences to the model would only reinforce the female-dominated college gender gap. Furthermore, the female-dominated college gender gap can be sustained even when the gender differences that deter women's college investments are included. ${ }^{15}$ Therefore, the model highlights a new fundamental force, rooted in differential fecundity and propagated through the marriage market, that contributes to the global college gender gap. At the same time, the earnings gender gap is maintained; this result is unattainable from previous models that explain the college gender gap without including additional gender differences.

While I will present a formal proof of the proposition by contradiction in Appendix A.4, I provide an economic explanation here. Define the difference between the marriage payoffs of a fertile high-income earner and a fertile low-income earner, $\pi_{i} \equiv v_{i H}-v_{i L}, i=m, w$, as the marriage premium. The college ability cutoffs are simply determined by the investment cost divided by the income premium and the marriage premium, $\theta_{i}=c_{i} /\left(z_{i H}-z_{i L}+\pi_{i}\right), i=m, w .{ }^{16}$ When the setting is gender-symmetric, more women than men go to college if and only if the endogenous marriage premium $\pi_{i}$ is higher for women than for men. If the marriage premiums $\pi_{m}$ and $\pi_{w}$ were exogenously fixed to be the same, the same number of men and women would go to college, and fewer women than men would make a career investment because of differential fecundity. Consequently, fewer women than men earn a high income. However, the marriage premiums are endogenously determined in the model. Precisely because fewer women than men earn a high income, women who earn a high income are more scarce and more "valuable" in the marriage market than men who achieve the same feat. Women's endogenously higher marriage premium prompts more women than men to make a college investment. Hence, a key implication of the model is a higher marriage premium for women than for men. I test and confirm this implication empirically in Appendix C.1.

The two key drivers of my main result are differential fecundity and the endogenous division of the marriage surplus. In a model without differential fecundity, the setting is entirely gendersymmetric, so the same number of men and women would go to college, make career investments, and earn a high income. In a model that incorporates differential fecundity but omits the endogenous division of the marriage surplus (i.e., the marriage premiums are exogenously the same for the two genders), the same number of men and women would go to college, but fewer women than men would make a career investment and earn a high income; such a model would be able to

\footnotetext{
${ }^{15}$ For example, it has been argued that women's college income premium is lower than men's. Dougherty (2005) shows that the college income premium for women (defined as the difference in log wages of non-college-educated female high school graduates and female college graduates) is higher than men's. Hubbard (2011) shows that the gender difference in the college income premium is nonexistent after correcting for income top-coding bias, which has previously underestimated men's college income premium. Estimates presented in Figure 6 of DiPrete and Buchmann (2006) and Figure 9 of Chiappori et al. (2017) provide additional evidence that the gender difference in the college income premium is not enough to explain the college gender gap.

${ }^{16}$ The shares of men and women who go to college are $1-F_{i}\left(c_{i} /\left(z_{i H}-z_{i L}+\pi_{i}^{*}\right)\right), i=m, w$.
} 
explain the earnings gender gap, but not the college gender gap.

Hence, the combination of differential fecundity and endogenous surplus division is needed to account for the opposite gender gaps. Differential fecundity directly reduces women's career investments but does not directly increase their college investments. College and career investments are not direct substitutes to improve income, but endogenous marriage surplus division renders these investments strategic substitutes. ${ }^{17}$ Specifically, the decline in fertility directly discourages intermediate-ability college-investing women (women with an ability close to $\theta_{w 2}^{*}$ ) from making career investments, and indirectly encourages lower-ability women (women with an ability close to $\theta_{w 1}^{*}$ ) to go to college through endogenous marriage surplus division.

Furthermore, surplus supermodularity in incomes is necessary to explain the college gender gap. If the surplus is submodular in incomes, the same number of men and women would go to college. Surplus supermodularity in incomes is theoretically grounded in the intrahousehold allocation model presented in Appendix B.3, and is empirically supported by our subsequent estimates of the marriage surplus function as well as findings on positive assortative matching in incomes and educations in the United States and other countries (Lam, 1988; Blossfeld and Timm, 2003; Schwartz and Mare, 2005; Stevenson and Wolfers, 2007; Greenwood et al., 2014; Siow, 2015; Greenwood et al., 2016; Chiappori et al., 2017).

In addition, the model's predictions are consistent with the empirical literature that studies the rise of women's college enrollment and labor force participation, as cited in the introduction. In the model, women's college investment rate and average income in equilibrium both increase if any or any combination of the following events occurs: (i) women face a lower investment cost; (ii) women's labor-market opportunities improve; (iii) women's college income premium increases; and (iv) women's college marriage premium increases.

\section{(b) Relationships between age at marriage and income for men and women}

Proposition 2. The relationship between age at marriage and income for men is hump-shaped in equilibrium. The relationship between age at marriage and income for women can be positive or hump-shaped in equilibrium.

Early grooms in the model are men with an ability below $\theta_{m}^{*}$, and they earn a low lifetime income without making any investment. Middle grooms are men with an ability above $\theta_{m}^{*}$ who get on the path to a high lifetime income after college. Late grooms are the remaining men with an ability above $\theta_{m}^{*}$ who fail to realize a high income after college and consequently make a career investment; some of them receive a high income and the rest receive a low income, so the average income is lower for late grooms than for middle grooms.

For the upward-sloping portion of the relationship, early grooms earn less than middle grooms

\footnotetext{
${ }^{17}$ Thomas (2018) considers the possibility that college and career investments are direct substitutes.
} 
on average, because early grooms invest less than middle grooms. Bergstrom and Bagnoli (1993) also predict a positive relationship between age at marriage and income for men, but there is a difference between their model and mine. In their model, high-income men wait to marry because they cannot credibly signal their earning abilities when they are young. In contrast, there is no private information in my model. Even if a man can choose to marry during college, he weakly prefers to wait until after he resolves his post-college income uncertainty (as shown in Appendix B.1). The reason for delaying marriage in this model is rooted in the inherent nature of the marriage market. A man who has uncertainty about his future lifetime income may not be able to marry the woman he could marry when he has a high lifetime income for sure, so he chooses to delay marriage. ${ }^{18}$ Moreover, the downward-sloping portion of the relationship cannot be explained by Bergstrom and Bagnoli (1993), but can be explained by my model, as follows.

For the downward-sloping portion of the relationship, middle grooms earn more than late grooms on average, because middle grooms are college-educated men who get on the path to a high lifetime income soon after college, and late grooms are college-educated men who fail to do so and end up with a lower income on average. Becker (1974) and Keeley (1979) also predict a negative relationship, but their explanation is different. Whereas higher-ability men in their models marry earlier because they encounter less marriage-market friction, higher-ability men in my model do so because they are less likely to encounter an adverse labor-market shock. Lower-income men involuntarily delay marriage due to marriage-market frictions in their models but voluntarily delay marriage due to labor-market shocks in my model.

In equilibrium, early brides earn a low income because they are low-ability women (those with an ability below $\theta_{w 1}^{*}$ ) who do not go to college. Middle brides consist of all intermediateability women (those with an ability between $\theta_{w 1}^{*}$ and $\theta_{w 2}^{*}$ ) and higher-ability women (those with an ability above $\theta_{w 2}^{*}$ ) who earn a high income right after college. Late brides are higher-ability women who do not receive a high income after college. The model predicts that early brides earn less than middle brides and late brides, but does not make a definitive prediction about whether middle brides or late brides earn more.

In the model, early brides earn less than middle brides, because early brides are those who do not go to college. Middle brides, in contrast, are those who go to college; many end up with a high income. The impact of human capital investment on women's marriage timing is completely missing in Becker (1974) and Keeley (1979) (who predict a positive relationship between age at marriage and income due to marriage-market frictions), as well as in Bergstrom and Bagnoli (1993) (who predict no relationship between age at marriage and income for women). My naturally incorporates this effect.

\footnotetext{
${ }^{18}$ The discussion in Oppenheimer (1988) that people would like to be sure of their career prospects before marrying is formalized by this model.
} 
In the model, middle brides tend to earn less than late brides, because middle brides mostly consist of intermediate-ability women who fail to receive a high income after college but nonetheless choose to marry; late brides are high-ability women who do not receive a high income right out of college but receive a high income with a large probability after career investments. In short, labor-market shocks and the fertility-income tradeoff result in positive selection in delayed marriage. Becker (1974) predicts a positive relationship between age at marriage and income driven by marriage-market frictions.

In summary, for both men and women, Becker (1974) and Keeley (1979) focus on the impacts of marriage-market frictions on marriage timing, and I focus on the impacts of labor-market shocks on marriage timing. I will present in Section 4.1 lifecycle income paths that can only be explained by the impacts of labor-market shocks on marriage timing. The calibration in Appendix D will quantify the respective impacts of marriage-market frictions and labor-market shocks on marriage timing.

\section{(c) Relationship between age at marriage and spousal income for women}

Proposition 3. The relationship between age at marriage and spousal income for women is hump-shaped in equilibrium: Average spousal income is the highest for those who marry in the second period.

In the model, early brides are fertile low-income earners, and middle brides are both fertile lowincome earners and fertile high-income earners. Because fertile high-income women's husbands almost always have a higher income than fertile low-income women's, middle brides are predicted to have a higher average spousal income than early brides. Late brides consist of both high-income and low-income earners, but they are less fertile than middle brides. Since (i) for any two women with the same income, the more fertile one marries a higher-income husband in equilibrium, and (ii) late brides do not earn significantly more than middle brides on average, the average spousal income is predicted to be lower for late brides than for middle brides.

The key to explaining whether early brides or late brides marry higher-income husbands is nonassortative matching in incomes (Low, 2017) in the marriage market. According to the model, early brides are fertile low-income earners, and late brides are less fertile women with a higher average income. If fertility is more important than income in the marriage market (i.e., $\delta_{L}>\delta_{h}$ ), type- $L$ women marry higher-income husbands than type- $h$ women, and consequently, early brides' average spousal income would be lower than late brides'. Otherwise (i.e., $\delta_{h}>\delta_{L}$ ), it is possible that less fertile high-income women's husbands have a higher income than fertile low-income women's, and the average spousal income is higher for less fertile women than for fertile lowincome women.

The fact that late brides have higher-income husbands than early brides in states with infertility 
treatment mandates suggests that the evolution of the difference in average spousal income between early brides and late brides is at least partially driven by the change in the relative importance of income and fertility in the marriage market. These changes in the marriage market can be thought of as a decrease in the demand for and/or an increase in the supply of "reproductive capital" (Low, 2017) in the marriage market.

On the one hand, the demand for "reproductive capital" has decreased. First, the desired (and actual) family size has decreased; in the United States, the average desired number of children has declined from 3.6 to 2.6 from 1960 to 2010 (Livingston and Cohn, 2010). Many families have shifted from a demand for quantity of children to a demand for quality, as Becker and Lewis (1973) predicted. Women's fertility has become less of a concern in marriage decisions than women's income and education. Second, an increase in income gain from college and career investments also contributes to a decrease in the relative importance of fertility; the benefit of the career investment in the labor market outweighs the cost of delayed marriage in the marriage market.

On the other hand, an increase in the supply of reproductive capital has been achieved by advances in medical technology such as in vitro fertilization, egg freezing, and more cost-effective maternal health services, all of which have resulted in a higher probability of staying fertile and conceiving. Older women can have children with less financial burden, more physical ease, and fewer adverse health effects than in the past. Gershoni and Low (2017) present causal evidence that policies that have made assistive reproductive technology less expensive and more accessible directly improved the education, labor, and marital outcomes of Israeli women who married late. I show similar evidence for American women in Section 4.1.

\section{Supporting the Explanations}

In this section, I briefly summarize the key evidence that supports my explanations of the stylized facts as well as the calibration results that validate the quantitative fit of the model and counterfactual analyses based on the calibrated models. I leave the details to online appendices.

\subsection{Key Empirical Evidence}

\section{(a) College and earnings gender gaps}

A key implication of the model is a higher marriage premium for women than for men when more women than men go to college. I estimate marriage premiums from 1960 to 2015 . Figure 3 shows that women's marriage premium was indeed smaller than men's in 1960, 1970, and 1980, when fewer women than men graduated from college; it was greater than men's in 2010 and 2015, when more women than men graduated from college. I adopt the technique developed by Choo and Siow (2006) to exactly identify the marriage surplus function and compute the marriage premiums from the estimated marriage surplus function. I describe the estimation details in Appendix C.1. 
Figure 3: Marriage premiums from 1960 to 2015

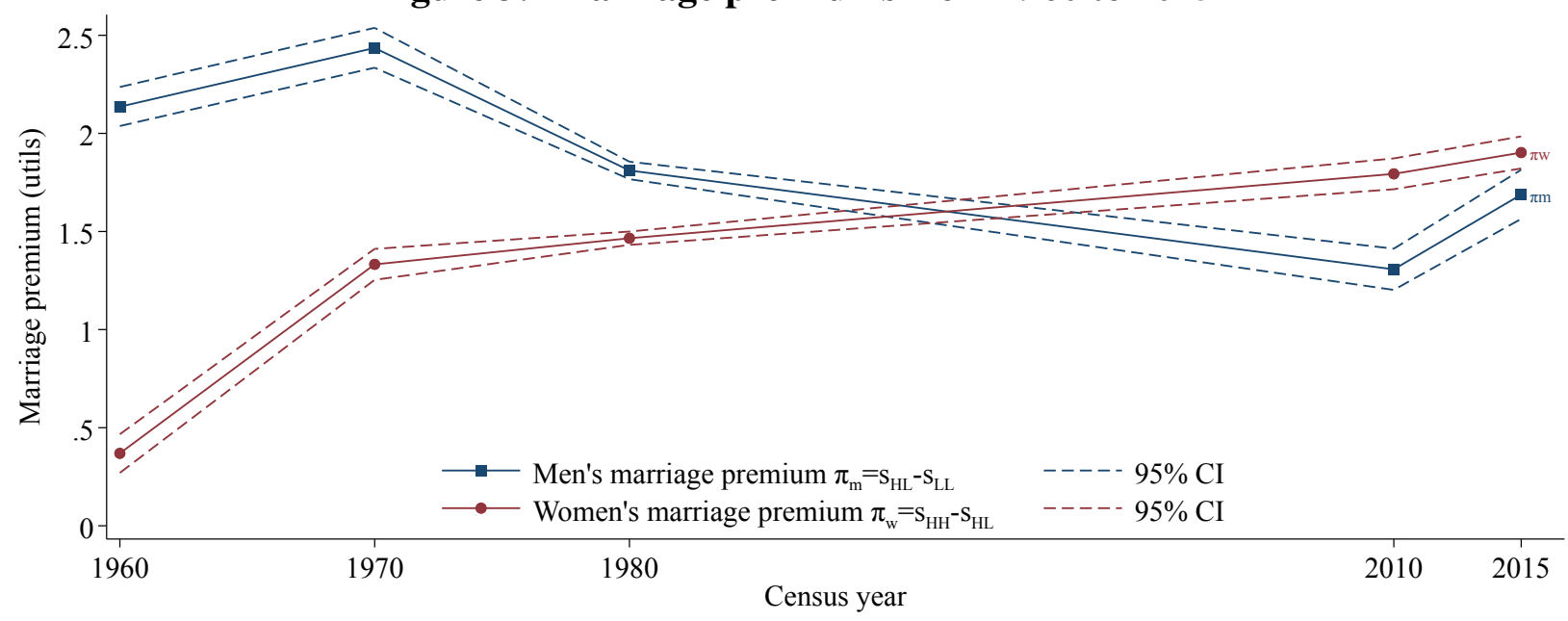

(b) Relationships between age at marriage and income for men and women

If labor-market shocks indeed delay marriage for college-educated men and women, as the model suggests, we would expect that, compared to college-educated individuals who married between ages 23 and 29, college-educated individuals who married between ages 30 and 39 should have (i) a lower average income when they have just finished college and (ii) a higher income growth rate following college, because they engaged in more career investments. In contrast, if marriage-market friction were the sole determinant of marriage timing, then we would expect that college-educated individuals who married between ages 30 and 39 should have (i) a lower income and (ii) a lower income growth rate following college than college-educated individuals who married between ages 23 and 29. Figure 4 shows that for the three cohorts tracked by the National Longitudinal Study of Youth (NLSY), four-year-college-educated men (resp., women) who married between ages 30 and 39 (i) earned a lower average income than four-year-collegeeducated middle grooms (resp., middle brides) in their twenties, and (ii) caught up and earned almost as much as (resp., more than) four-year-college-educated middle grooms (resp., middle brides) by age 30 . The pattern is consistent with a theory where early labor-market outcome and career investment decisions affect marriage timing decisions.

\section{(c) Relationship between age at marriage and spousal income for women}

If fertility and income are two important factors that determine women's marital outcome, then a potential technological improvement in fertility should improve the relative marital outcome of late brides. The marital outcome of late brides, measured by spousal income and education ranks, indeed improved in the 13 states that passed mandates to cover or offer infertility treatments by insurance between 1985 and 1995 (Figures 5a and 5b). The same results hold if the marital outcome is measured by absolute spousal income or statewide spousal income z-score (Figure C1). It is also worth mentioning that the mandates did not significantly improve the average education or income rank of late brides in those states (Figures $5 \mathrm{c}$ and $5 \mathrm{~d}$ ), consistent with previous studies 
Figure 4: Lifecycle income paths explained by the model

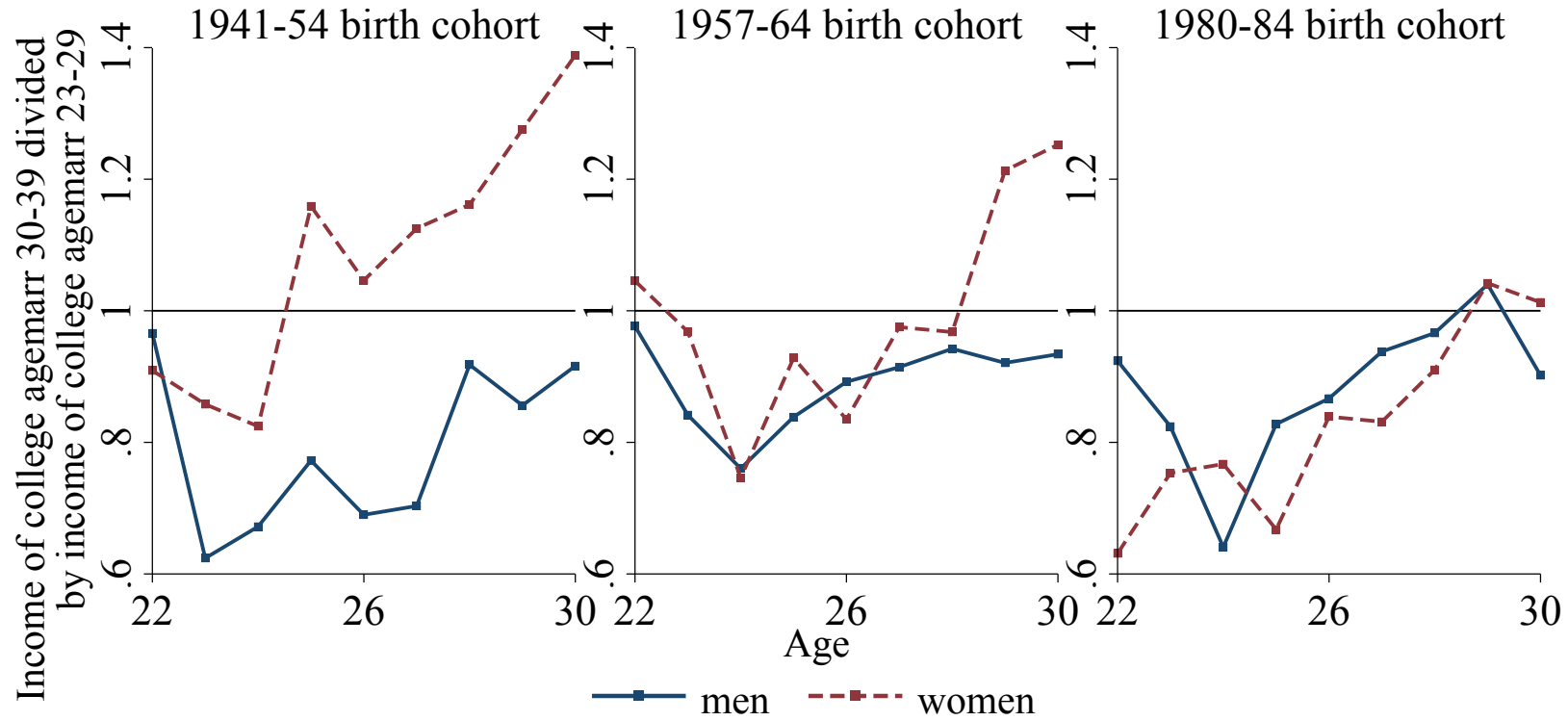

such as Buckles (2007). The result is also consistent with my theory: More women may make a career investment following a relaxed fertility constraint, but since these women have intermediate abilities and may have a relatively low chance of receiving a high income, late brides' average income may not increase. ${ }^{19}$

\subsection{Calibration}

I calibrate my theoretical model on U.S. data to demonstrate its good quantitative fit. Furthermore, based on the calibrated parameters, I quantify the relative impacts of marriage frictions and labor-market shocks on marriage timing and provide counterfactual analyses of the infertility treatment insurance mandate and gender equality in the marriage market and labor market. Key results of the calibration exercise are summarized in the following four steps. Detailed results and tables are provided in Appendix D.

First, I calibrate the benchmark model to examine the model's quantitative validity. The calibration matches each targeted marriage-age distribution within 0.7 percent, and except for the average income of late grooms born in the 1930s and that of late brides in the 1960s, the calibration matches each of the targeted average incomes within 5 percent. Non-targeted average spousal incomes were also matched fairly well.

Second, I incorporate marriage-market frictions into the benchmark model to separate investment and marital timing decisions in order to match (i) age distributions at marriage by education level, (ii) average personal midlife income by age at marriage for men and for women, (iii) average spousal income by women's age at marriage, and (iv) men's and women's college enrollment rates. With the calibration of the extended model, I quantify the relative impacts of marriage-market fric-

\footnotetext{
${ }^{19}$ In contrast, improvements in Israeli women's education and earnings were more pronounced (Gershoni and Low, 2017), in part because Israelis go to college later due to mandatory military service.
} 


\section{Figure 5: Labor income and education in mandated versus nonmandated states}

(a) Spousal labor income percentile rank by birth year
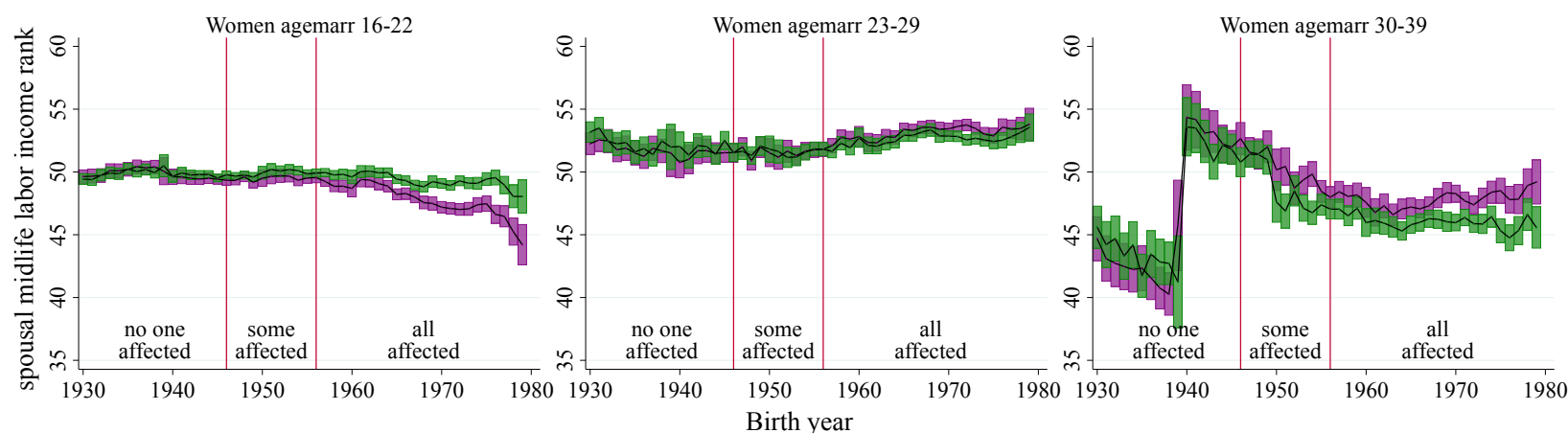

mandated states $\square$ nonmandated states

(b) Spousal education percentile rank by birth year

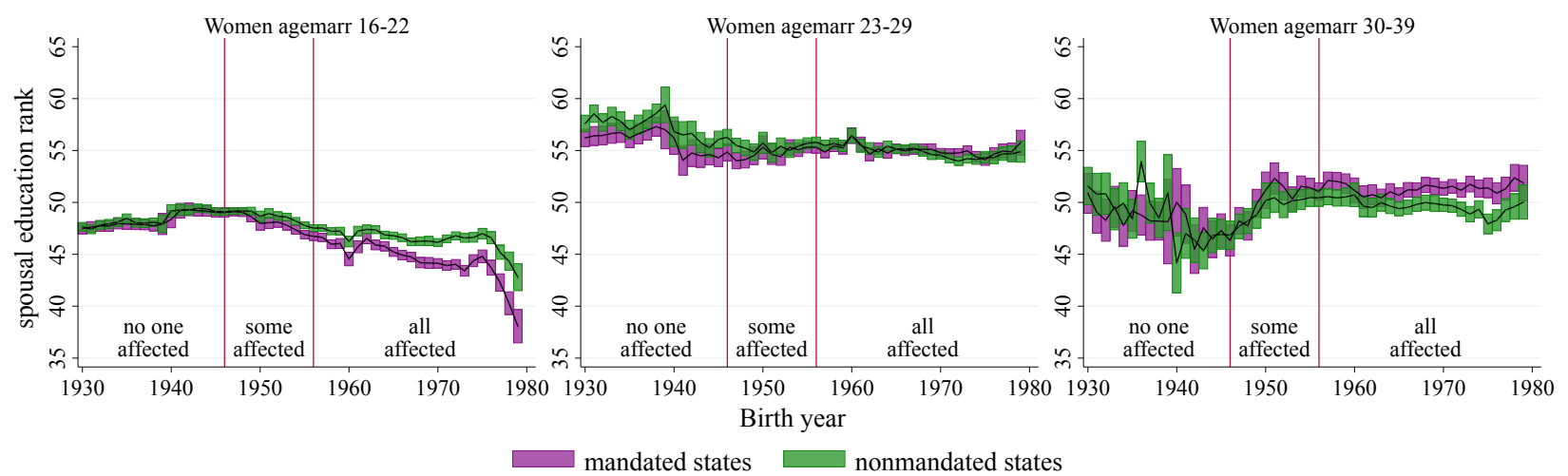

(c) Personal labor income percentile rank by birth year

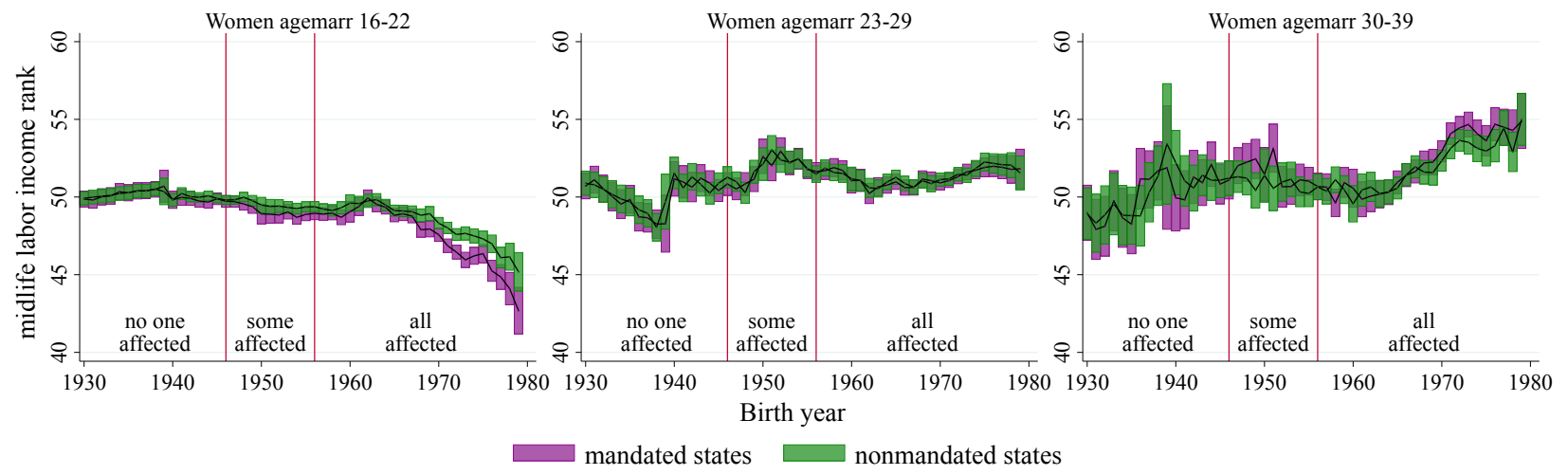

(d) Personal education percentile rank by birth year

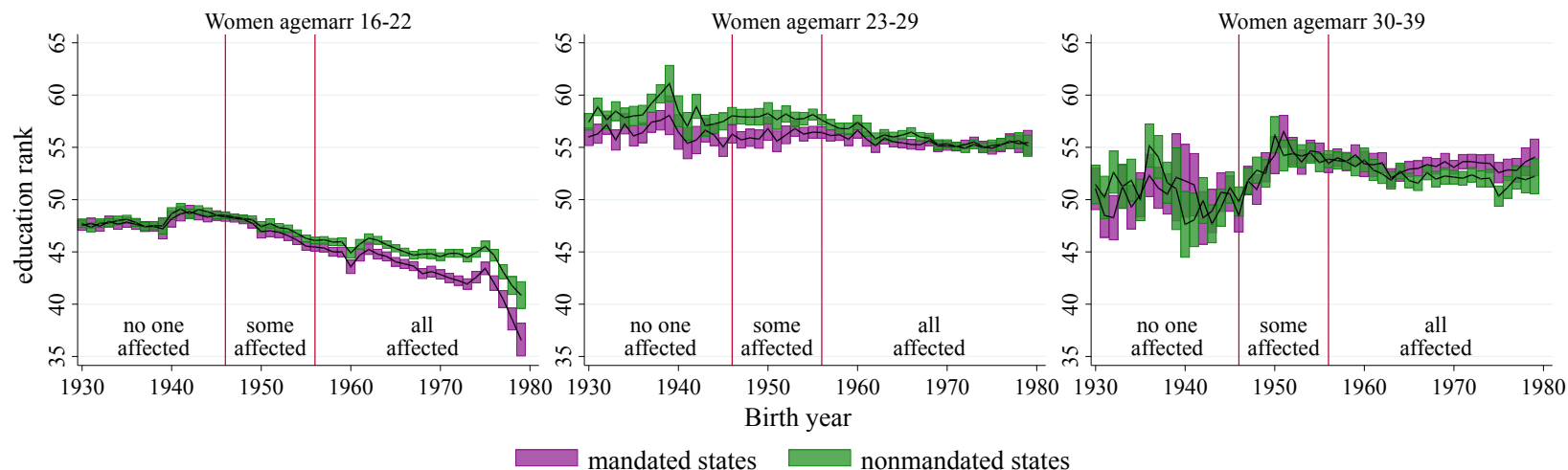


tions and labor-market shocks on marriage timing decisions, as follows.

For the 1930s birth cohort, there was an estimated 17.1 percent chance that college-educated women who decided to enter the marriage market before age 30 involuntarily delayed their marriage until after age 30 . For college-educated men and women who married between ages 30 and 39 , essentially all men delayed marriage due to labor-market shocks and all women delayed marriages due to marriage-market frictions, consistent with the fact that a tiny portion of women in this cohort chose to make a career investment. For the 1960s birth cohort, the chance of a collegeeducated man who decided to enter the marriage market between ages 23 and 29 not being able to marry before age 30 was 22.2 percent, and the chance that a college-educated woman who decided to enter the marriage market between ages 23 and 29 not being able to marry before age 30 was 23.8 percent. The calibration shows that 42.7 percent of college-educated men and 24.6 percent of college-educated women delayed marriage due to labor-market shocks, and the rest delayed due to marriage-market frictions.

Third, I examine the counterfactual impacts of the mandates on marriage and labor outcomes by calibrating the model on four groups: the 1930s birth cohort and the 1960s birth cohort in mandated and nonmandated states. The quantitative fit of the model is not affected by the division into two groups of states. In general, the mandate increases the marriage age of women and the marital outcome of those women who marry after age 30. Namely, without the mandate, the fraction of late brides in mandated states would decrease from 19.4 percent to 17 percent, the average spousal income of late brides would decrease by 0.12 percent, and the average spousal income of early brides would increase by 2.92 percent. In nonmandated states, the mandate would increase the fraction of late brides in the nonmandated from 15.9 percent to 18.2 percent, decrease the average spousal income of early brides by 2.97 percent, and increase the average spousal income of late brides by 0.07 percent.

Fourth and finally, I use the calibrated parameters of the 1960s birth cohort to obtain the counterfactual effects of equalizing men and women in the marriage market and the labor market. The first counterfactual analysis shows that removing differential fecundity would (i) delay 4.96 percent of women's marriage age from between 23 and 29 to between 30 and 39, (ii) increase middle and late brides' average spousal income (by 5.43 percent and 3.61 percent, respectively), but (iii) not increase the average personal income of those who marry in their thirties, as the relationship between age at marriage and income for women would become more similarly hump-shaped to the relationship for men.

The second counterfactual analysis shows that equalizing labor market opportunities for women would decrease the college enrollment of women (by 1.74 percent) because the opportunity cost of college increases, and would increase the incentives for women to make career investments because the labor premiums of investments increase. The two effects result in the reduction of 
those who marry between ages 23 and 29 (by 2.94 percent) and an increase in those who marry earlier (by 0.35 percent) and later (by 5.64 percent). The marital outcome of middle and late brides increases (by 0.68 percent and 0.37 percent) because of their increased income.

The third counterfactual analysis shows that if the ability distributions are the same for men and women, then college enrollment for women would decrease (by 1.14 percent) and the fraction of those who marry after age 30 would also decrease (by 4.45 percent), which is in line with the empirical findings that women's noncognitive skills on average are higher than men's. The average personal income and spousal income of middle and late brides would increase, however, because the higher-ability women would have higher chances of succeeding after college. The average income of middle and late brides would increase by 7.28 percent and 3.79 percent, respectively, and their average spousal incomes would increase by 1.85 percent and 3.66 percent, respectively.

\section{Conclusion}

I built an equilibrium investment-and-marriage model with one gender asymmetry-differential fecundity-to account for a set of phenomena that have not previously been explained under a unified framework. Most notably, I (i) provide a new explanation for the college gender gap and the earnings gender gap, based on differential fecundity and the equilibrium marriage market, (ii) ex-

plain the relationships between age at marriage and personal income for both men and women, and (iii) encapsulate in my model the previous explanation of the relationship between age at marriage and spousal income for women. The model accounts for these phenomena both qualitatively and quantitatively. Labor-market shocks, marriage-market frictions, and differential fecundity were shown to play important roles. I believe the theoretical and empirical analyses contribute to a better understanding of complex labor-market and marriage-market phenomena, and could serve as stepping-stones to achieve an even better understanding of these intertwined phenomena.

\section{References}

Adda, Jérôme, Christian Dustmann, and Katrien Stevens, “The Career Costs of Children," Journal of Political Economy, 2017, 125 (2), 293-337.

Becker, Gary S., “A Theory of Marriage: Part I,” Journal of Political Economy, July-August 1973, $81(4), 813-846$.

_, "A Theory of Marriage: Part II," Journal of Political Economy, March-April 1974, 82 (2), S11-S26.

— and H. Gregg Lewis, "On the Interaction between the Quantity and Quality of Children," Journal of Political Economy, March - April 1973, 81 (2), S279-S288. 
_ , William H. J. Hubbard, and Kevin M. Murphy, "Explaining the Worldwide Boom in Higher Education of Women," Journal of Human Capital, 2010, 4 (3), 203-241.

_, _, and _ , "The Market for College Graduates and the Worldwide Boom in Higher Education of Women," American Economic Review: Papers \& Proceedings, May 2010, 100, 229-233.

Bergstrom, Theodore C. and Mark Bagnoli, “Courtship as a Waiting Game,” Journal of Political Economy, February 1993, 101 (1), 185-202.

_ and Robert F. Schoeni, "Income Prospects and Age-at-Marriage," Journal of Population Economics, 1996, 9, 115-130.

Bitler, Marianne P. and Lucie Schmidt, "Utilization of Infertility Treatments: The Effects of Insurance Mandates," Demography, 2012, 49, 125-149.

Blossfeld, Hans-Peter and Andreas Timm, Who Marries Whom? Educational Systems as Marriage Markets in Modern Societies, Dordrecht: Kluwer Academic, 2003.

Bronson, Mary Ann, "Degrees Are Forever: Marriage, Educational Investment, and Lifecycle Labor Decisions of Men and Women," January 2015. Working Paper, Department of Economics, Georgetown University.

Bruze, Gustaf, "Male and Female Marriage Returns to Schooling," International Economic Review, February 2015, 56 (1), 207-234.

Buchmann, Claudia and Thomas A. DiPrete, "The Growing Female Advantage in College Completion: The Role of Family Background and Academic Achievement," American Sociological Review, August 2006, 71 (4), 515-541.

Buckles, Kasey S., "Stopping the Biological Clock: Infertility Treatments and the Career-Family Tradeoff," 2007. Working Paper, Department of Economics, Boston University.

_ , "Understanding the Returns to Delayed Childbearing for Working Women," American Economic Review: Papers \& Proceedings, May 2008, 98 (2), 403-407.

Charles, Kerwin Kofi and Ming-Ching Luoh, "Gender Differences in Completed Schooling," The Review of Economics and Statistics, August 2003, 85 (3), 559-577.

Chiappori, Pierre-André and Sonia Oreffice, "Birth Control and Female Empowerment: An Equilibrium Analysis," Journal of Political Economy, 2008, 116 (1), 113-140. 
Chiappori, Pierre-André, Bernard Salanié, and Yoram Weiss, "Partner Choice, Investment in Children, and the Marital College Premium," American Economic Review, August 2017, 107 (8), 2109-2167.

_, Murat Iyigun, and Yoram Weiss, "Investment in Schooling and the Marriage Market," American Economic Review, 2009, 99 (5), 1689-1713.

Chiappori, Pierre-André, Sonia Oreffice, and Climent Quintana-Domeque, "Fatter Attraction: Anthropometric and Socioeconomic Matching on the Marriage Market," Journal of Political Economy, August 2012, 120 (4), 659-695.

${ }_{-},{ }_{-}$, and $\ldots$, "Multidimensional Matching with a Potential Handicap: Smoking in the Marriage Market," August 2012. Working Paper, Department of Economics, Columbia University.

Choo, Eugene and Aloysius Siow, "Who Marries Whom and Why," Journal of Political Economy, 2006, 114 (1), 175-201.

Chuan, Amanda, "Non-College Occupations and the Gender Gap in College Enrollment," October 2018. School of Human Resources and Labor Relation, Michigan State University.

Coles, Melvyn G. and Marco Francesconi, "On the Emergence of Toyboys: The Timing of Marriage with Aging and Uncertain Careers," International Economic Review, August 2011, 52 (3), 825-853.

_ and _, "Equilibrium Search and the Impact of Equal Opportunities for Women," June 2017. IZA DP No. 10827.

_ and _, "Equilibrium Search with Multiple Attributes and the Impact of Equal Opportunities for Women," Journal of Political Economy, 2018.

Dessy, Sylvain and Habiba Djebbari, "High-Powered Careers and Marriage: Can Women Have It All?," The B.E. Journal of Economic Analysis and Policy, 2010, 10 (1), Article 42.

Díaz-Giménez, Javier and Eugenio Giolito, “Accounting for the Timing of First Marriage," International Economic Review, February 2013, 54 (1), 135-158.

DiPrete, Thomas A. and Claudia Buchmann, "Gender-Specific Trends in the Value of Education and the Emerging Gender Gap in College Completion," Demography, 2006, 43 (1), 1-24.

Dougherty, Christopher, "Why Are the Returns to Schooling Higher for Women Than for Men?," Journal of Human Resources, 2005, 40 (4), 969-988. 
Garcia-Moran, Eva M., "Differential Fecundity and Child Custody," Journal of Economic Dynamics and Control, May 2018, 90, 156-170.

Ge, Suqin, “Women's College Decisions: How Much Does Marriage Matter?," Journal of Labor Economics, October 2011, 29 (4), 773-818.

Gershoni, Naomi and Corinne Low, "The Impact of Extended Reproductive Time Horizons: Evidence from Israel's Expansion of IVF Access," December 2017. Working Paper, Business Economics and Public Policy Department, the Wharton School, University of Pennsylvania.

Goldin, Claudia, Understanding the Gender Gap: An Economic History of American Women, New York: Oxford University Press, 1990.

_ , "The Quiet Revolution That Transformed Women's Employment, Education, and Family," American Economic Review, 2006, 96 (2), 1-21.

_ , “A Grand Gender Convergence: Its Last Chapter,” American Economic Review, 2014, 104 (4), $1-30$.

_, Lawrence Katz, and Ilyana Kuziemko, "The Homecoming of American College Women: The Reversal of the College Gender Gap," Journal of Economic Perspectives, Fall 2006, 20 (4), $133-156$.

Greenwood, Jeremy, Nezih Guner, and John A. Knowles, "More on Marriage, Fecundity, and the Distribution of Income," International Economic Review, August 2003, 44 (3), 827-862.

_, _, Georgi Kocharkov, and Cezar Santos, "Marry Your Like: Assortative Mating and Income Inequality," American Economic Review: Papers \& Proceedings, May 2014.

_ , _ , , and _ , "Technology and the Changing Family: A Unified Model of Marriage, Divorce, Educational Attainment, and Married Female Labor-Force Participation," American Economic Journal: Macroeconomics, 2016, 8 (1), 1-41.

Gretsky, Neil E., Joseph M. Ostroy, and William R. Zame, "The Nonatomic Assignment Model," Economic Theory, 1992, 2, 103-127.

Hubbard, William, "The Phantom Gender Difference in the College Wage Premium," The Journal of Human Resources, 2011, 46 (3), 568-586.

Iyigun, Murat and Jeanne Lafortune, "Why Wait? A Century of Education, Marriage Timing and Gender Roles," January 2016. IZA DP No. 9671. 
— and Randall P. Walsh, "Building the Family Nest: Premarital Investments, Marriage Markets, and Spousal Allocations," Review of Economic Studies, 2007, 74, 507-535.

Keeley, Michael C., "A Model of Marital Formation: The Determinants of the Optimal Age at First Marriage.” PhD dissertation, University of Chicago June 1974.

_ , "The Economics of Family Formation: An Investigation of the Age at First Marriage," Economic Inquiry, April 1977, 15, 238-250.

_ , "An Analysis of the Age Pattern of First Marriage," International Economic Review, June 1979, $20(2), 527-544$.

Lafortune, Jeanne, "Making Yourself Attractive: Pre-Marital Investments and the Returns to Education in the Marriage Market," American Economic Journal: Applied Economics, April 2013, 5 (2), 151-178.

Lam, David, "Marriage Markets and Assortative Mating with Household Public Goods: Theoretical Results and Empirical Implications," The Journal of Human Resources, 1988, 23 (4), $462-487$.

Livingston, Gretchen and D'Vera Cohn, “The New Demography of American Motherhood," August 2010. Pew Research Center: A Social and Demographic Trends Report.

Low, Corinne, “A 'Reproductive Capital’ Model of Marriage Market Matching,” December 2017. Working Paper, Business Economics and Public Policy Department, the Wharton School, University of Pennsylvania.

Mulligan, Casey B. and Yona Rubinstein, “Selection, Investment, and Women's Relative Wages Over Time," Quarterly Journal of Economics, August 2008, 123 (3), 1061-1110.

Olivieri, Elisa, "Occupational Choice and the College Gender Gap," November 2014. Working Paper, Department of Economics, University of Chicago.

Oppenheimer, Valerie Kincade, "A Theory of Marriage Timing," American Journal of Sociology, November 1988, 94 (3), 563-591.

Ruggles, Steven, Katie Genadek, Ronald Goeken, Josiah Grover, and Matthew Sobek, Integrated Public Use Microdata Series: Version 7.0 [dataset] Minneapolis: University of Minnesota 2017.

Schmidt, Lucie, "Infertility Insurance Mandates and Fertility," The American Economic Review, May 2005, May (2), 204-208. 
_ , "Effects of Infertility Insurance Mandates on Fertility," Journal of Health Economics, May 2007, 26 (3), 431-446.

Schwartz, Christine R. and Robert D. Mare, "Trends in Educational Assortative Marriage from 1940 to 2003," Demography, 2005, 42 (4), 621-646.

Shapley, Lloyd S. and Martin Shubik, “The Assignment Game I: The Core,” International Journal of Game Theory, 1972, 1 (1), 111-130.

Siow, Aloysius, "Differential Fecundity, Markets, and Gender Roles," Journal of Political Economy, April 1998, 106 (2), 334-354.

_ , "Assortative Matching in the Marriage Market," in James D. Wright, ed., International Encyclopedia of the Social \& Behavioral Sciences, 2nd edition, Vol. 2 Elsevier 2015, pp. 100-107.

_ and Xiaodong Zhu, "Differential Fecundity and Gender-Biased Parental Investments in Health," Review of Economic Dynamics, 2002, 5, 999-1024.

Stevenson, Betsey and Justin Wolfers, "Marriage and Divorce: Changes and Their Driving Forces," Journal of Economic Perspectives, Spring 2007, 21 (2), 27-52.

Thomas, Mallika, "The Impact of Mandated Maternity Benefits on the Gender Differential in Promotions," January 2018. Working Paper, Department of Economics, Cornell University.

Todd, Peter M., Francesco C. Billari, and Jorge Simao, "Aggregate Age-at-Marriage Patterns from Individual Mate-Search Heuristics,” Demography, August 2005, 42 (3), 559-574.

Zhang, Hanzhe, "Essays in Matching, Auctions, and Evolution." PhD dissertation, University of Chicago June 2015.

_ , "Courtship as an Investing Game: Labor-Market and Marriage-Market Outcomes by Age at Marriage," August 2017. Working Paper, Department of Economics, Michigan State University.

_ , "A Marriage-Market Perspective of the College Gender Gap," October 2017. Working Paper, Department of Economics, Michigan State University.

Zhang, Junsen, "Do Men with Higher Wages Marry Earlier or Later?,” Economics Letters, 1995, 49, 193-196. 


\section{Appendix}

\section{A Omitted Figures and Proofs}

\section{A.1 Omitted Figures}

Figure A1 shows average labor income difference between marriage-age groups by birth-year.

\section{A.2 Determination of Stable Marriage Payoff Differences}

The determination of stable marriage payoff difference between any two adjacently ranked types can be described separately for two possible cases, as illustrated in Figure A2: (a) the mass of high-income men is strictly between the mass of women strictly higher ranked than $\tau_{w}^{*}$ and the mass of women weakly higher ranked than $\tau_{w}^{*}$, for some $\tau_{w}^{*} \in T_{w}$, and (b) the mass of highincome men equals the mass of women weakly higher ranked than $\tau_{w}^{*}$, for some $\tau_{w}^{*} \in T_{w}$. In case (a), type- $\tau_{w}^{*}$ women marry both high-income men and low-income men with positive probabilities,

so $v_{m H}+v_{w \tau_{w}^{*}}=s_{H \tau_{w}^{*}}$ and $v_{m L}+v_{w \tau_{w}^{*}}=s_{L \tau_{w}^{*}}$, which together imply $\pi_{m}=v_{m H}-v_{m L}=\delta_{\tau_{w}^{*}}$; the marriage payoff difference between any two adjacently ranked female types can be determined similarly, with the dashed arrows denoting the line of reasoning in Figure A2. In case (b), type $\tau_{w} \succeq \tau_{w}^{*}$ women almost surely marry high-income men, and type $\tau_{w} \prec \tau_{w}^{*}$ women almost surely marry low-income men. Since there is no type of women that marries both types of men with positive probabilities, $\pi_{m}$ is indeterminate, and it can take any value between $\delta_{\tau_{w}}$ and $\delta_{\tau_{w}^{*}}$, where $\tau_{w}$ is the female type ranked just below $\tau_{w}^{*}$. This indeterminacy in $\pi_{m}$ will dissipate in equilibrium, however, when marriage payoffs and investments are jointly determined. For women, almost all $\tau_{w}^{\prime} \succeq \tau_{w}^{*}$ women marry high-income men and almost all $\tau_{w} \prec \tau_{w}^{*}$ women marry low-income men, so $v_{w} \tau_{w}^{\prime}-v_{w} \tau_{w}=s_{H \tau_{w}^{\prime}}-s_{L \tau_{w}}-\pi_{m}$.

\section{A.3 Proof of Theorem 1}

Let $\theta_{m}\left(\pi_{m}\right), \theta_{w 1}\left(\pi_{m}\right)$, and $\theta_{w 2}\left(\pi_{m}\right)$ denote the ability cutoffs characterizing optimal human capital investments when men's stable marriage premium is $\pi_{m}$ (and women's stable marriage-payoff differences are pinned down by $\left.\pi_{m}\right)$. Let $G_{m}\left(\pi_{m}\right)$ and $G_{w}\left(\pi_{m}\right)$ denote the induced distributions of men's and women's marriage characteristics, respectively, when the investment strategies are the ones characterized by the ability cutoffs $\theta_{m}\left(\pi_{m}\right), \theta_{w 1}\left(\pi_{m}\right)$, and $\theta_{w 2}\left(\pi_{m}\right)$. Let $\Pi_{m}\left(G_{m}, G_{w}\right)$ denote the set of men's stable marriage premiums (and associated stable marriage payoffs of women) in the marriage market $\left(G_{m}, G_{w}\right)$. Construct the correspondence

$$
D_{m H}\left(\pi_{m}\right):=\left\{G_{m H} \in[0,1]: \pi_{m} \in \Pi_{m}\left(\left(G_{m H}, 1-G_{m H}\right), G_{w}\left(\pi_{m}\right)\right)\right\} .
$$

For any $\pi_{m} \in\left[\delta_{l}, \delta_{H}\right]$, each element in the set $D_{m H}\left(\pi_{m}\right)$ is a mass $G_{m H}$ of high-income men such that $\pi_{m}$ is men's stable marriage premium in the marriage market $\left(\left(G_{m H}, 1-G_{m H}\right), G_{w}\left(\pi_{m}\right)\right)$. Ex- 
Figure A1: Average labor income differences between age-at-marriage groups, by birth year (a) Average log midlife labor income difference from middle grooms

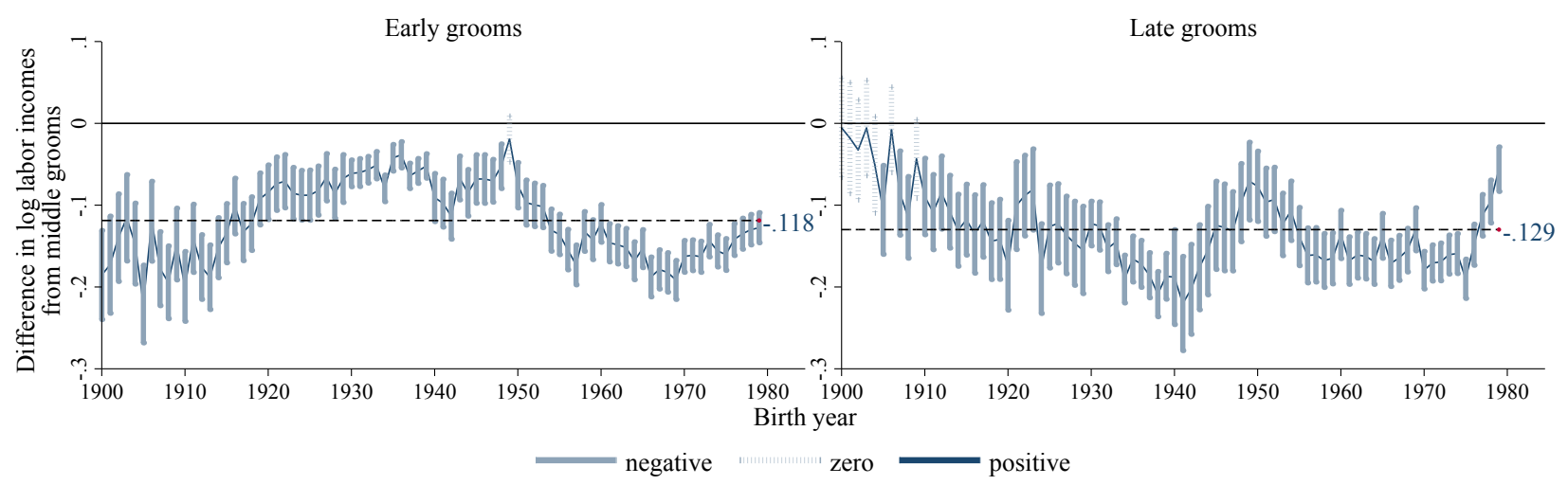

(b) Average log midlife labor income difference from middle brides

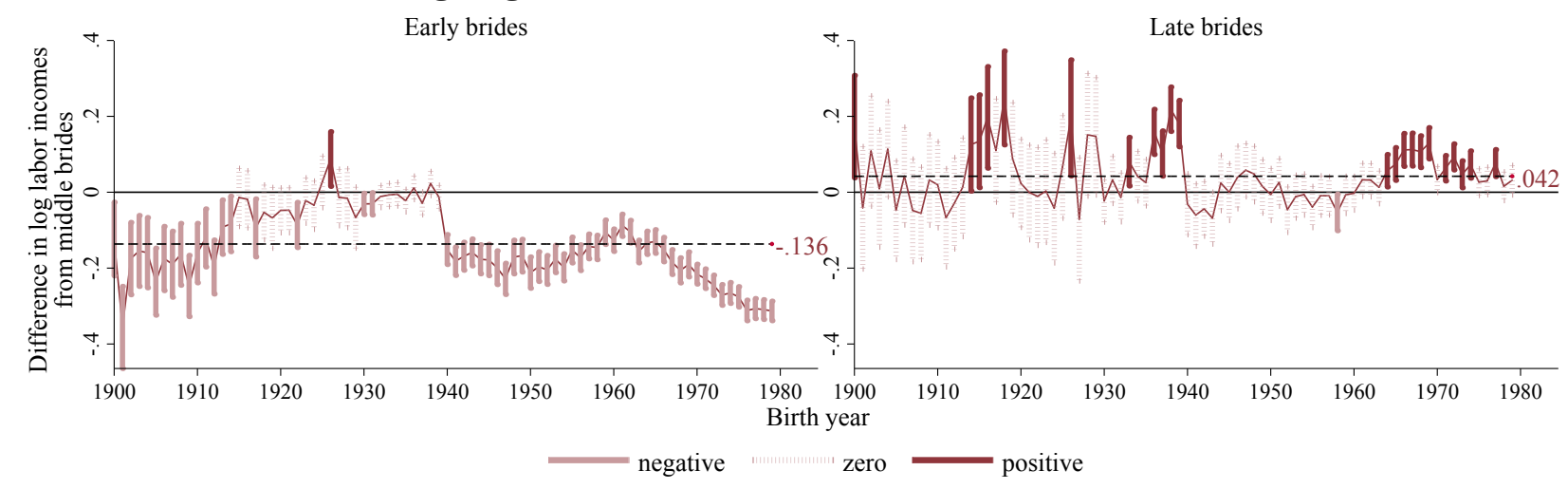

(c) Average log spousal labor income difference from middle brides

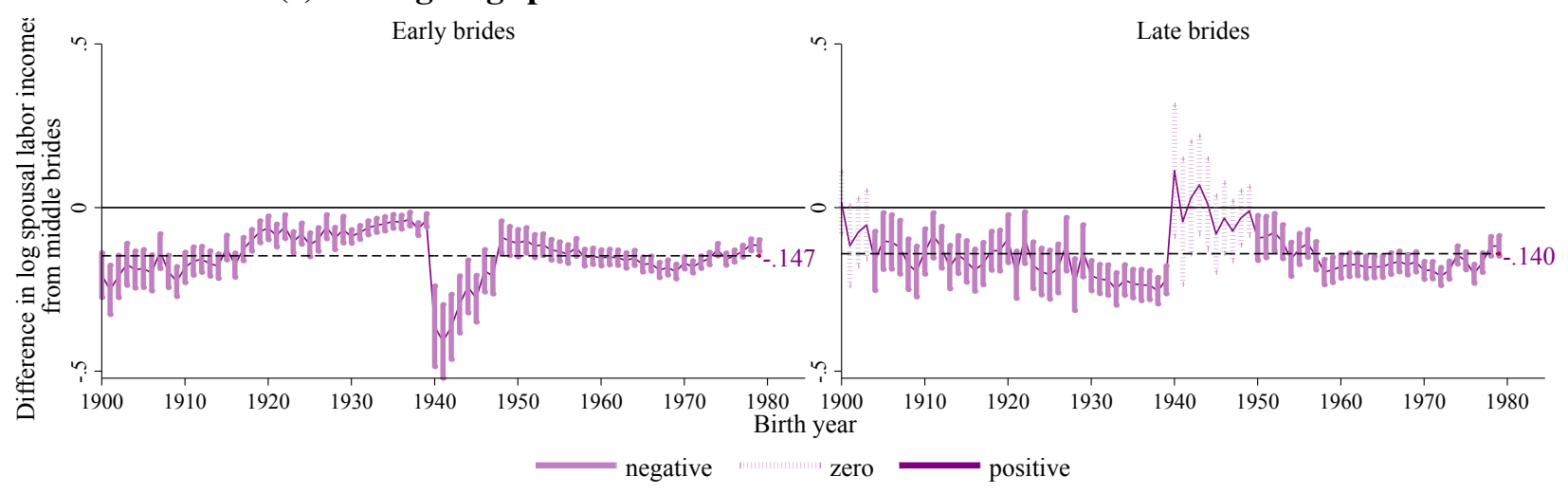

(d) Average spousal labor income difference between early and late brides
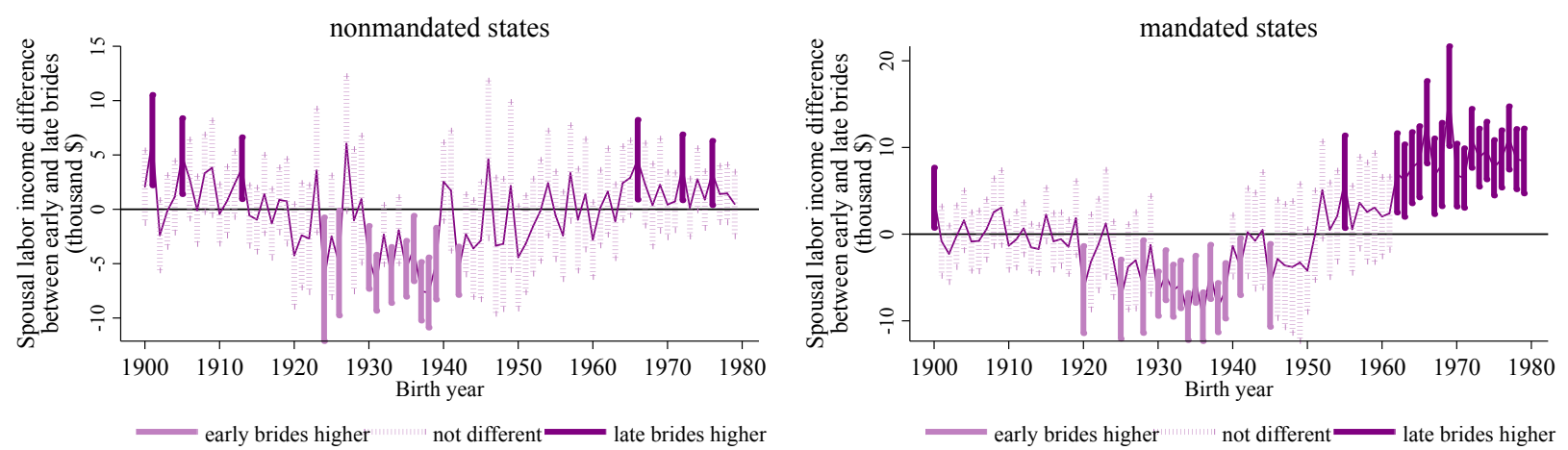
Figure A2: Determination of payoff difference between adjacently ranked marriage types (a) Mass of high-income men between mass of type $\tau_{w} \succ \tau_{w}^{*}$ women and mass of type $\tau_{w} \succeq \tau_{w}^{*}$ women

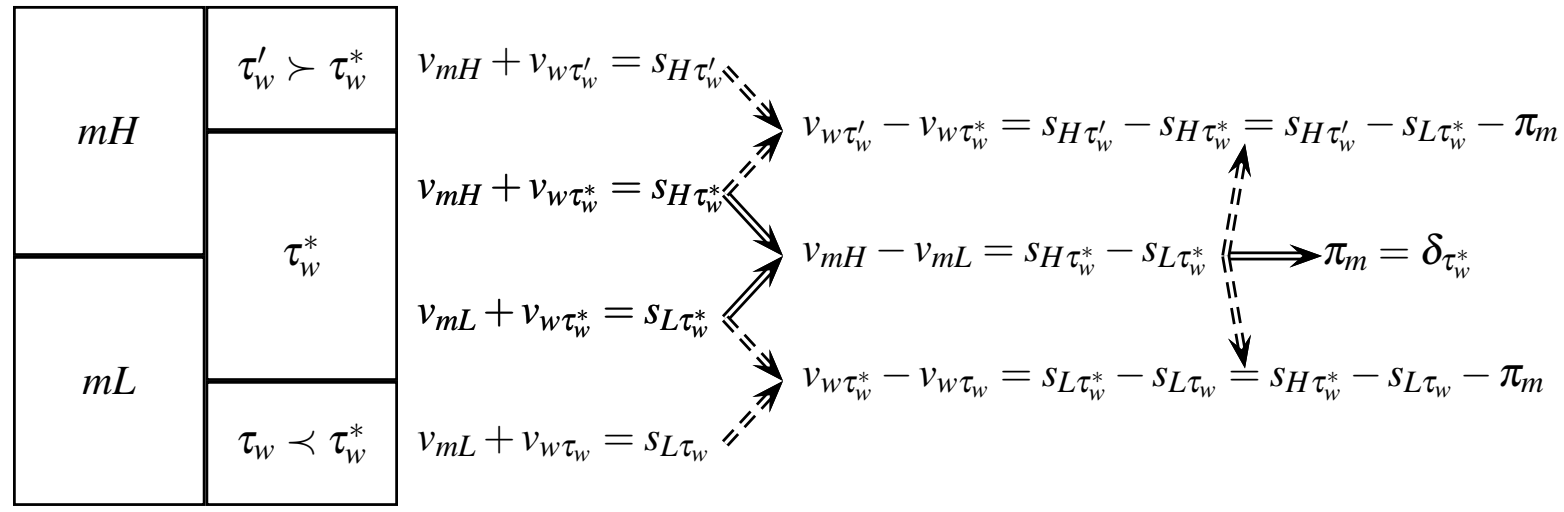

(b) Mass of high-income men equals mass of type women weakly higher ranked than $\tau_{w}^{*}$

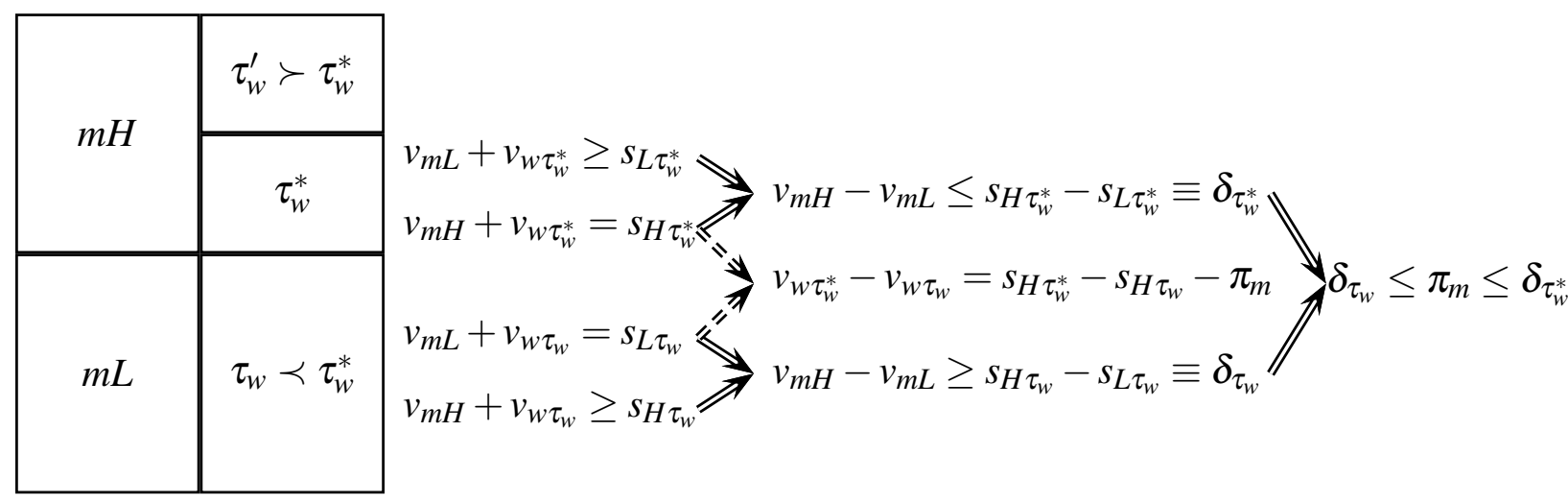

plicitly, (i) $D_{m H}\left(\pi_{m}\right)=\left[G_{w, \succ \tau_{w}^{*}}\left(\pi_{m}\right), G_{w, \succeq \tau_{w}^{*}}\left(\pi_{m}\right)\right]$ if $\pi_{m}=\delta_{\tau_{w}^{*}}$ for a certain type $\tau_{w}^{*} \in T_{w}$; and (ii) $D_{m H}\left(\pi_{m}\right)=G_{w, \succeq \tau_{w}^{*}}\left(\pi_{m}\right)$ if $\pi_{m} \in\left(\delta_{\tau_{w}^{\prime}}, \delta_{\tau_{w}^{*}}\right)$ for a pair of adjacently ranked types $\tau_{w}^{*}$ and $\tau_{w}^{\prime} \prec \tau_{w}^{*}$.

I prove the claim that there exists an equilibrium in which men's stable marriage premium is $\pi_{m}^{*}$ if and only if $G_{m H}\left(\pi_{m}^{*}\right) \in D_{m H}\left(\pi_{m}^{*}\right)$. First, the only if part. Suppose men's equilibrium marriage premium is $\pi_{m}^{*}$. The induced mass of high-income men is $G_{m H}\left(\pi_{m}^{*}\right)$, and the induced distribution of women's marriage characteristics is $G_{w}\left(\pi_{m}^{*}\right)$. Since $\pi_{m}^{*} \in \Pi_{m}\left(\left(G_{m H}\left(\pi_{m}^{*}\right), 1-G_{m H}\left(\pi_{m}^{*}\right)\right), G_{w}\left(\pi_{m}^{*}\right)\right)$, by definition of $D_{m H}\left(\pi_{m}^{*}\right)$, we have $G_{m H}\left(\pi_{m}^{*}\right) \in D_{m H}\left(\pi_{m}^{*}\right)$. Reversely, the if only part. If $G_{m H}\left(\pi_{m}^{*}\right) \in$ $D_{m H}\left(\pi_{m}^{*}\right)$, then by definition of $D_{m H}\left(\pi_{m}^{*}\right), \pi_{m}^{*} \in \Pi_{m}\left(\left(G_{m H}\left(\pi_{m}^{*}\right), 1-G_{m H}\left(\pi_{m}^{*}\right)\right), G_{w}\left(\pi_{m}^{*}\right)\right)$, so $\pi_{m}^{*}$ is men's equilibrium marriage premium.

It follows from the claim above that an equilibrium exists if and only if the graph of function $G_{m H}(\cdot)$ and the graph of correspondence $D_{m H}(\cdot)$ intersect at least once. Equilibrium marriagepayoff differences and equilibrium investments are uniquely determined if and only if the graph of function $G_{m H}(\cdot)$ and the graph of correspondence $D_{m H}(\cdot)$ intersect once and only once. The existence of an equilibrium is guaranteed because $G_{m H}(\cdot)$ has a range $[0,1]$ and is continuous, and $D_{m H}(\cdot)$ has a range $[0,1]$ and is upperhemicontinuous.

It remains to prove equilibrium uniqueness. $G_{m H}\left(\pi_{m}\right)=\int_{\theta_{m}\left(\pi_{m}\right)}^{1} \theta(2-\theta) d F_{m}(\theta)$ is strictly increasing in $\pi_{m}$ because $\theta_{m}\left(\pi_{m}\right)=c_{m} /\left(z_{m H}-z_{m L}+\pi_{m}\right)$ is strictly decreasing in $\pi_{m}$. It suf- 
fices to show $D_{m H}\left(\pi_{m}\right)$ is weakly decreasing in the following sense: for any $\pi_{m}$ and $\pi_{m}^{\prime}>\pi_{m}$, $\max D_{m H}\left(\pi_{m}^{\prime}\right) \leq \min D_{m H}\left(\pi_{m}\right)$. For the remainder of the proof, we mechanically show that $D_{m H}\left(\pi_{m}\right)$ is decreasing. Depending on $\delta_{h}>\delta_{L}, \delta_{h}<\delta_{L}$, or $\delta_{h}=\delta_{L}, D_{m H}\left(\pi_{m}\right)$ is characterized differently. I discuss the three cases separately.

Case 1. Suppose $\delta_{L}>\delta_{h}$. Explicitly,

$$
D_{m H}\left(\pi_{m}\right)= \begin{cases}{\left[G_{w, \succeq h}\left(\pi_{m}\right), 1\right]} & \text { if } \pi_{m}=\delta_{l} \\ G_{w, \succeq h}\left(\pi_{m}\right) & \text { if } \pi_{m} \in\left(\delta_{l}, \delta_{h}\right) \\ {\left[G_{w, \succeq L}\left(\pi_{m}\right), G_{w, \succeq h}\left(\pi_{m}\right)\right]} & \text { if } \pi_{m}=\delta_{h} \\ G_{w, \succeq L}\left(\pi_{m}\right) & \text { if } \pi_{m} \in\left(\delta_{h}, \delta_{L}\right) . \\ {\left[G_{w H}\left(\pi_{m}\right), G_{w, \succeq L}\left(\pi_{m}\right)\right]} & \text { if } \pi_{m}=\delta_{L} \\ G_{w H}\left(\pi_{m}\right) & \text { if } \pi_{m} \in\left(\delta_{L}, \delta_{H}\right) \\ {\left[0, G_{w H}\left(\pi_{m}\right)\right]} & \text { if } \pi_{m}=\delta_{H}\end{cases}
$$

It remains to show that (i) $G_{w, \succeq h}\left(\pi_{m}\right)$ is strictly decreasing when $\pi_{m} \in\left(\delta_{l}, \delta_{h}\right)$, (ii) $G_{w, \succeq L}\left(\pi_{m}\right)$ is strictly decreasing when $\pi_{m} \in\left(\delta_{h}, \delta_{L}\right)$, and (iii) $G_{w H}\left(\pi_{m}\right)$ is strictly decreasing when $\pi_{m} \in\left(\delta_{L}, \delta_{H}\right)$.

(i) To show $G_{w, \succeq h}\left(\pi_{m}\right)=1-\int_{\theta_{w 2}\left(\pi_{m}\right)}^{1}(1-\theta)^{2} d F_{w}(\theta)$ is strictly decreasing when $\pi_{m} \in\left(\delta_{l}, \delta_{h}\right)$, it suffices to show $\theta_{w 2}\left(\pi_{m}\right)$ is strictly decreasing when $\pi_{m} \in\left(\delta_{l}, \delta_{h}\right)$. Men's stable marriage premium can be $\pi_{m} \in\left(\delta_{l}, \delta_{h}\right)$ only when $G_{m H}=G_{w, \succeq h}$. When $G_{m H}=G_{w, \succeq h}$, given men's stable marriage premium $\pi_{m}$, women's stable marriage-payoff differences are $v_{w L}-v_{w l}=$ $s_{H L}-s_{L l}-\pi_{m}, v_{w H}-v_{w L}=s_{H H}-s_{H L}$, and $v_{w h}-v_{w l}=s_{H h}-s_{L l}-\pi_{m}$, so

$$
\begin{aligned}
\theta_{w 2}\left(\pi_{m}\right) & =\frac{c_{w}+\left(v_{w L}-v_{w l}\right)}{z_{w H}-z_{w L}+\left(v_{w h}-v_{w l}\right)}=\frac{c_{w}+\left(s_{H L}-s_{L l}-\pi_{m}\right)}{z_{w H}-z_{w L}+\left(s_{H h}-s_{L l}-\pi_{m}\right)} \\
& =\frac{c_{w}+\left(s_{H L}-s_{L l}\right)-\pi_{m}}{z_{w H}-z_{w L}+\left(s_{H h}+s_{L l}\right)-\pi_{m}} .
\end{aligned}
$$

Since $\theta_{w 2}\left(\pi_{m}\right)<1, \theta_{w 2}^{\prime}\left(\pi_{m}\right)<0$ when $\pi_{m} \in\left(\delta_{l}, \delta_{h}\right)$.

(ii) To show $G_{w, \succeq L}\left(\pi_{m}\right)=1-\int_{\theta_{w 2}\left(\pi_{m}\right)}^{1}(1-\theta) d F_{w}(\theta)$ is strictly decreasing when $\pi_{m} \in\left(\delta_{h}, \delta_{L}\right)$, it suffices to show $\theta_{w 2}\left(\pi_{m}\right)$ is strictly decreasing when $\pi_{m} \in\left(\delta_{h}, \delta_{L}\right)$. Men's stable marriage premium can be $\pi_{m} \in\left(\delta_{h}, \delta_{L}\right)$ only when $G_{m H}=G_{w, \succeq L}$. When $G_{m H}=G_{w, \succeq L}$, given men's stable marriage premium $\pi_{m}$, women's stable marriage-payoff differences are $v_{w L}-v_{w l}=$ $s_{H L}-s_{L l}-\pi_{m}, v_{w H}-v_{w L}=s_{H H}-s_{H L}$, and $v_{w h}-v_{w l}=s_{L h}-s_{L l}$, so

$$
\theta_{w 2}\left(\pi_{m}\right)=\frac{c_{w}+\left(s_{H L}-s_{L l}-\pi_{m}\right)}{z_{w H}-z_{w L}+\left(s_{L h}-s_{L l}\right)} .
$$

Therefore, $\theta_{w 2}\left(\pi_{m}\right)$ is strictly decreasing when $\pi_{m} \in\left(\delta_{h}, \delta_{L}\right)$.

(iii) To show $G_{w H}\left(\pi_{m}\right)=\int_{\theta_{w 1}\left(\pi_{m}\right)}^{1} \theta d F_{w}(\theta)+\int_{\theta_{w 2}\left(\pi_{m}\right)}^{1}(1-\theta) \theta d F_{w}(\theta)$ is strictly decreasing when $\pi_{m} \in\left(\delta_{L}, \delta_{H}\right)$, it suffices to show $\theta_{w 1}\left(\pi_{m}\right)$ and $\theta_{w 2}\left(\pi_{m}\right)$ are strictly increasing when $\pi_{m} \in$ 
$\left(\delta_{L}, \delta_{H}\right)$. Men's stable marriage premium is $\pi_{m} \in\left(\delta_{L}, \delta_{H}\right)$ only when $G_{m H}=G_{w H}\left(\pi_{m}\right)$. When $G_{m H}=G_{w H}$, given men's stable marriage premium $\pi_{m}$, women's stable marriagepayoff differences are $v_{w L}-v_{w l}=s_{L L}-s_{L l}, v_{w H}-v_{w L}=s_{H L}-s_{L l}-\pi_{m}$, and $v_{w h}-v_{w l}=$ $s_{L h}-s_{L l}$, so

and

$$
\theta_{w 1}\left(\pi_{m}\right)=\frac{c_{w}}{z_{w H}-z_{w L}+s_{H H}-s_{L L}-\pi_{m}},
$$

$$
\theta_{w 2}\left(\pi_{m}\right)=\frac{c_{w}+\left(s_{L L}-s_{L l}\right)}{z_{w H}-z_{w L}+\left(s_{L h}-s_{L l}\right)} .
$$

Therefore, both $\theta_{w 1}\left(\pi_{m}\right)$ and $\theta_{w 2}\left(\pi_{m}\right)$ are increasing when $\pi_{m} \in\left(\delta_{L}, \delta_{H}\right)$.

Case 2. Suppose $\delta_{h} \geq \delta_{L}$. Explicitly,

$$
D_{m H}\left(\pi_{m}\right)= \begin{cases}{\left[G_{w, \succeq L}\left(\pi_{m}\right), 1\right]} & \text { if } \pi_{m}=\delta_{l} \\ G_{w, \succeq L}\left(\pi_{m}\right) & \text { if } \pi_{m} \in\left(\delta_{l}, \delta_{L}\right) \\ {\left[G_{w, \succeq h}\left(\pi_{m}\right), G_{w, \succeq L}\left(\pi_{m}\right)\right]} & \text { if } \pi_{m}=\delta_{L} \\ G_{w, \succeq h}\left(\pi_{m}\right) & \text { if } \pi_{m} \in\left(\delta_{L}, \delta_{h}\right) . \\ {\left[G_{w H}\left(\pi_{m}\right), G_{w, \succeq h}\left(\pi_{m}\right)\right]} & \text { if } \pi_{m}=\delta_{h} \\ G_{w H}\left(\pi_{m}\right) & \text { if } \pi_{m} \in\left(\delta_{h}, \delta_{H}\right) \\ {\left[0, G_{w H}\left(\pi_{m}\right)\right]} & \text { if } \pi_{m}=\delta_{H}\end{cases}
$$

It suffices to show that (i) $G_{w, \succeq L}\left(\pi_{m}\right)$ is strictly decreasing when $\pi_{m} \in\left(\delta_{l}, \delta_{L}\right)$, (ii) $G_{w, \succeq h}\left(\pi_{m}\right)$ is strictly decreasing when $\pi_{m} \in\left(\delta_{L}, \delta_{h}\right)$, and (iii) $G_{w H}\left(\pi_{m}\right)$ is strictly decreasing when $\pi_{m} \in\left(\delta_{h}, \delta_{H}\right)$.

(i) To show $G_{w, \succeq L}\left(\pi_{m}\right)=1-\int_{\theta_{w 2}\left(\pi_{m}\right)}^{1}(1-\theta)^{2} d F_{w}(\theta)$ is strictly decreasing when $\pi_{m} \in\left(\delta_{l}, \delta_{L}\right)$, it suffices to show $\theta_{w 2}\left(\pi_{m}\right)$ is strictly decreasing when $\pi_{m} \in\left(\delta_{l}, \delta_{L}\right)$. Men's stable marriage premium can be $\pi_{m} \in\left(\delta_{l}, \delta_{L}\right)$ only when $G_{m H}=G_{w, \succeq L}$. When $G_{m H}=G_{w, \succeq L}$, given men's stable marriage premium $\pi_{m}$, women's stable marriage-payoff differences are $v_{w L}-v_{w l}=$ $s_{H L}-s_{L l}-\pi_{m}, v_{w H}-v_{w L}=s_{H H}-s_{H L}$, and $v_{w h}-v_{w l}=s_{H h}-s_{H l}-\pi_{m}$, so

$$
\theta_{w 2}\left(\pi_{m}\right)=\frac{c_{w}+\left(s_{H L}-s_{L l}-\pi_{m}\right)}{z_{w H}-z_{w L}+\left(s_{H h}-s_{H l}-\pi_{m}\right)} .
$$

Since $\theta_{w 2}\left(\pi_{m}\right)<1, \theta_{w 2}^{\prime}\left(\pi_{m}\right)<0$ when $\pi_{m} \in\left(\delta_{l}, \delta_{L}\right)$.

(ii) To show $G_{w, \succeq h}\left(\pi_{m}\right)$, it suffices to show both $\theta_{w 1}\left(\pi_{m}\right)$ and $\theta_{w 2}\left(\pi_{m}\right)$ are strictly increasing when $\pi_{m} \in\left(\delta_{h}, \delta_{L}\right)$. Men's stable marriage payoff can be $\pi_{m} \in\left(\delta_{h}, \delta_{L}\right)$ only when $G_{m H}=G_{w, \succeq h}$. When $G_{m H}=G_{w, \succeq h}$, given men's stable marriage premium $\pi_{m}$, women's stable marriage-payoff differences are $v_{w H}-v_{w L}=s_{H H}-s_{L L}-\pi_{m}, v_{w L}-v_{w l}=s_{L L}-s_{L l}$, and $v_{w h}-v_{w l}=s_{H h}-s_{L l}-\pi_{m}$, so

$$
\theta_{w 1}\left(\pi_{m}\right)=\frac{c_{w}}{z_{w H}-z_{w L}+\left(s_{H H}-s_{L L}-\pi_{m}\right)}
$$


and

$$
\theta_{w 2}\left(\pi_{m}\right)=\frac{c_{w}+\left(s_{L L}-s_{L l}\right)}{z_{w H}-z_{w L}+\left(s_{H h}-s_{L l}-\pi_{m}\right)} .
$$

Therefore, both $\theta_{w 1}\left(\pi_{m}\right)$ and $\theta_{w 2}\left(\pi_{m}\right)$ are strictly increasing when $\pi_{m} \in\left(\delta_{L}, \delta_{h}\right)$.

(iii) To show $G_{w H}\left(\pi_{m}\right)=\int_{\theta_{w 1}\left(\pi_{m}\right)}^{1} \theta d F_{w}(\theta)$ is strictly decreasing when $\pi_{m} \in\left(\delta_{h}, \delta_{H}\right)$, it suffices to show $\theta_{w 1}\left(\pi_{m}\right)$ is strictly increasing when $\pi_{m} \in\left(\delta_{h}, \delta_{L}\right)$. Men's stable marriage premium can be $\pi_{m} \in\left(\delta_{h}, \delta_{L}\right)$ only when $G_{m H}=G_{w H}$. When $G_{m H}=G_{w H}$, given men's stable marriage premium $\pi_{m}$, women's stable marriage-payoff difference $v_{w H}-v_{w L}=s_{H H}-s_{L L}-\pi_{m}$, so

$$
\theta_{w 1}\left(\pi_{m}\right)=\frac{c_{w}}{z_{w H}-z_{w L}+s_{H H}-s_{L L}-\pi_{m}} .
$$

Therefore, $\theta_{w 1}\left(\pi_{m}\right)$ is strictly decreasing when $\pi_{m} \in\left(\delta_{h}, \delta_{L}\right)$.

Case 3. Suppose $\delta_{h}=\delta_{L}$. Types are ranked as $H \succ L \sim h \succ l$. Let $\tau_{2}:=L \sim h$. Explicitly,

$$
D_{m H}\left(\pi_{m}\right)=\left\{\begin{array}{ll}
{\left[G_{w, \succeq \tau_{2}}\left(\pi_{m}\right), 1\right]} & \text { if } \pi_{m}=\delta_{l} \\
G_{w, \succeq \tau_{2}}\left(\pi_{m}\right) & \text { if } \pi_{m} \in\left(\delta_{l}, \delta_{\tau_{2}}\right) \\
{\left[G_{w H}\left(\pi_{m}\right), G_{w, \succeq \tau_{2}}\left(\pi_{m}\right)\right]} & \text { if } \pi_{m}=\delta_{\tau_{2}} \\
G_{w H}\left(\pi_{m}\right) & \text { if } \pi_{m} \in\left(\delta_{\tau_{2}}, \delta_{H}\right) \\
{\left[0, G_{w H}\left(\pi_{m}\right)\right]} & \text { if } \pi_{m}=\delta_{H}
\end{array} .\right.
$$

It remains to show that (i) $G_{w, \succeq \tau_{2}}\left(\pi_{m}\right)$ is strictly decreasing when $\pi_{m} \in\left(\delta_{l}, \delta_{\tau_{2}}\right)$, and (ii) $G_{w H}\left(\pi_{m}\right)$ is strictly decreasing when $\pi_{m} \in\left(\delta_{\tau_{2}}, \delta_{H}\right)$.

(i) To show $G_{w, \succeq \tau_{2}}\left(\pi_{m}\right)=1-\int_{\theta_{w 2}\left(\pi_{m}\right)}^{1}(1-\theta)^{2} d F_{w}(\theta)$ is strictly decreasing when $\pi_{m} \in\left(\delta_{l}, \delta_{\tau_{2}}\right)$, it suffices to show $\theta_{w 2}\left(\pi_{m}\right)$ is strictly decreasing when $\pi_{m} \in\left(\delta_{l}, \delta_{\tau_{2}}\right)$. Men's stable marriage premium can be $\pi_{m} \in\left(\delta_{l}, \delta_{L}\right)$ only when $G_{m H}=G_{w, \succeq \tau_{2}}$. When $G_{m H}=G_{w, \succeq \tau_{2}}$, given men's stable marriage premium $\pi_{m}$, women's stable marriage-payoff differences are $v_{w L}-v_{w l}=$ $s_{H L}-s_{L l}-\pi_{m}, v_{w H}-v_{w L}=s_{H H}-s_{H L}$, and $v_{w h}-v_{w l}=s_{H h}-s_{H l}-\pi_{m}$, so

$$
\theta_{w 2}\left(\pi_{m}\right)=\frac{c_{w}+s_{H L}-s_{L l}-\pi_{m}}{z_{w H}-z_{w L}+s_{H h}-s_{H l}-\pi_{m}} .
$$

Since $\theta_{w 2}\left(\pi_{m}\right)<1, \theta_{w 2}\left(\pi_{m}\right)$ is strictly decreasing when $\pi_{m} \in\left(\delta_{l}, \delta_{\tau_{2}}\right)$.

(ii) To show $G_{w H}\left(\pi_{m}\right)=\int_{\theta_{w 1}\left(\pi_{m}\right)}^{1} \theta d F_{w}(\theta)$ is strictly decreasing when $\pi_{m} \in\left(\delta_{\tau_{2}}, \delta_{H}\right)$, it suffices to show $\theta_{w 1}\left(\pi_{m}\right)$ is strictly increasing when $\pi_{m} \in\left(\delta_{\tau_{2}}, \delta_{H}\right)$. Men's stable marriage premium can be $\pi_{m}$ only when $G_{m H}=G_{w H}$. When $G_{m H}=G_{w H}$, given men's stable marriage premium $\pi_{m}$, women's stable marriage-payoff difference $v_{w H}-v_{w L}=s_{H H}-s_{L L}-\pi_{m}$, so

$$
\theta_{w 1}\left(\pi_{m}\right)=\frac{c_{w}}{z_{w H}-z_{w L}+s_{H H}-s_{L L}-\pi_{m}} .
$$

Therefore, $\theta_{w 1}\left(\pi_{m}\right)$ is strictly increasing when $\pi_{m} \in\left(\delta_{\tau_{2}}, \delta_{H}\right)$. 


\section{A.4 Proof of Proposition 1}

I first prove the college gender gap. Suppose by way of contradiction that weakly fewer women than men go to college in equilibrium: $1-F_{w}\left(\theta_{w 1}^{*}\right) \leq 1-F_{m}\left(\theta_{m}^{*}\right)$. First, since $F_{m}=F_{w}$ by assumption, $F_{w}\left(\theta_{w 1}^{*}\right) \geq F_{m}\left(\theta_{m}^{*}\right)$ implies $\theta_{w 1}^{*}=c_{w} /\left(z_{w H}-z_{w L}+v_{w H}^{*}-v_{w L}^{*}\right) \geq \theta_{m}^{*}=c_{m} /\left(z_{m H}-z_{m L}+v_{m H}^{*}-\right.$ $\left.v_{m L}^{*}\right)$. Since $z_{w H}-z_{w L}=z_{m H}-z_{m L}$ by assumption, $v_{w H}^{*}-v_{w L}^{*} \leq v_{m H}^{*}-v_{m L}^{*}$.

Second, $\theta_{w 2}^{*}>\theta_{w 1}^{*}$, so strictly fewer women than men make a career investment in equilibrium. Since weakly fewer women go to college by our premise and strictly fewer women make a career investment, strictly fewer women than men earn a high income, i.e., $G_{w H}^{*}+G_{w h}^{*}<G_{m H}^{*}$. As a result, there is a positive mass of type- $L$ women marrying high-income men. By pairwise efficiency, $v_{w L}^{*}=s_{H L}-v_{m H}^{*}$. Since there is always a positive mass of $(H, H)$ couples, by pairwise efficiency, $v_{w H}^{*}=s_{H H}-v_{m H}^{*}$. The two pairwise efficiency conditions together imply $v_{w H}^{*}-v_{w L}^{*}=s_{H H}-s_{H L}$. By $s_{H L}=s_{L H}, v_{w H}^{*}-v_{w L}^{*}=s_{H H}-s_{H L}=s_{H H}-s_{L H}=\delta_{H}$. Because a positive mass of type- $H$ men marries type- $L$ women in equilibrium, $v_{m H}^{*}=s_{H L}-v_{w L}^{*}$. Furthermore, by Pareto efficiency, $v_{m L}^{*} \geq s_{L L}-v_{w L}^{*}$. The two conditions together imply $v_{m H}^{*}-v_{m L}^{*} \leq s_{H L}-s_{L L}$. Since the surplus is strictly super-modular in incomes, $v_{w H}^{*}-v_{w L}^{*}=\delta_{H}>\delta_{L}=v_{m H}^{*}-v_{m L}$.

The two conclusions, $v_{w H}^{*}-v_{w L}^{*} \leq v_{m H}^{*}-v_{m L}^{*}$ and $v_{w H}^{*}-v_{w L}^{*}>v_{m H}^{*}-v_{m L}^{*}$, contradict each other. Therefore, there must be strictly more women than men going to college.

I now prove the earnings gender gap. Consider the assumption $G_{m H}\left(\delta_{l}\right)>G_{w H}\left(\delta_{l}\right)+G_{w h}\left(\delta_{l}\right)$. It states that when men's stable marriage premium $\pi_{m}$ is $\delta_{l}$ the lowest value possible, mass $G_{m H}\left(\delta_{l}\right)$ of high-income men is strictly greater than the mass $G_{w H}\left(\delta_{l}\right)+G_{w h}\left(\delta_{l}\right)$ of high-income women. That is, even when men have the smallest possible marriage premium $\pi_{m}=\delta_{l}=s_{H l}-s_{H l}$ and women have the largest possible marriage premium $\pi_{w}=s_{H H}-s_{H L}$, fewer women will end up with a high income than men. Therefore, the earnings gender gap always holds.

$Q E D$

Discussion. Without the assumption $G_{m H}\left(\delta_{l}\right)>G_{w H}\left(\delta_{l}\right)+G_{w h}\left(\delta_{l}\right)$, I can show that there are weakly fewer fertile high-income women than high-income men in equilibrium. Suppose by way of contradiction that there are strictly fewer high-income men than fertile high-income women in equilibrium: $G_{m H}^{*}<G_{w H}^{*}$. As a result, low-income men marry type $H$ women with a positive probability: $v_{m L}^{*}=s_{L H}-v_{w L}^{*}$. In addition, almost all high-income men marry type $H$ women, so $v_{m H}^{*}=s_{H H}-v_{w L}^{*}$. The two conditions together imply $v_{m H}^{*}-v_{m L}^{*}=s_{H H}-s_{L H}=\delta_{H}$. Since lowincome men marry both high-income men and low-income men with positive probabilities, $v_{w H}^{*}{ }^{-}$ $v_{w L}^{*}=s_{L H}-s_{L L}=\delta_{L}$, where the second equality follows $s_{H L}=s_{L H}$. Since $v_{m H}^{*}-v_{m L}^{*}>v_{w H}^{*}-v_{w L}^{*}$, $\theta_{m}^{*}>\theta_{w 1}^{*}>\theta_{w 2}^{*}$. Since more men make college investments as well as career investments, there cannot be strictly fewer high-income men than high-income fertile women:

$$
G_{m H}^{*}=\int_{\theta_{m}^{*}}^{1} p d F_{m}(p)+\int_{\theta_{m}^{*}} p(1-p) d F_{m}(p)>\int_{\theta_{w 1}^{*}}^{1} p d F_{w}(p)+r \int_{\theta_{w 2}^{*}}^{1} p(1-p) d F_{w}(p)=G_{w H}^{*},
$$

contradicting the premise. 


\section{Online Appendix}

\section{B Justifications for Assumptions}

\section{B.1 Entering the Marriage Market After Investing}

I claimed in footnote 8 that the strategy of entering the marriage market while investing is weakly dominated by the strategy of entering the marriage market after investing. I extend the basic model to allow this strategy, and show that the strategy is weakly dominated in the extended model. ${ }^{20}$ Since lifetime income can only be high or low in the model, a man's marriage type can be simply represented by the probability of obtaining a high lifetime income when he enters the marriage market. The marriage surplus of a man who obtains a high income with probability $\theta_{m}$ and a fertile woman who obtains a high income with probability $\theta_{w}$ is

$$
\widetilde{s}\left(\theta_{m}, \theta_{w},+\right)=\theta_{m} \theta_{w} s_{H H}+\theta_{m}\left(1-\theta_{w}\right) s_{H L}+\left(1-\theta_{m}\right) \theta_{w} s_{L H}+\left(1-\theta_{m}\right)\left(1-\theta_{w}\right) s_{L L} .
$$

The marriage surplus of a type- $\theta_{m}$ man and a less fertile type- $\theta_{w}$ woman is

$$
\widetilde{s}\left(\theta_{m}, \theta_{w},-\right)=\theta_{m} \theta_{w} s_{H h}+\theta_{m}\left(1-\theta_{w}\right) s_{H l}+\left(1-\theta_{m}\right) \theta_{w} s_{L h}+\left(1-\theta_{m}\right)\left(1-\theta_{w}\right) s_{L l} .
$$

The marriage market in the extended model is organized in the same way as in the basic model. Namely, let $\widetilde{T}_{m}=[0,1]$ and $\widetilde{T}_{w}=[0,1] \times \Phi$ represent the expanded sets of marriage types, $\widetilde{G}_{m}$ and $\widetilde{G}_{w}$ distributions of marriage types, $\widetilde{G}$ a matching, and $\widetilde{v}_{m}$ and $\widetilde{v}_{w}$ marriage payoffs. The outcome $\left(\widetilde{G}, \widetilde{v}_{m}, \widetilde{v}_{w}\right)$ is stable in the marriage market $\left(\widetilde{G}_{m}, \widetilde{G}_{w}\right)$ if (1) (individual rationality) $\widetilde{v}_{m} \tau_{m} \geq 0$ for all $\tau_{m} \in \widetilde{T}_{m}$ and $\widetilde{v}_{w} \tau_{w} \geq 0$ for all $\tau_{w} \in \widetilde{T}_{w}$, (2) (pairwise efficiency) $\widetilde{v}_{m} \tau_{m}+\widetilde{v}_{w} \tau_{w}=\widetilde{s}_{\tau_{m}} \tau_{w}$ when $\widetilde{G}\left(\tau_{m}, \tau_{w}\right)>0$, and (3) (Pareto efficiency) $\widetilde{v}_{m} \tau_{m}+\widetilde{v}_{w} \tau_{w} \geq \widetilde{s}_{\tau_{m}} \tau_{w}$ for any pair of $\tau_{m} \in \widetilde{T}_{m}$ and $\tau_{w} \in \widetilde{T}_{w}$.

I now show that the strategy of simultaneously investing and marrying is weakly dominated by investing and then marrying after income is realized for a college man. Let $\tau_{w}$ denote the type of woman an ability- $\theta$ man who has made the college investment and will not make the career investment marries in the stable matching. His stable marriage payoff is

$$
\widetilde{v}_{m \theta}=\widetilde{s}_{\theta \tau_{w}}-\widetilde{v}_{w} \tau_{w}=p \widetilde{s}_{1} \tau_{w}+(1-\theta) \widetilde{s}_{0 \tau_{w}}-\widetilde{v}_{w} \tau_{w} .
$$

By Pareto efficiency, the marriage payoff of each man weakly exceeds what he would get if he marries a type- $\tau_{w}$ woman: for type-1 (i.e., high-income) and probability-0 (i.e., low-income) men, $\widetilde{v}_{m 1} \geq \widetilde{s}_{1} \tau_{w}-\widetilde{v}_{w} \tau_{w}$ and $\widetilde{v}_{m 0} \geq \widetilde{s}_{0} \tau_{w}-\widetilde{v}_{w} \tau_{w}$. If the same ability- $\theta$ man makes a college investment and marries after income is realized, his expected marriage payoff is $p \widetilde{v}_{m 1}+(1-\theta) \widetilde{v}_{m 0}$, which, by the two inequalities above, is greater than $p \widetilde{s}_{1} \tau_{w}+(1-\theta) \widetilde{s}_{0} \tau_{w}-\widetilde{v}_{w} \tau_{w}$, which is the expected payoff the man gets from simultaneously investing and marrying. The same argument applies to any man or

\footnotetext{
${ }^{20}$ Because income is uncertain when agents enter the marriage market while investing, their marriage characteristics are represented by distributions of incomes rather than realized incomes (Borch, 1962; Wilson, 1968; Chiappori and Reny, 2016; Zhang, 2017a,b).
} 
any woman who chooses an investment strategy that results in a high income with probability $\theta$, for any $\theta$.

Empirically, most people chose not to marry when they were making human capital investments. First, 86 to 96 percents of college-educated men and 80 to 90 percents of college-educated women did not marry between ages 18 and 21, their college years (Table B1), besides the two outliers, 1930s and 1940s birth cohorts, many of whom were rushed into marriage to avoid being drafted to the Vietnam War. Second, 78 to 92 percents of men with advanced degrees and 79 to 92 percents of women with advanced degrees did not marry between ages 22 and 23 (Table B2).

Table B1: Proportion of college degrees marrying between ages 18 and 21

\begin{tabular}{|l|c|c|c|c|c|c|c|c|}
\hline & $1900 \mathrm{~s}$ & $1910 \mathrm{~s}$ & $1920 \mathrm{~s}$ & $1930 \mathrm{~s}$ & $1940 \mathrm{~s}$ & $1950 \mathrm{~s}$ & $1960 \mathrm{~s}$ & $1970 \mathrm{~s}$ \\
\hline Men & 0.06 & 0.06 & 0.14 & 0.18 & 0.19 & 0.12 & 0.06 & 0.04 \\
\hline Women & 0.10 & 0.12 & 0.23 & 0.29 & 0.29 & 0.20 & 0.12 & 0.10 \\
\hline
\end{tabular}

Table B2: Proportion of advanced degrees marrying between ages 22 and 23

\begin{tabular}{|l|c|c|c|c|c|c|c|c|}
\hline & $1900 \mathrm{~s}$ & $1910 \mathrm{~s}$ & $1920 \mathrm{~s}$ & $1930 \mathrm{~s}$ & $1940 \mathrm{~s}$ & $1950 \mathrm{~s}$ & $1960 \mathrm{~s}$ & $1970 \mathrm{~s}$ \\
\hline Men & 0.09 & 0.13 & 0.20 & 0.21 & 0.22 & 0.15 & 0.09 & 0.08 \\
\hline Women & 0.08 & 0.13 & 0.20 & 0.21 & 0.20 & 0.15 & 0.12 & 0.11 \\
\hline
\end{tabular}

\section{B.2 More Career Investments By Low-Income Individuals}

I define a career investment as obtaining additional education beyond college, obtaining additional training, or switching to a new job. I use NLSY79 and NLSY97 to verify a key assumption of the model: Those who earned a lower income were more likely to make a career investment between ages 23 and 29 .

I run the simple OLS regression, probit regression, as well as logistic regression to test the following relation,

1investment $_{i, \text { age }}=$ age $_{i}+\beta$ logincome $_{i, \text { age }-1}+\varepsilon_{i, \text { age }}$.

Table B3: relation between career and logincome, men

\begin{tabular}{lcccccc}
\hline \hline & ols79 & dlogit79 & dprobit79 & ols97 & dlogit97 & dprobit97 \\
\hline logincome & $-0.0969^{* * *}$ & $-0.110^{* * *}$ & $-0.103^{* * *}$ & $-0.0947^{* * *}$ & $-0.0951^{* * *}$ & $-0.0949^{* * *}$ \\
& $(0.0142)$ & $(0.0158)$ & $(0.0146)$ & $(0.0161)$ & $(0.0169)$ & $(0.0167)$ \\
\multirow{4}{*}{ age } & & & & & & \\
& -0.000539 & 0.00138 & -0.000204 & $-0.0244^{* * *}$ & $-0.0253^{* * *}$ & $-0.0252^{* * *}$ \\
& $(0.00741)$ & $(0.00756)$ & $(0.00739)$ & $(0.00719)$ & $(0.00759)$ & $(0.00755)$ \\
\hline \hline
\end{tabular}

Marginal effects; Standard errors in parentheses

(d) for discrete change of dummy variable from 0 to 1

${ }^{*} p<0.05,{ }^{* *} p<0.01,{ }^{* * *} p<0.001$

College-educated men with a lower income in the previous year were more likely to make a career investment between ages 23 and 29. Table B3 shows that college-educated men with a one- 
percent lower income in the previous year were more than nine percentage points more likely to make a career investment for both the NLSY79 and NLSY97 cohorts.

Table B4: relation between career and logincome, women

\begin{tabular}{lcccccc}
\hline \hline & ols79 & dlogit79 & dprobit79 & ols97 & dlogit97 & dprobit97 \\
\hline logincome & -0.0231 & -0.0244 & -0.0238 & $-0.0538^{* * *}$ & $-0.0564^{* * *}$ & $-0.0552^{* * *}$ \\
& $(0.0133)$ & $(0.0133)$ & $(0.0130)$ & $(0.0124)$ & $(0.0128)$ & $(0.0124)$ \\
& & & & & & \\
age & $-0.0320^{* * *}$ & $-0.0323^{* * *}$ & $-0.0324^{* * *}$ & $-0.0503^{* * *}$ & $-0.0521^{* * *}$ & $-0.0520^{* * *}$ \\
& $(0.00602)$ & $(0.00612)$ & $(0.00607)$ & $(0.00563)$ & $(0.00609)$ & $(0.00601)$ \\
\hline$N$ & 2155 & 2155 & 2155 & 2284 & 2284 & 2284 \\
\hline \hline
\end{tabular}

Marginal effects; Standard errors in parentheses

(d) for discrete change of dummy variable from 0 to 1

${ }^{*} p<0.05,{ }^{* *} p<0.01,{ }^{* * *} p<0.001$

College-educated women with a lower income in the previous year were also more likely to make a career investment between ages 23 and 29 (and to a lesser extent than men). Table B4 shows that a one-percent lower income in the previous year was associated with more than two percentage points higher chance of making a career investment for the NLSY79 cohort and more than five percentage points higher chance for the NLSY97 cohort.

\section{B.3 Monotonicity, Supermodularity, and Transferable Utility of Surplus}

The following intrahousehold public-good consumption problem justifies the surplus monotonicity assumptions, the surplus supermodularity assumptions, and the assumption of transferable utilities in the marriage market. Low (2017) presents a similar microfoundation. Bergstrom and Cornes (1983); Chiappori and Gugl (2015); Chiappori et al. (2017) provide more general discussions of the microfoundation.

An unmarried income- $y_{m}$ man who derives utility $q_{m}$ from consuming $q_{m}$ units of a composite private good derives a utility of $z\left(y_{m}\right)=y_{m}$, and an unmarried income- $y_{w}$ woman who derives utility $q_{w}$ from consuming $q_{w}$ units of the same composite private good derives a utility of $z\left(y_{w}\right)=$ $y_{w}$. A couple with children spends their income $y_{m}+y_{w}$ on $q_{m}$ and $q_{w}$ units of the private good as well as on $Q$ units of a public good to derive a utility of $q_{m}(1+Q)$ for the husband and a utility of $q_{w}(1+Q)$ for the wife. To maximize joint utility $\left(q_{m}+q_{w}\right)(1+Q)$ subject to the budget constraint $q_{m}+q_{w}+Q \leq y_{m}+y_{w}$, the couple consumes $q_{m}+q_{w}=\left(y_{m}+y_{w}+1\right) / 2$ units of the private good and $Q=\left(y_{m}+y_{w}-1\right) / 2$ units of the public good for a joint utility $\left(y_{m}+y_{w}+1\right)^{2} / 4=$ $\left(y_{m}+y_{w}-1\right)^{2} / 4+y_{m}+y_{w}$. A couple without children spends income on the composite private good only to derive a joint utility of $y_{m}+y_{w}$. With probability $\phi_{w}$ a woman with fitness level $\phi_{w}$ can have children. Therefore, the marriage surplus an income- $y_{m}$ man and an income- $y_{w}$ woman with fitness level $\phi_{w}$ generate is

$$
s\left(y_{m}, y_{w}, \phi_{w}\right)=z\left(y_{m}, y_{w}, \phi_{w}\right)-z\left(y_{m}\right)-z\left(y_{w}\right)
$$




$$
\begin{aligned}
& =\phi_{w}\left[\left(y_{m}+y_{w}-1\right)^{2} / 4+y_{m}+y_{w}\right]+\left(1-\phi_{w}\right)\left(y_{m}+y_{w}\right)-y_{m}-y_{w} \\
& =\phi_{w}\left(y_{m}+y_{w}-1\right)^{2} / 4 .
\end{aligned}
$$

The surplus is strictly increasing in $y_{m}, y_{w}$, and $\phi_{w}$, when $y_{m}+y_{w}-1>0$. The surplus is strictly supermodular in $y_{m}$ and $y_{w}$ as well as in $y_{m}$ and $\phi_{w}$. Moreover, any division of the marriage surplus between a couple can be achieved through the allocation of the private good. When there are children, $q_{m}$ units of the private good are allocated to the husband and $q_{w}$ units of the private good are allocated to the wife, where $q_{m}+q_{w}=\left(y_{m}+y_{w}+1\right) / 2$.

\section{References in Appendix B}

Bergstrom, Theodore C. and Richard C. Cornes, "Independence of Allocative Efficiency from Distribution in the Theory of Public Goods," Econometrica, 1983, 51 (6), 1753-1765.

Borch, Karl, “Equilibrium in a Reinsurance Market,” Econometrica, July 1962, 30 (3), 424-444.

Chiappori, Pierre-André and Elisabeth Gugl, "Necessary and Sufficient Conditions for Transferable utility," May 2015. Working Paper, Department of Economics, Columbia University.

_ and Philip J. Reny, "Matching to Share Risk,” Theoretical Economics, 2016.

Chiappori, Pierre-André, Bernard Salanié, and Yoram Weiss, "Partner Choice, Investment in Children, and the Marital College Premium," American Economic Review, August 2017, 107 (8), 2109-2167.

Low, Corinne, “A 'Reproductive Capital’ Model of Marriage Market Matching,” December 2017. Working Paper, Business Economics and Public Policy Department, the Wharton School, University of Pennsylvania.

Wilson, Robert, “The Theory of Syndicates,” Econometrica, January 1968, 36 (1), 119-123.

Zhang, Hanzhe, “A Marriage-Market Perspective of Career Choices,” May 2017. Working Paper, Department of Economics, Michigan State University.

_ , "Pre-Matching Gambles," August 2017. Working Paper, Department of Economics, Michigan State University. 


\section{Online Appendix}

\section{Empirical Evidence, Details}

\section{C.1 College and Earnings Gender Gaps}

The model predicts that women's marriage premium is higher than men's when more women than men go to college, but is lower than men's when fewer women than men go to college.

Claim 1. Suppose the marriage surpluses $s_{H L}$ and $s_{L H}$ are gender-symmetric and more men than women earn a high income in equilibrium. Women's marriage premium $\pi_{w}^{*}=s_{H H}-s_{H L}$ is larger than men's marriage premium $\pi_{m}^{*}=s_{H L}-s_{L L}$ in equilibrium.

Previous literature has presented evidence consistent with this prediction (Chiappori et al., 2009, 2017). However, in the previous papers, each individual's marriage type is education or age rather than income or fertility. Although income is positively correlated with education and fertility is negatively correlated with age, these papers do not provide direct evidence for our predictions. I directly test this key implication with data.

Figure 3 shows estimated marriage premiums from 1960 to 2015. The estimation is consistent with our prediction: women's marriage premium (i) was smaller than men's in 1960, 1970, and 1980, when fewer women than men, ages 35-39, graduated from college; and (ii) was greater than men's in 2010 and 2015, when more women than men, ages 35-39, graduated from college. ${ }^{21}$ I adopt the technique developed by Choo and Siow (2006) to exactly identify the marriage surplus function, and compute the marriage premiums from the estimated marriage surplus function. I detail the estimation procedure below.

I only need to estimate $s_{H H}, s_{H L}$, and $s_{L L}$ to compute the marriage premiums, because, according to Claim 1, men's marriage premium is $\pi_{m}^{*}=s_{H L}-s_{L L}$, and women's marriage premium is $\pi_{w}^{*}=s_{H H}-s_{H L}$. I modify the matching model to adopt the technique of Choo and Siow (2006). The marriage payoff of a type- $\tau_{m}$ man $i$ married to a type- $\tau_{w}$ woman is

$$
v_{m \tau_{m} \tau_{w}}^{i}=z_{\tau_{m}}^{m} \tau_{w}-t_{\tau_{m}} \tau_{w}+\varepsilon_{\tau_{m}}^{i} \tau_{w}
$$

where $z_{\tau_{m}}^{m} \tau_{w}$ is the systematic gross return to a type- $\tau_{m}$ man married to a type- $\tau_{w}$ woman, $t_{\tau_{m}} \tau_{w}$ is the transfer from a type- $\tau_{m}$ man to a type- $\tau_{w}$ woman, and $\varepsilon_{\tau_{m}}^{i} \tau_{w}$ is an independently and identically distributed random variable with a type I extreme-value distribution, i.e., $F(\varepsilon)=\exp [-\exp (-\varepsilon)]$. The marriage payoff of a type- $\tau_{w}$ woman $j$ married to a type- $\tau_{m}$ man is

$$
v_{w}^{j} \tau_{w} \tau_{m}=z_{\tau_{m}}^{w} \tau_{w}+t_{\tau_{m}} \tau_{w}+\varepsilon_{\tau_{m}}^{j} \tau_{w}
$$

\footnotetext{
${ }^{21}$ I am not able to produce estimates for 1990 and 2000, because age at marriage, the information needed to construct the marriage market, was neither reported nor inferable in the censuses in these years. I am also not able to produce estimates for years prior to 1960, because spousal income - the information needed to construct marriage types and to compute the number of marriages between different marriage types - was not reported in the censuses.
} 
where $z_{\tau_{m}}^{w} \tau_{w}$ is the systematic return to a type- $\tau_{w}$ woman married to a type- $\tau_{m}$ man, and $\varepsilon_{\tau_{m}}^{j} \tau_{w}$ is an i.i.d. random variable with a T1EV distribution. The payoff to man $i$ who remains unmarried is

$$
v_{\tau_{m} \emptyset}^{i}=z_{\tau_{m} \emptyset}^{m}+\varepsilon_{\tau_{m} \emptyset}^{i}
$$

where $\varepsilon_{\tau_{m} \emptyset}^{i}$ is also an i.i.d. random variable with a T1EV distribution. The systematic marriage surplus for a type- $\tau_{m}$ man married to a type- $\tau_{w}$ woman is $s_{\tau_{m}}^{m} \tau_{w}=z_{\tau_{m}}^{m} \tau_{w}-z_{\tau_{m} \emptyset}^{m}$. Similarly, the systematic marriage surplus for a type- $\tau_{w}$ woman married to a type- $\tau_{m}$ man is $s_{\tau_{m}}^{w} \tau_{w}=z_{\tau_{m}}^{w} \tau_{w}-z_{\emptyset \tau_{w}}^{w}$.

Therefore, the total systematic marriage surplus of a type- $\tau_{m}$ man and a type- $\tau_{w}$ woman is $s_{\tau_{m} \tau_{w}}=s_{\tau_{m} \tau_{w}}^{m}+s_{\tau_{m}}^{w} \tau_{w}$. Following Choo and Siow (2006),

$$
\widehat{s}_{\tau_{m} \tau_{w}}=2 \ln \left[\frac{\widehat{G}_{\tau_{m} \tau_{w}}}{\sqrt{\widehat{G}_{\tau_{m} \emptyset} \widehat{G}_{\emptyset \tau_{w}}}}\right],
$$

where $\widehat{G}_{\tau_{m}} \tau_{w}$ is the estimated measure of marriages between type- $\tau_{m}$ men and type- $\tau_{w}$ women, $\widehat{G}_{\tau_{m} \emptyset}$ is the estimated measure of unmarried type- $\tau_{m}$ men, and $\widehat{G}_{\emptyset \tau_{w}}$ is the estimated measure of unmarried type- $\tau_{w}$ women. By Claim 1, point estimates of the marriage premiums are $\widehat{\pi}_{m H}^{*}=$ $\widehat{s}_{H L}-\widehat{s}_{L L}$ and $\widehat{\pi}_{w H}^{*}=\widehat{s}_{H H}-\widehat{s}_{H L}$. Standard errors of the marriage premiums are obtained from simulated measures of marriage characteristics.

What remains is to specify the marriage market and to assign each individual fertility and income marriage characteristics. I include in the marriage market all never-married individuals between ages 16-39 who were not in school, and all heterosexual couples who were both between ages 16-39 and who had both married for the first time within the two years under consideration. I categorize an agent as a high-income type if he or she earns more than the median personal labor income of the college graduates of the same age, and as a low-income agent otherwise. I treat men between ages 16-39 and women between ages 16-29 as fertile, and treat women between ages 30-39 as less fertile.

The model also shows the factors that contribute to the rise of women's college enrollment and earnings over time.

Claim 2. Suppose more men than women earn a high income in equilibrium before and after the changes in the primitives of the model. Women's college investment rate and average income in equilibrium both increase if any or any combination of the following events happens: (i) women's investment $\cos t c_{w}$ decreases; (ii) women's labor-market opportunities $F_{w}$ (first-order stochastically) increase; (iii) women's income premium $z_{w H}-z_{w L}$ increases; and (iv) the surplus difference $s_{H H}-s_{H L}$ (women's equilibrium marriage premium $\pi_{w}^{*}$ ) increases.

Previous literature (cited in the introduction) has thoroughly studied how monetary and psychic college investment costs, labor-market opportunities, and income premium for women (as well as for men) have evolved over the past decades, and how these changes have contributed to 
the changes in the college and earnings gender gaps. Predictions (i)-(iii) are consistent with previous findings and do not add any new theoretical insights. The change in the marriage premium is relatively less studied. In equilibrium, women's marriage premium equals the difference between (i) the marriage surplus when a high-income man marries a high-income woman and (ii) the marriage surplus when he marries a low-income woman. Its increase is associated with technological and social changes that affect intrahousehold consumption and time-allocation decisions. Technological progress freed women from some household activities and made women with high earning abilities more valuable in the labor market as well as in the marriage market (Greenwood et al., 2014, 2016). In addition, an increasing focus on human capital of children also made highly educated and highly skilled women more valuable in the marriage market (Chiappori et al., 2009, 2017).

\section{C.2 Relationship between Age at Marriage and Spousal Income for Women}

Figures 5a and 5b show that early brides' marital outcome deteriorated and late brides' marital outcome improved in mandated states, relative to nonmandated states, where the marital outcome is measured by spousal income rank and spousal education rank. Figures $5 \mathrm{c}$ and $5 \mathrm{~d}$ show that the marital outcome of the middle brides did not evolve differently for the two sets of states.

The same pattern emerges even when we use alternative measures of the marital outcome, such as spousal labor income statewide z-score (Figures C1a) or the raw spousal labor income (Figure $\mathrm{C} 1 \mathrm{~b}$ ). The difference in the marital outcome in the two sets of states was not statistically significant, but became statistically significant after the mandates were passed. Figures $\mathrm{C} 1 \mathrm{c}$ and C1d show that the marital outcome, measured by spousal labor income z-score and spousal income, was not significantly different for early brides in the mandated and nonmandated states before the mandates were passed, but became statistically significantly worse for early brides in mandated states. Quantitatively, the average spousal income of early brides born in mandated states in 1980 were about 0.15 standard deviation worse than that of early brides born in nonmandated states. In contrast, the marital outcome was not significantly different for late brides in the mandated and nonmandated states before the mandates were passed, but became significantly better for late brides in mandated states. The average spousal income of late brides born in mandated states in 1980 was about 0.15 standard deviation better than that of late brides in nonmandated in 1980 . Meanwhile, the average marital outcome of middle brides did not differ by much.

\section{References in Appendix C}

Chiappori, Pierre-André, Bernard Salanié, and Yoram Weiss, "Partner Choice, Investment in Children, and the Marital College Premium," American Economic Review, August 2017, 107 (8), 2109-2167. 


\section{Figure C1: Robustness checks with labor income}

(a) Spousal labor income z-score by birth year
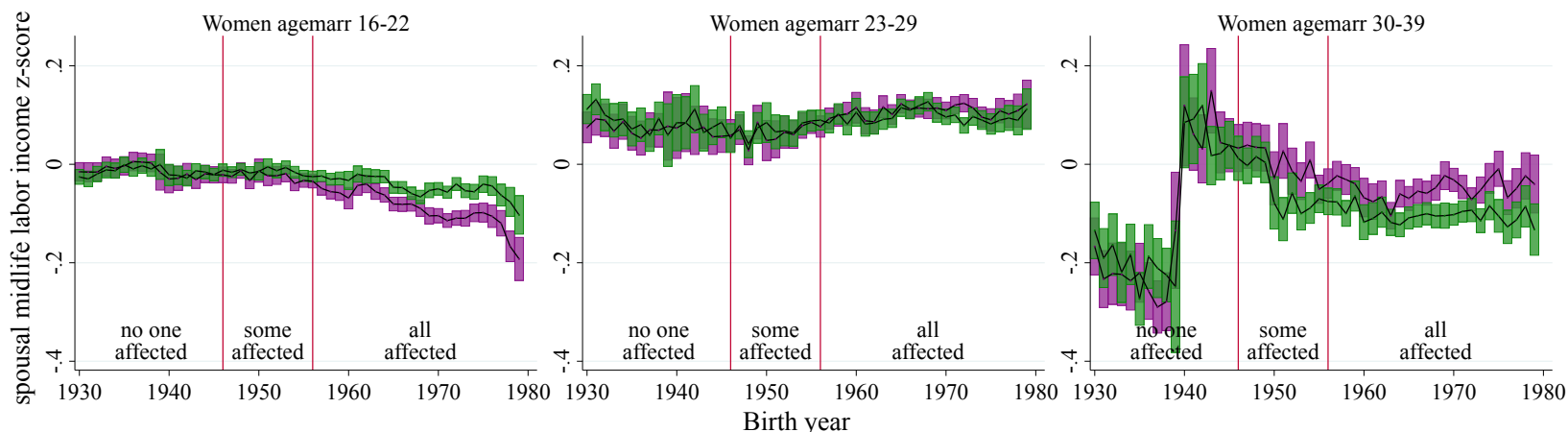

mandated states $\square$ nonmandated states

(b) Spousal labor income by birth year
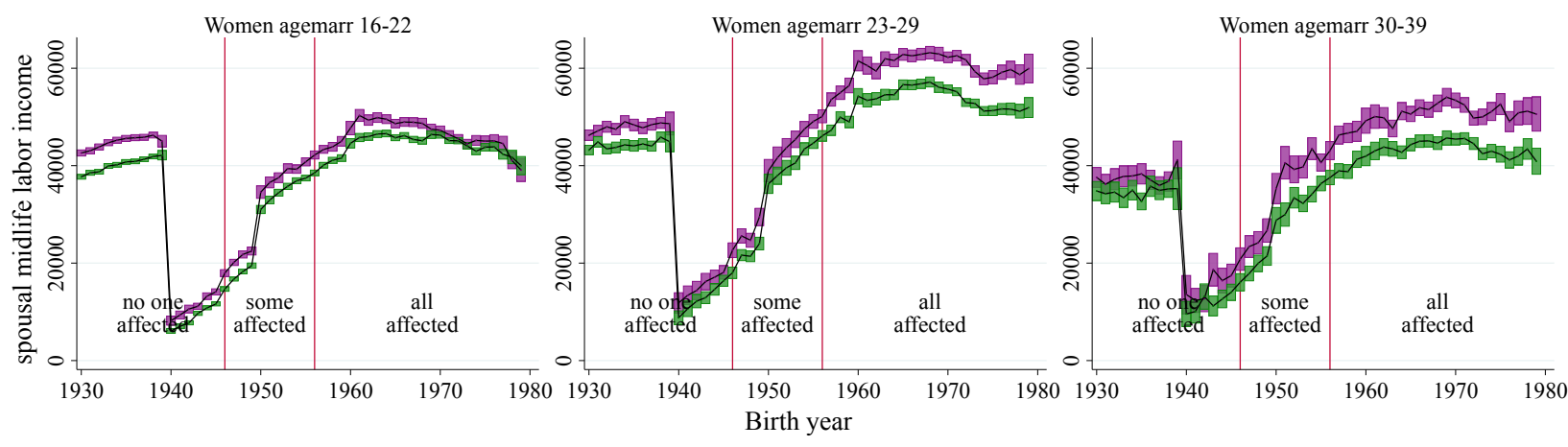

$\square$ mandated states $\square$ nonmandated states

(c) Spousal labor income z-score difference by birth year

Difference between mandated and nonmandated states

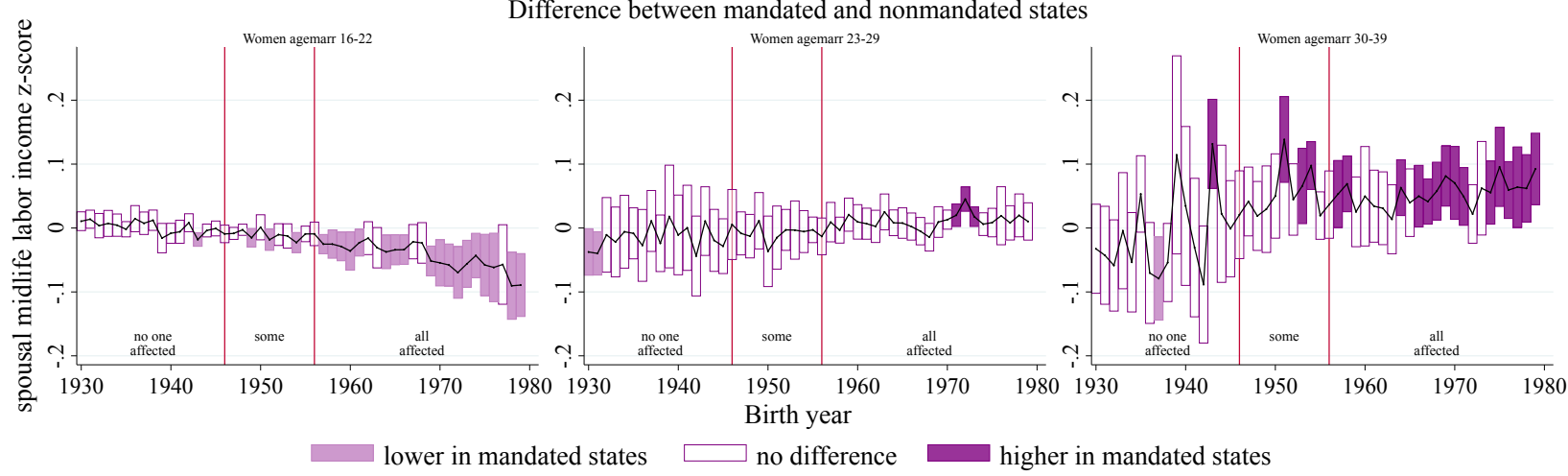

(d) Spousal labor income difference by birth year

Difference between mandated and nonmandated states

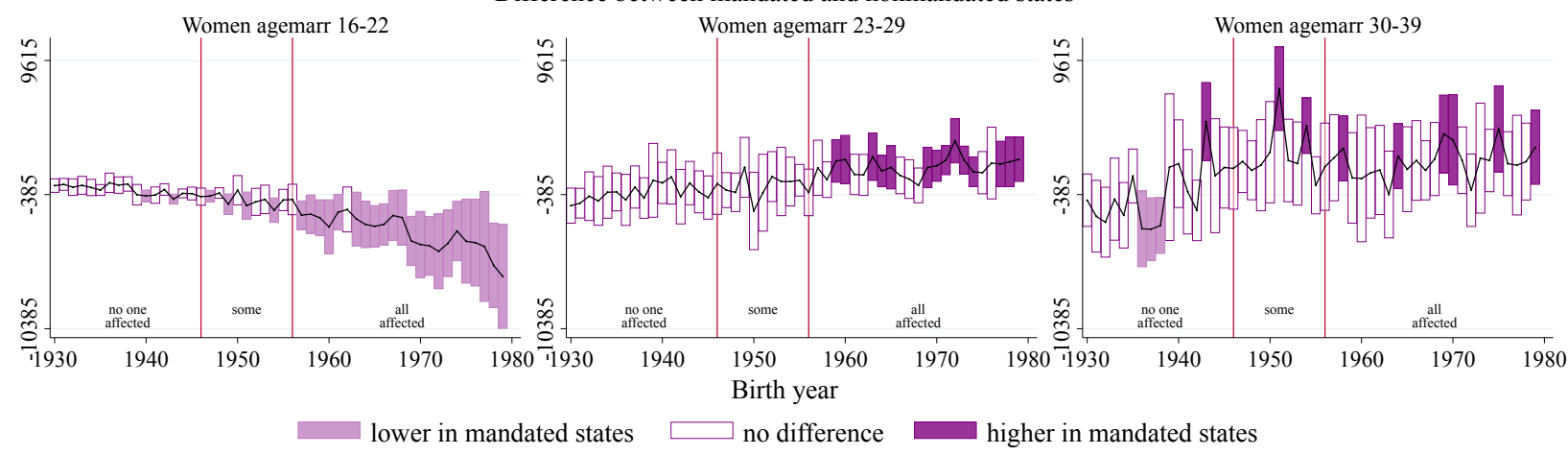


_ , Murat Iyigun, and Yoram Weiss, "Investment in Schooling and the Marriage Market," American Economic Review, 2009, 99 (5), 1689-1713.

Choo, Eugene and Aloysius Siow, "Who Marries Whom and Why," Journal of Political Economy, 2006, 114 (1), 175-201.

Gershoni, Naomi and Corinne Low, "The Impact of Extended Reproductive Time Horizons: Evidence from Israel's Expansion of IVF Access," December 2017. Working Paper, Business Economics and Public Policy Department, the Wharton School, University of Pennsylvania.

Greenwood, Jeremy, Nezih Guner, Georgi Kocharkov, and Cezar Santos, "Marry Your Like: Assortative Mating and Income Inequality," American Economic Review: Papers \& Proceedings, May 2014.

_, _, , , and _ , "Technology and the Changing Family: A Unified Model of Marriage, Divorce, Educational Attainment, and Married Female Labor-Force Participation," American Economic Journal: Macroeconomics, 2016, 8 (1), 1-41. 


\section{Online Appendix}

\section{Calibration, Details}

\section{D.1 Benchmark Model}

Suppose the ability distributions for men and for women are beta distributions with parameters $\left(\alpha_{m}, \beta_{w}\right)$ and $\left(\alpha_{w}, \beta_{w}\right)$, respectively. Since the model predicts that those who marry in the first period are low-income earners, I use the average labor income of men and women who first married between ages 16 and 22 to estimate $y_{m L}$ and $y_{w L}$, respectively. Since the model predicts that men who marry in the second period are high-income earners, I use the average labor income of men who married between ages 23 and 29 to estimate $y_{m H}$. I use the average labor income of the unmarried women to estimate $y_{w H}$. Total investment costs $c_{m}$ and $c_{w}$ are two years of low incomes. I use two years because the college-educated on average marry two years later than the non-collegeeducated (Coles and Francesconi (2017) use four years of minimum wages). Annual investment cost is total investment cost divided by 40 . The marriage surplus in monetary terms is $k$ times the marriage surplus in utils estimated in Section 3.3.

Twelve moments are targeted: observed percentage and average midlife labor income of early, middle, and late grooms (denoted by $\widehat{G}_{m a}$ and $\widehat{y}_{m a}, a \in\{1,2,3\}$ ), and of early, middle, and late brides $\left(\widehat{G}_{w a}\right.$ and $\left.\widehat{y}_{w a}, a \in\{1,2,3\}\right)$. Define the penalty function with five arguments, $\alpha_{m}, \alpha_{w}, \beta_{m}$, $\beta_{w}$, and $k$ and find the parameters to minimize it:

$$
D_{1}\left(\alpha_{m}, \alpha_{w}, \beta_{m}, \beta_{w}, k\right)=\sqrt{\sum_{i \in\{m, w\}}\left[\sum_{a=1}^{3}\left|\frac{G_{i a}-\widehat{G}_{i a}}{\widehat{G}_{i a}}\right|^{2}+\sum_{a=1}^{3}\left|\frac{y_{i a}-\widehat{y}_{i a}}{\widehat{y}_{i a}}\right|^{2}\right]} .
$$

I find the parameters for the 1930s and the 1960s birth cohorts, respectively. Table D1 shows the fit of the model. The calibration matches each targeted marriage-age distribution within 0.7 percent, and except for the average income of late grooms born in the 1930s and that of late brides in the $1960 \mathrm{~s}$, the calibration matches each of the targeted average incomes within 5 percent. The non-targeted average spousal incomes are also matched fairly well. Table D2 shows the estimated parameters of the model. Labor-market opportunities are estimated to be much greater for women born in the 1960s and slightly lower for men born in the 1960s (Figure D1), consistent with the results in Coles and Francesconi (2018).

\section{D.2 Extended Model}

Not everyone who decides to marry can get married right away, and not everyone who goes to college waits to marry after college. To separate college attendance and marriage timing, I extend the model to allow college men and women to marry in the first period and noncollege men and 
Table D1: Fit of the benchmark model

\begin{tabular}{||l|l|l|l|l|l|l||} 
moments & 30 s target & 30 s model & difference & 60 s target & 60 s model & difference \\
$G_{\mathrm{m} 1}$ & 0.48476 & 0.484927 & $0.0346 \%$ & 0.30756 & 0.307632 & $0.0233 \%$ \\
$G_{\mathrm{m} 2}$ & 0.411344 & 0.411096 & $-0.0605 \%$ & 0.451633 & 0.451472 & $-0.0356 \%$ \\
$G_{\mathrm{m} 3}$ & 0.103896 & 0.103977 & $0.0782 \%$ & 0.240807 & 0.240896 & $0.037 \%$ \\
$G_{\mathrm{w} 1}$ & 0.740591 & 0.740641 & $0.00673 \%$ & 0.4494 & 0.450621 & $0.272 \%$ \\
$G_{\mathrm{w} 2}$ & 0.206928 & 0.206863 & $-0.0314 \%$ & 0.381204 & 0.378867 & $-0.613 \%$ \\
$G_{\mathrm{w} 3}$ & 0.0524809 & 0.0524961 & $0.0289 \%$ & 0.169396 & 0.170512 & $0.659 \%$ \\
$y_{\mathrm{m} 1}$ & 40209.7 & 40209.7 & $0 . \%$ & 44571.6 & 44571.6 & $0 . \%$ \\
$y_{\mathrm{m} 2}$ & 43820.8 & 43820.8 & $0 . \%$ & 56434.2 & 56434.2 & $0 . \%$ \\
$y_{\mathrm{m} 3}$ & 37442. & 42783.4 & $14.3 \%$ & 48376.5 & 49895. & $3.14 \%$ \\
$y_{\mathrm{w} 1}$ & 12049. & 12049. & $0 . \%$ & 20091. & 20091. & $0 . \%$ \\
$y_{\mathrm{w} 2}$ & 12457.2 & 12066.3 & $-3.14 \%$ & 24627.8 & 24216. & $-1.67 \%$ \\
$y_{\mathrm{w} 3}$ & 12886.1 & 13445.7 & $4.34 \%$ & 26080.1 & 28028.3 & $7.47 \%$ \\
average & & & $1.83 \%$ & & & $1.16 \%$ \\
$x_{\mathrm{w} 1}$ & 41269.2 & 41445.5 & $0.427 \%$ & 47016.2 & 48873.3 & $3.95 \%$ \\
$x_{\mathrm{w} 2}$ & 45269.5 & 43806.4 & $-3.23 \%$ & 61434.7 & 54923.9 & $-10.6 \%$ \\
$x_{\mathrm{w} 3}$ & 35537.5 & 41977.3 & $18.1 \%$ & 53644.3 & 49131.2 & $-8.41 \%$
\end{tabular}

\section{Table D2: Estimated parameters of the benchmark model}

\begin{tabular}{||l|l|l|l|l|l||} 
& $1930 \mathrm{~s}$ & $1960 \mathrm{~s}$ & & $1930 \mathrm{~s}$ & $1960 \mathrm{~s}$ \\
$F_{m}$ & $\operatorname{Beta}(1.02,0.837)$ & $\operatorname{Beta}(0.462,0.523)$ & $s_{\mathrm{HH}}$ & $\$ 43.8148$ & $\$ 5782.23$ \\
$F_{w}$ & $\operatorname{Beta}(0.0535,0.196)$ & $\operatorname{Beta}(0.165,0.373)$ & $s_{\mathrm{HL}}$ & $\$ 39.2241$ & $\$ 4296.6$ \\
$c_{m}$ & $\$ 2010.48$ & $\$ 2228.58$ & $s_{\mathrm{Hh}}$ & $\$ 14.6042$ & $\$ 3370.09$ \\
$c_{w}$ & $\$ 602.452$ & $\$ 1004.55$ & $s_{\mathrm{Hl}}$ & $\$ 21.0646$ & $\$ 2055.66$ \\
$y_{\mathrm{mH}}$ & $\$ 43820.8$ & $\$ 56434.2$ & $s_{\mathrm{LH}}$ & $\$ 28.4427$ & $\$ 3604.2$ \\
$y_{\mathrm{mL}}$ & $\$ 40209.7$ & $\$ 44571.6$ & $s_{\mathrm{LL}}$ & $\$ 32.6076$ & $\$ 3302.76$ \\
$y_{\mathrm{wH}}$ & $\$ 14902.3$ & $\$ 40741.3$ & $s_{\mathrm{Lh}}$ & $\$ 0$. & $\$ 0$. \\
$y_{\mathrm{wL}}$ & $\$ 12049$. & $\$ 20091$. & $s_{\mathrm{Ll}}$ & $\$ 14.6112$ & $\$ 1750.35$
\end{tabular}

Figure D1: Estimated CDF and PDF of abilities in the benchmark model
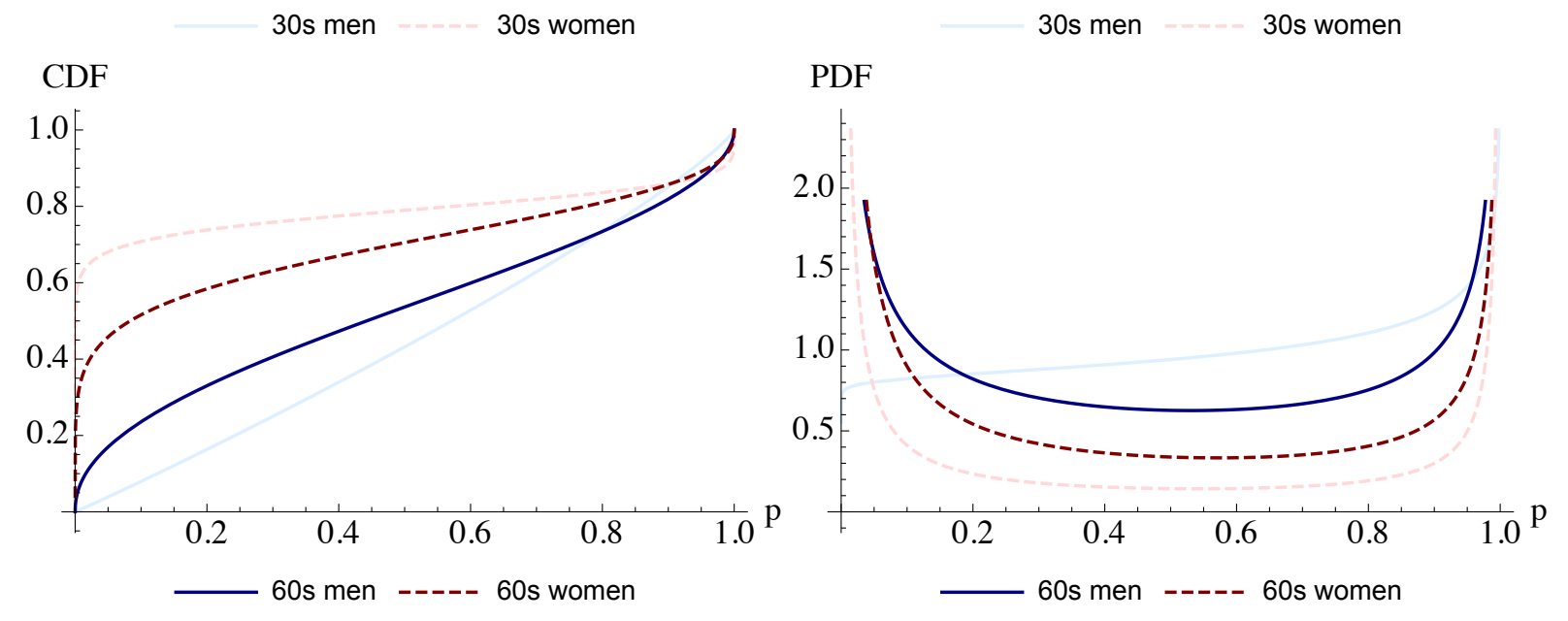
women to marry in the second and third periods.

The ability distributions are beta distributions as in the benchmark model. I use the average incomes of noncollege men and women as low incomes $y_{m L}$ and $y_{w L}$, respectively, and the average incomes of college men and women as high incomes $y_{m H}$ and $y_{w H}$, respectively. The total investment cost is the opportunity cost in the form of two years of low incomes. The annual investment cost is the total investment cost divided by 40. The surplus in monetary terms is again $k$ times the surplus in utils estimated in Section 3.3. Now, frictions. First, not all noncollege men and women marry between ages 16 and 22. The actual probabilities that they married after age 22 are taken from the data. Let $h_{i N a}, i \in\{m, w\}, a \in\{1,2\}$, denote the hazard rate of a noncollege man or a noncollege woman marrying in period $a$. Let $h_{i C 2}$ denote the hazard rate of a college man or a college woman marrying between ages 23 and 29. Second, not all college men and college women delay marriage until after college: let $h_{i C 1}, i \in\{m, w\}$, denote the probability that a college man or a college woman marries between ages 16 and 22 .

I target seventeen moments: the college enrollment rates of men and women (denoted by $G_{m C}$ and $G_{w C}$, respectively), the average incomes of men who married early, middle, and late brides (denoted by $x_{w 1}, x_{w 2}$, and $x_{w 3}$, respectively), as well as the twelve moments targeted in the benchmark model.

To estimate the seven parameters $\left(\alpha_{m}, \alpha_{w}, \beta_{m}, \beta_{w}, k, \mu_{m}, \mu_{w}\right)$, I define the penalty function

$$
D_{2}=\sqrt{\sum_{i \in\{m, w\}}\left[\left|\frac{G_{i C}-\widehat{G}_{i C}}{\widehat{G}_{i, \mathrm{col}}}\right|^{2}+\sum_{a=1}^{3}\left|\frac{G_{i a}-\widehat{G}_{i a}}{\widehat{G}_{i a}}\right|^{2}+\sum_{a=1}^{3}\left|\frac{y_{i a}-\widehat{y}_{i a}}{\widehat{y}_{i a}}\right|^{2}\right]+\sum_{a=1}^{3}\left|\frac{x_{w a}-\widehat{x}_{w a}}{\widehat{x}_{w a}}\right|^{2}} .
$$

I find the parameters to minimize the penalty.

I test the performance of the extended model for the 1930s and 1960s birth cohorts, too. Table D3 shows how well the model matches the data. The average error between targeted and calibrated moments is 1.71 percent for the 1930s birth cohort, and is 1.51 percent for the $1960 \mathrm{~s}$ birth cohort. Table D4 shows the model's calibrated parameters.

With the extended model, I can examine the relative importance of labor-market shocks to marriage-market frictions in influencing marriage timing.

For the 1930s birth cohort, there was an estimated 17.1 percent chance that college-educated women who decided to enter the marriage market before age 30 involuntarily delayed their marriage until after age 30 , slightly lower than the 21.2 percent chance that noncollege women involuntarily delayed their marriage until after age 30. Among the men and women who married between ages 30 and 39, among the college-educated, essentially all men delayed marriages due to labormarket shocks, and all women delayed marriages due to marriage-market frictions (consistent with the fact that a tiny portion of women in this cohort chose to make a career investment).

For the 1960s birth cohort, the chance for a college-educated man who decided to enter the 
Table D3: Fit of the extended model

\begin{tabular}{||l|l|l|l|l|l|l||} 
moments & 30 s target & 30s model & difference & 60 s target & 60 s model & difference \\
$G_{\mathrm{m} 1}$ & 0.48476 & 0.484451 & $-0.0637 \%$ & 0.30756 & 0.307372 & $-0.0613 \%$ \\
$G_{\mathrm{m} 2}$ & 0.411344 & 0.412559 & $0.295 \%$ & 0.451633 & 0.452309 & $0.15 \%$ \\
$G_{\mathrm{m} 3}$ & 0.103896 & 0.102989 & $-0.872 \%$ & 0.240807 & 0.24032 & $-0.202 \%$ \\
$G_{\mathrm{w} 1}$ & 0.740591 & 0.740591 & $0.000051 \%$ & 0.4494 & 0.449534 & $0.0299 \%$ \\
$G_{\mathrm{w} 2}$ & 0.206928 & 0.206847 & $-0.0393 \%$ & 0.381204 & 0.380081 & $-0.295 \%$ \\
$G_{\mathrm{w} 3}$ & 0.0524809 & 0.0525618 & $0.154 \%$ & 0.169396 & 0.170385 & $0.584 \%$ \\
$G_{m, \mathrm{col}}$ & 0.218733 & 0.220363 & $0.745 \%$ & 0.379722 & 0.380819 & $0.289 \%$ \\
$G_{w, \mathrm{col}}$ & 0.119257 & 0.119255 & $-0.00131 \%$ & 0.390058 & 0.389479 & $-0.148 \%$ \\
$y_{\mathrm{m} 1}$ & 40209.7 & 39603.7 & $-1.51 \%$ & 44571.6 & 44730.5 & $0.357 \%$ \\
$y_{\mathrm{m} 2}$ & 43820.8 & 43915.8 & $0.217 \%$ & 56434.2 & 56524.6 & $0.16 \%$ \\
$y_{\mathrm{m} 3}$ & 37442. & 38350.9 & $2.43 \%$ & 48376.5 & 48589.3 & $0.44 \%$ \\
$y_{\mathrm{w} 1}$ & 12049. & 11696.3 & $-2.93 \%$ & 20091. & 20510. & $2.09 \%$ \\
$y_{\mathrm{w} 2}$ & 12457.2 & 12739.2 & $2.26 \%$ & 24627.8 & 25169.9 & $2.2 \%$ \\
$y_{\mathrm{w} 3}$ & 12886.1 & 12421. & $-3.61 \%$ & 26080.1 & 24207.1 & $-7.18 \%$ \\
$x_{\mathrm{w} 1}$ & 41269.2 & 41155.8 & $-0.275 \%$ & 46138.3 & 47051.6 & $1.98 \%$ \\
$x_{\mathrm{w} 2}$ & 45269.5 & 42290.6 & $-6.58 \%$ & 58701.2 & 55594.8 & $-5.29 \%$ \\
$x_{\mathrm{w} 3}$ & 35537.5 & 38066.9 & $7.12 \%$ & 48666.8 & 50699.8 & $4.18 \%$ \\
average & $->$ & $->$ & $1.71 \%$ & $->$ & $->$ & $1.51 \%$
\end{tabular}

Table D4: Estimated parameters of the extended model

\begin{tabular}{||l|l|l|l|l|l||} 
& $1930 \mathrm{~s}$ & $1960 \mathrm{~s}$ & & $1930 \mathrm{~s}$ & $1960 \mathrm{~s}$ \\
$F_{m}$ & $\operatorname{Beta}(0.0165,0.0757)$ & $\operatorname{Beta}(0.0244,0.0501)$ & $y_{\mathrm{mH}}$ & $\$ 62730.8$ & $\$ 84142.6$ \\
$F_{w}$ & $\operatorname{Beta}(0.0236,0.519)$ & $\operatorname{Beta}(0.0507,0.138)$ & $y_{\mathrm{mL}}$ & $\$ 36320.4$ & $\$ 34021.1$ \\
$c_{m}$ & $\$ 1816.02$ & $\$ 1701.05$ & $y_{\mathrm{wH}}$ & $\$ 31524.1$ & $\$ 40741.3$ \\
$c_{w}$ & $\$ 553.415$ & $\$ 798.058$ & $y_{\mathrm{wL}}$ & $\$ 11068.3$ & $\$ 15961.2$ \\
$s_{\mathrm{HH}}$ & $\$ 135315$. & $\$ 40212.5$ & $h_{\mathrm{mC} 1}$ & 0.336696 & 0.200993 \\
$s_{\mathrm{HL}}$ & $\$ 121137$. & $\$ 29880.7$ & $h_{\mathrm{mC} 2}$ & 0.999999 & 0.777833 \\
$s_{\mathrm{Hh}}$ & $\$ 45102.6$ & $\$ 23437.3$ & $h_{\mathrm{mN} 1}$ & 0.526214 & 0.372798 \\
$s_{\mathrm{H} 1}$ & $\$ 65054.6$ & $\$ 14296.1$ & $h_{\mathrm{mN} 2}$ & 0.795684 & 0.641768 \\
$s_{\mathrm{LH}}$ & $\$ 87840.5$ & $\$ 25065.4$ & $h_{\mathrm{wC} 1}$ & 0.527418 & 0.307963 \\
$s_{\mathrm{LL}}$ & $\$ 100703$. & $\$ 22969$. & $h_{\mathrm{wC} 2}$ & 0.829379 & 0.761695 \\
$s_{\mathrm{Lh}}$ & $\$ 0$. & $\$ 0$. & $h_{\mathrm{wN} 1}$ & 0.769455 & 0.539849 \\
$s_{\mathrm{L} 1}$ & $\$ 45124.3$ & $\$ 12172.8$ & $h_{\mathrm{wN} 2}$ & 0.788497 & 0.675267
\end{tabular}

Figure D2: Estimated CDF and PDF of abilities in the extended model
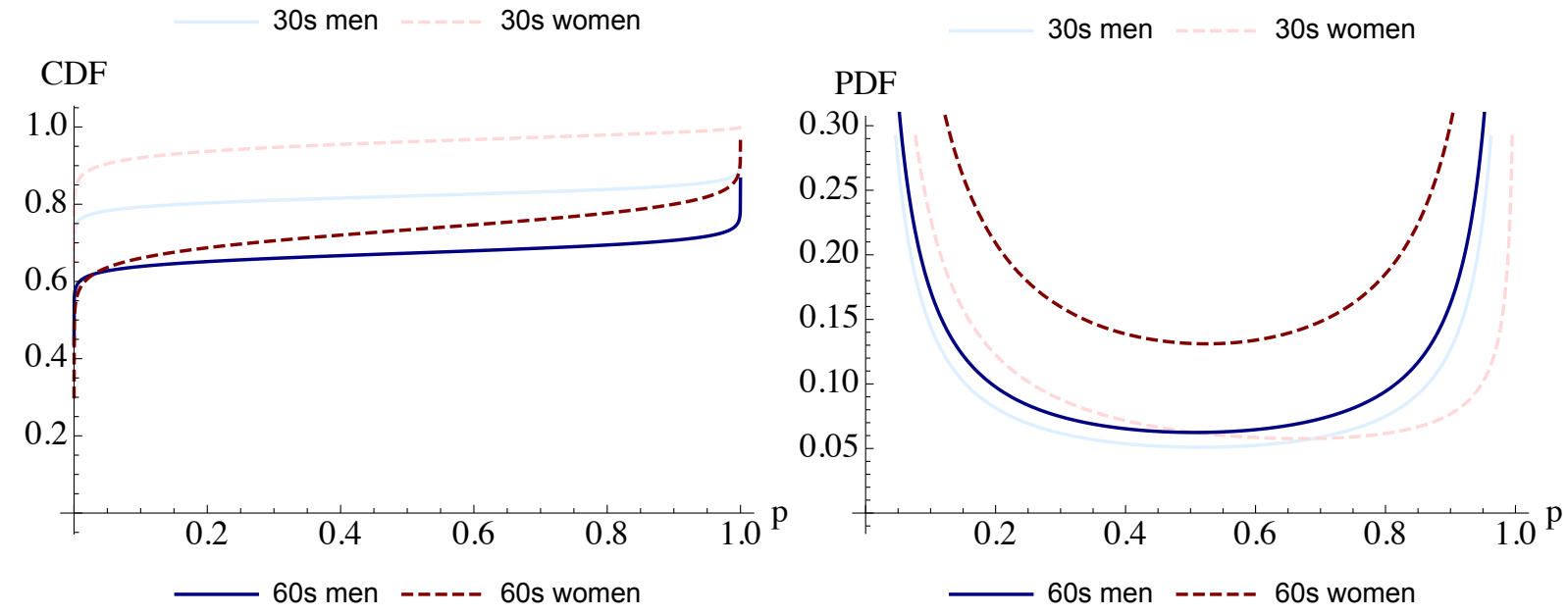

D4 
marriage market between ages 23 and 29 not being able to marry before age 30 was 22.2 percent, and the chance that a college-educated woman who decided to enter the marriage market between ages 23 and 29 not being able to marry before age 30 was 23.8 percent. I find that 42.7 percent of college-educated men and 24.6 percent of college-educated women delayed their marriages due to labor-market shocks (and the rest delayed due to marriage-market frictions).

Men's and women's marriage premiums can also be calculated. Comparing these two birth cohorts, men's marriage premium decreased from $\$ 26410.4$ to $\$ 6911.67$, and women's marriage premium increased from $\$ 10331.8$ to $\$ 14177.6$. Furthermore, I find that the marriage premium is 43.6 percent of the total premium for men and 40.9 percent of the total premium for women born in the 1930s, and is 12.6 percent for men and 29.4 percent for women born in the 1960s. In comparison, Bruze (2015) estimates that the marriage premium is about 40 to 70 percent of the total premium for men and women.

\section{D.3 Mandate Analyses}

In this section, I calculate the counterfactual impacts of the mandate on men and women's investment and marriage decisions. I do so by first calibrating the extended model on the 1930s and 1960s birth cohorts in the mandated states and the nonmandated states.

The quantitive fit of the model on the 1930s and 1960s cohorts in the mandated states is shown in Tables D5 and D6. The quantitative fit of the model on the two cohorts in the nonmandated states is shown in Tables D7 and D8. The fits are similar to those on the entire birth cohorts shown in Tables D3 and D4 in the previous section. The moments are calibrated within 4 percent of the targets on average. Figures D3 and D4 show the estimated ability distributions. They all take the same shape as those in Figure D2, further suggesting the stability of the calibration results.

Tables D9 and D10 show the results of two counterfactual analyses for the 1960s cohort - the outcome when mandated states did not pass the mandates and the outcome when nonmandated states become mandated. Namely, I examine the marriage, college, and income patterns when the mandated states have a marriage market that operates as that in the nonmandated states and when the nonmandated states have a marriage market that operates as that in the mandated states.

Table D9 shows that without the mandate, the fraction of late brides would decrease from 19.4 percent to 17 percent. The fraction of women attending college would decrease from 37.1 percent to 35.9 percent. The average spousal income of late brides would decrease, and the average spousal income of early brides would increase by 2.9 percent. The average spousal income does not decrease by much because of a countervailing effect that removing the mandate would deter intermediate ability women from making career investments and increase the average income of those who choose to make career investments and delay marriages. These results are qualitatively and quantitatively sensible. 
Table D5: Fit of the extended model, mandated states

\begin{tabular}{||l|l|l|l|l|l|l||} 
moments & 30 s target & 30 s model & difference & 60 s target & 60 s model & difference \\
$G_{\mathrm{m} 1}$ & 0.451869 & 0.451556 & $-0.0693 \%$ & 0.271852 & 0.271602 & $-0.092 \%$ \\
$G_{\mathrm{m} 2}$ & 0.430358 & 0.431748 & $0.323 \%$ & 0.462758 & 0.463643 & $0.191 \%$ \\
$G_{\mathrm{m} 3}$ & 0.117773 & 0.116697 & $-0.914 \%$ & 0.26539 & 0.264754 & $-0.239 \%$ \\
$G_{\mathrm{w} 1}$ & 0.712169 & 0.714571 & $0.337 \%$ & 0.40867 & 0.415509 & $1.67 \%$ \\
$G_{\mathrm{w} 2}$ & 0.227668 & 0.221022 & $-2.92 \%$ & 0.403811 & 0.390709 & $-3.24 \%$ \\
$G_{\mathrm{w} 3}$ & 0.0601629 & 0.0644064 & $7.05 \%$ & 0.187518 & 0.193783 & $3.34 \%$ \\
$G_{m, \mathrm{col}}$ & 0.240621 & 0.242344 & $0.716 \%$ & 0.392051 & 0.393502 & $0.37 \%$ \\
$G_{w, \mathrm{col}}$ & 0.131002 & 0.12084 & $-7.76 \%$ & 0.400299 & 0.370931 & $-7.34 \%$ \\
$y_{\mathrm{m} 1}$ & 42549.9 & 41471.4 & $-2.53 \%$ & 45833.3 & 46347.3 & $1.12 \%$ \\
$y_{\mathrm{m} 2}$ & 46013.6 & 46116. & $0.223 \%$ & 59531.3 & 59658.5 & $0.214 \%$ \\
$y_{\mathrm{m} 3}$ & 38934.8 & 40058.4 & $2.89 \%$ & 52070.5 & 52371.7 & $0.579 \%$ \\
$y_{\mathrm{w} 1}$ & 12664.9 & 12918.8 & $2.01 \%$ & 20453.6 & 21866.4 & $6.91 \%$ \\
$y_{\mathrm{w} 2}$ & 13050.4 & 15802.5 & $21.1 \%$ & 25514.7 & 28767.5 & $12.7 \%$ \\
$y_{\mathrm{w} 3}$ & 13429.7 & 12946.1 & $-3.6 \%$ & 27373.5 & 25741.2 & $-5.96 \%$ \\
$x_{\mathrm{w} 1}$ & 43941.9 & 42819.1 & $-2.56 \%$ & 48004.4 & 47777.3 & $-0.473 \%$ \\
$x_{\mathrm{w} 2}$ & 47304.5 & 45972.1 & $-2.82 \%$ & 62317.6 & 60849.6 & $-2.36 \%$ \\
$x_{\mathrm{w} 3}$ & 37059.8 & 39648.9 & $6.99 \%$ & 52485. & 54120.2 & $3.12 \%$ \\
average & $->$ & $->$ & $3.81 \%$ & $->$ & $->$ & $2.94 \%$
\end{tabular}

Table D6: Estimated parameters of the extended model, mandated states

\begin{tabular}{||l|l|l|l|l|l||} 
& $1930 \mathrm{~s}, \mathrm{M}$ & $1960 \mathrm{~s}, \mathrm{M}$ & & $1930 \mathrm{~s}, \mathrm{M}$ & $1960 \mathrm{~s}, \mathrm{M}$ \\
$F_{m}$ & $\operatorname{Beta}(0.0198,0.0821)$ & $\operatorname{Beta}(0.0233,0.0448)$ & $y_{\mathrm{mH}}$ & $\$ 64700.7$ & $\$ 89168.9$ \\
$F_{w}$ & $\operatorname{Beta}(0.00759,0.0748)$ & $\operatorname{Beta}(0.0161,0.0325)$ & $y_{\mathrm{mL}}$ & $\$ 37863.7$ & $\$ 34953$. \\
$c_{m}$ & $\$ 1893.18$ & $\$ 1747.65$ & $y_{\mathrm{wH}}$ & $\$ 32931.3$ & $\$ 43717.6$ \\
$c_{w}$ & $\$ 576.1$ & $\$ 795.52$ & $y_{\mathrm{wL}}$ & $\$ 11522$. & $\$ 15910.4$ \\
$s_{\mathrm{HH}}$ & $\$ 68279$. & $\$ 20532$. & $h_{\mathrm{mC} 1}$ & 0.313768 & 0.16701 \\
$s_{\mathrm{HL}}$ & $\$ 44160.9$ & $\$ 9067.66$ & $h_{\mathrm{mC} 2}$ & 0.999997 & 0.742094 \\
$s_{\mathrm{Hh}}$ & $\$ 41450.1$ & $\$ 19328.8$ & $h_{\mathrm{mN} 1}$ & 0.495628 & 0.339463 \\
$s_{\mathrm{H} 1}$ & $\$ 45358.4$ & $\$ 10326.6$ & $h_{\mathrm{mN} 2}$ & 0.7824 & 0.62995 \\
$s_{\mathrm{LH}}$ & $\$ 22639.5$ & $\$ 2409.42$ & $h_{\mathrm{wC} 1}$ & 0.506763 & 0.269031 \\
$s_{\mathrm{LL}}$ & $\$ 20218.5$ & $\$ 399.895$ & $h_{\mathrm{wC} 2}$ & 0.973855 & 0.747071 \\
$s_{\mathrm{Lh}}$ & $\$ 0$. & $\$ 0$. & $h_{\mathrm{wN} 1}$ & 0.743135 & 0.501879 \\
$s_{\mathrm{L} 1}$ & $\$ 20815.7$ & $\$ 3742.54$ & $h_{\mathrm{wN} 2}$ & 0.783044 & 0.670358
\end{tabular}

Figure D3: Estimated CDF and PDF of abilities in the extended model, mandated
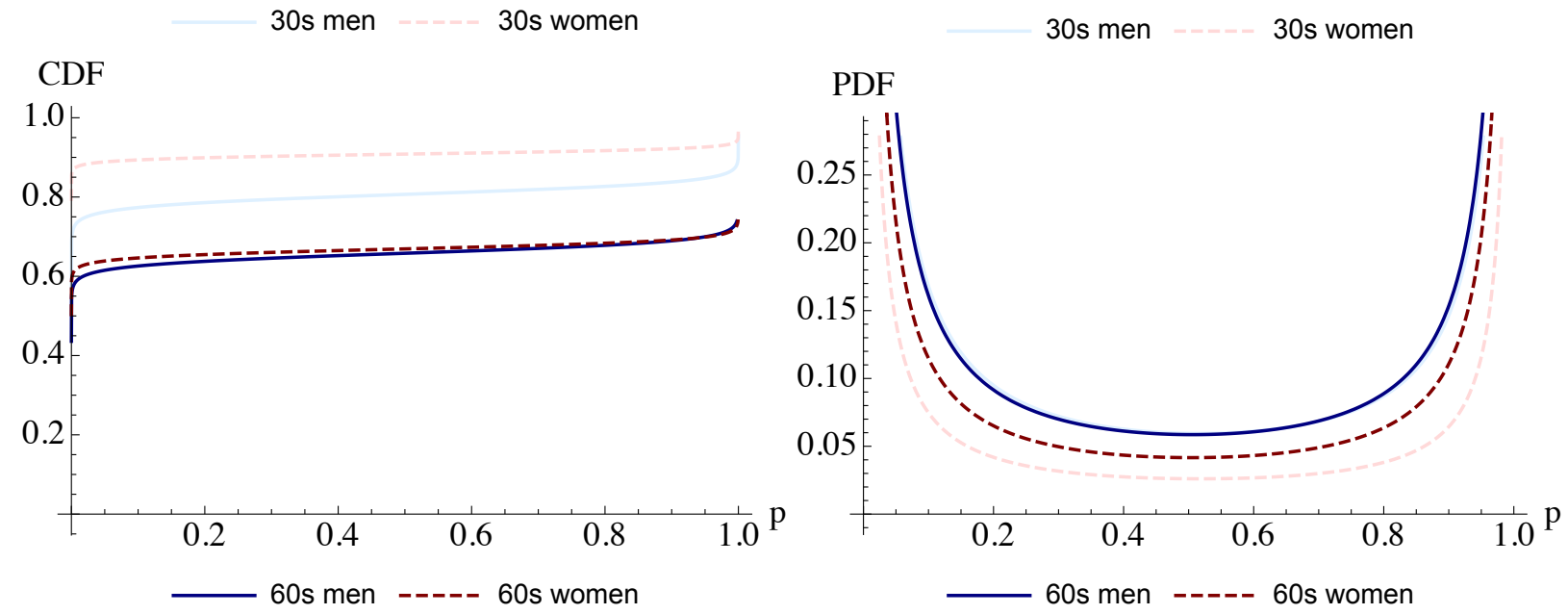

D6 
Table D7: Fit of the extended model, nonmandated states

\begin{tabular}{||l|l|l|l|l|l|l||} 
moments & 30 s target & 30 s model & difference & 60 s target & 60 s model & difference \\
$G_{\mathrm{m} 1}$ & 0.50978 & 0.509501 & $-0.0549 \%$ & 0.334886 & 0.334418 & $-0.14 \%$ \\
$G_{\mathrm{m} 2}$ & 0.39688 & 0.397736 & $0.216 \%$ & 0.443119 & 0.444872 & $0.396 \%$ \\
$G_{\mathrm{m} 3}$ & 0.0933392 & 0.0927631 & $-0.617 \%$ & 0.221995 & 0.220711 & $-0.578 \%$ \\
$G_{\mathrm{w} 1}$ & 0.762457 & 0.762457 & $0.000022 \%$ & 0.480704 & 0.485707 & $1.04 \%$ \\
$G_{\mathrm{w} 2}$ & 0.190972 & 0.190905 & $-0.0353 \%$ & 0.363829 & 0.354892 & $-2.46 \%$ \\
$G_{\mathrm{w} 3}$ & 0.0465706 & 0.0466378 & $0.144 \%$ & 0.155467 & 0.159401 & $2.53 \%$ \\
$G_{m, \mathrm{col}}$ & 0.202083 & 0.203549 & $0.725 \%$ & 0.370287 & 0.373063 & $0.75 \%$ \\
$G_{w, \mathrm{col}}$ & 0.11022 & 0.110219 & $-0.000626 \%$ & 0.382188 & 0.36033 & $-5.72 \%$ \\
$y_{\mathrm{m} 1}$ & 38631.7 & 38140.6 & $-1.27 \%$ & 43787.7 & 43444.2 & $-0.785 \%$ \\
$y_{\mathrm{m} 2}$ & 42012. & 42087.2 & $0.179 \%$ & 53959.1 & 54176.3 & $0.402 \%$ \\
$y_{\mathrm{m} 3}$ & 36009.2 & 36372.9 & $1.01 \%$ & 44997. & 45506. & $1.13 \%$ \\
$y_{\mathrm{w} 1}$ & 11606.5 & 11253.5 & $-3.04 \%$ & 19854. & 20950. & $5.52 \%$ \\
$y_{\mathrm{w} 2}$ & 11913. & 12196.3 & $2.38 \%$ & 23871.3 & 26551.5 & $11.2 \%$ \\
$y_{\mathrm{w} 3}$ & 12345.8 & 11857.2 & $-3.96 \%$ & 24881.1 & 22856.7 & $-8.14 \%$ \\
$x_{\mathrm{w} 1}$ & 39414. & 39452.6 & $0.0979 \%$ & 44926.9 & 43993.5 & $-2.08 \%$ \\
$x_{\mathrm{w} 2}$ & 43434.5 & 40533.2 & $-6.68 \%$ & 55639.5 & 55561.4 & $-0.14 \%$ \\
$x_{\mathrm{w} 3}$ & 34045.4 & 36624.4 & $7.58 \%$ & 45155.8 & 47599.5 & $5.41 \%$ \\
average & $->$ & $->$ & $1.65 \%$ & $->$ & $->$ & $2.85 \%$
\end{tabular}

Table D8: Estimated parameters of the extended model, nonmandated states

\begin{tabular}{||l|l|l|l|l|l||} 
& $1930 \mathrm{~s}, \mathrm{~N}$ & $1960 \mathrm{~s}, \mathrm{~N}$ & & $1930 \mathrm{~s}, \mathrm{~N}$ & $1960 \mathrm{~s}, \mathrm{~N}$ \\
$F_{m}$ & $\operatorname{Beta}(0.00898,0.0446)$ & $\operatorname{Beta}(0.0266,0.0573)$ & $y_{\mathrm{mH}}$ & $\$ 60887.7$ & $\$ 80024.9$ \\
$F_{w}$ & $\operatorname{Beta}(0.0137,0.345)$ & $\operatorname{Beta}(0.0218,0.0475)$ & $y_{\mathrm{mL}}$ & $\$ 35109.9$ & $\$ 33291.1$ \\
$c_{m}$ & $\$ 1755.49$ & $\$ 1664.55$ & $y_{\mathrm{wH}}$ & $\$ 29956.6$ & $\$ 38397.4$ \\
$c_{w}$ & $\$ 536.37$ & $\$ 799.952$ & $y_{\mathrm{wL}}$ & $\$ 10727.4$ & $\$ 15999$. \\
$s_{\mathrm{HH}}$ & $\$ 680119$. & $\$ 51.9573$ & $h_{\mathrm{mC} 1}$ & 0.357464 & 0.228529 \\
$s_{\mathrm{HL}}$ & $\$ 450406$. & $\$ 21.5937$ & $h_{\mathrm{mC} 2}$ & 0.999821 & 0.814503 \\
$s_{\mathrm{Hh}}$ & $\$ 413637$. & $\$ 40.9345$ & $h_{\mathrm{mN} 1}$ & 0.548357 & 0.397427 \\
$s_{\mathrm{Hl}}$ & $\$ 488232$. & $\$ 21.8796$ & $h_{\mathrm{mN} 2}$ & 0.806424 & 0.65134 \\
$s_{\mathrm{LH}}$ & $\$ 266926$. & $\$ 10.6494$ & $h_{\mathrm{wC} 1}$ & 0.546306 & 0.339304 \\
$s_{\mathrm{LL}}$ & $\$ 217798$. & $\$ 0$. & $h_{\mathrm{wC} 2}$ & 0.841826 & 0.807382 \\
$s_{\mathrm{Lh}}$ & $\$ 0$. & $\$ 1.41243$ & $h_{\mathrm{wN} 1}$ & 0.789233 & 0.568177 \\
$s_{\mathrm{L} 1}$ & $\$ 200257$. & $\$ 6.3891$ & $h_{\mathrm{wN} 2}$ & 0.79349 & 0.679492
\end{tabular}

Figure D4: Estimated CDF and PDF of abilities in the extended model, nonmandated
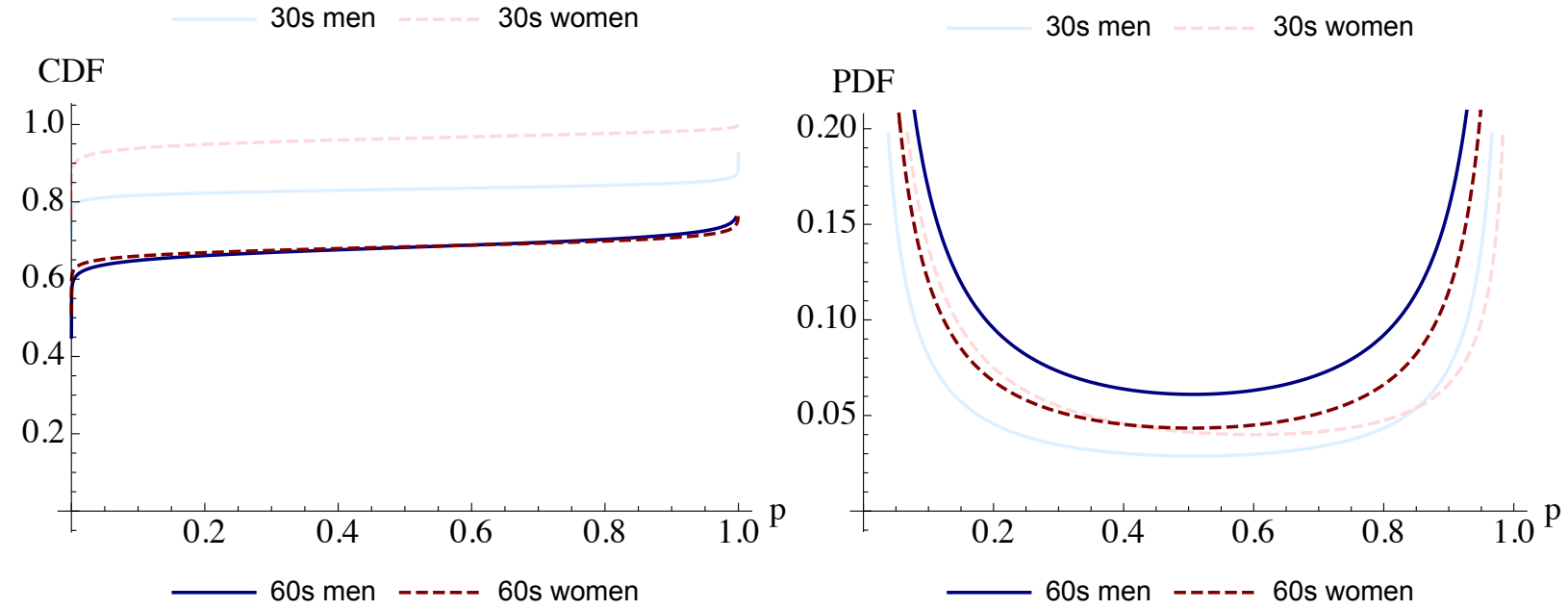

D7 
Table D9: Counterfactual $M \rightarrow N$. Mandated States Stay Nonmandated

\begin{tabular}{|c|c|c|c|c|}
\hline moment & note & calibrated & counterfactual & percent change \\
\hline$G_{\mathrm{m} 1}$ & fraction of early grooms & 0.271602 & 0.271591 & -0.00423343 \\
\hline$G_{\mathrm{m} 2}$ & fraction of middle grooms & 0.463643 & 0.463617 & -0.00573727 \\
\hline$G_{\mathrm{m} 3}$ & fraction of late grooms & 0.264754 & 0.264792 & 0.0143901 \\
\hline$G_{\mathrm{w} 1}$ & fraction of early brides & 0.415509 & 0.486025 & 16.971 \\
\hline$G_{\mathrm{w} 2}$ & fraction of middle brides & 0.390709 & 0.344268 & -11.8863 \\
\hline$G_{\mathrm{w} 3}$ & fraction of late brides & 0.193783 & 0.169708 & -12.4238 \\
\hline$G_{m, \mathrm{col}}$ & fraction of college men & 0.393502 & 0.393569 & 0.0169436 \\
\hline$G_{w, \mathrm{col}}$ & fraction of college women & 0.370931 & 0.358943 & -3.23186 \\
\hline$y_{\mathrm{m} 1}$ & avg inc of early grooms & 46347.3 & 46347.8 & 0.0011738 \\
\hline$y_{\mathrm{m} 2}$ & avg inc of middle grooms & 59658.5 & 59660. & 0.00260003 \\
\hline$y_{\mathrm{m} 3}$ & avg inc of late grooms & 52371.7 & 52369.6 & -0.0040448 \\
\hline$y_{\mathrm{w} 1}$ & avg inc of early brides & 21866.4 & 22052.5 & 0.850921 \\
\hline$y_{\mathrm{w} 2}$ & avg inc of middle brides & 28767.5 & 28524.5 & -0.844894 \\
\hline$y_{\mathrm{w} 3}$ & avg inc of late brides & 25741.2 & 25709.2 & -0.124429 \\
\hline$x_{\mathrm{w} 1}$ & avg spousal inc of early brides & 47777.3 & 49171.5 & 2.918 \\
\hline$x_{\mathrm{w} 2}$ & avg spousal inc of middle brides & 60849.6 & 61119.7 & 0.443882 \\
\hline$x_{\mathrm{w} 3}$ & avg spousal inc of late brides & 54120.2 & 54057.8 & -0.115388 \\
\hline
\end{tabular}

Table D10: Counterfactual $\mathbf{N} \rightarrow \mathbf{M}$. Nonmandated States Become Mandated

\begin{tabular}{||l|l} 
moment & description \\
$G_{\mathrm{m} 1}$ & fraction of early grooms \\
$G_{\mathrm{m} 2}$ & fraction of middle grooms \\
$G_{\mathrm{m} 3}$ & fraction of late grooms \\
$G_{\mathrm{w} 1}$ & fraction of early brides \\
$G_{\mathrm{w} 2}$ & fraction of middle brides \\
$G_{\mathrm{w} 3}$ & fraction of late brides \\
$G_{m, \mathrm{col}}$ & fraction of college men \\
$G_{w, \mathrm{col}}$ & fraction of college women \\
$y_{\mathrm{m} 1}$ & avg inc of early grooms \\
$y_{\mathrm{m} 2}$ & avg inc of middle grooms \\
$y_{\mathrm{m} 3}$ & avg inc of late grooms \\
$y_{\mathrm{w} 1}$ & avg inc of early brides \\
$y_{\mathrm{w} 2}$ & avg inc of middle brides \\
$y_{\mathrm{w} 3}$ & avg inc of late brides \\
$x_{\mathrm{w} 1}$ & avg spousal inc of early brides \\
$x_{\mathrm{w} 2}$ & avg spousal inc of middle brides \\
$x_{\mathrm{w} 3}$ & avg spousal inc of late brides
\end{tabular}

\begin{tabular}{l|l|l||} 
calibrated & counterfactual & percent change \\
0.334418 & 0.33459 & 0.0514688 \\
0.444872 & 0.445255 & 0.0861058 \\
0.220711 & 0.220155 & -0.251542 \\
0.485707 & 0.415194 & -14.5176 \\
0.354892 & 0.403018 & 13.5607 \\
0.159401 & 0.181788 & 14.0447 \\
0.373063 & 0.372044 & -0.273165 \\
0.36033 & 0.372282 & 3.31698 \\
43444.2 & 43438.1 & -0.0140087 \\
54176.3 & 54156.6 & -0.0364412 \\
45506. & 45531.6 & 0.0563763 \\
20950. & 20800.6 & -0.713539 \\
26551.5 & 26748.1 & 0.740465 \\
22856.7 & 22872.5 & 0.0691212 \\
43993.5 & 42686.1 & -2.97182 \\
55561.4 & 55306.3 & -0.459177 \\
47599.5 & 47632.5 & 0.0692529
\end{tabular}


Table D10 shows counterfactual effects of mandates in the nonmandated states. The mandate would (1) increase the fraction of late brides from 15.9 percent to 18.2 percent and decrease the fraction of early brides from 48.6 percent to 41.5 percent, (2) increase the fraction of women attending college from 36 percent to 37.2 percent, and (3) decrease the average spousal income of early brides by 2.97 percent and slightly increase the average spousal income of late brides.

\section{D.4 Gender Equality Analyses}

I conduct three counterfactual analyses on the 1960s birth cohort to investigate the effects of gender equality on women's marriage timing, college, income, and marital outcome.

First, I consider the possibility that differential fecundity is completely eradicated. Namely, women are distinguished by income just like men are, regardless of age. Table D11 shows the results. In equilibrium, 4.95 percent of women would switch from marrying between ages 23 and 29 to marrying between ages 30 and 39. The college investment is not affected directly. The average income of middle brides increases by 5.43 percent and that of late brides decreases by 3.61 percent, making the relationship between age at marriage and income for more hump-shaped like the relationship for men. The average spousal income of middle brides increases by 3.27 percent because the average income of middle brides increases. The average spousal income of late brides increases despite of a lower average personal income, because fertility is not a concern in the marriage market in this counterfactual environment.

\section{Table D11: Counterfactual 1. Equalized Fecundity}

\begin{tabular}{||l|l|l|l|l||} 
moment & note & calibrated & counterfactual & percent change \\
$G_{\mathrm{w} 1}$ & fraction of early brides & 0.449534 & 0.449534 & 0 \\
$G_{\mathrm{w} 2}$ & fraction of middle brides & 0.380081 & 0.330948 & -12.9269 \\
$G_{\mathrm{w} 3}$ & fraction of late brides & 0.170385 & 0.219518 & 28.8361 \\
$G_{w, \mathrm{col}}$ & fraction of college women & 0.389479 & 0.389479 & 0 \\
$y_{\mathrm{w} 1}$ & avg inc of early brides & 20510. & 20510. & 0 \\
$y_{\mathrm{w} 2}$ & avg inc of middle brides & 25169.9 & 26537. & 5.43158 \\
$y_{\mathrm{w} 3}$ & avg inc of late brides & 24207.1 & 23332.3 & -3.61388 \\
$x_{\mathrm{w} 1}$ & avg spousal inc of early brides & 47051.6 & 46073.3 & -2.07922 \\
$x_{\mathrm{w} 2}$ & avg spousal inc of middle brides & 55594.8 & 57414.3 & 3.27287 \\
$x_{\mathrm{w} 3}$ & avg spousal inc of late brides & 50699.8 & 51384.1 & 1.3497
\end{tabular}

Second, I consider the equalization of labor-market opportunities. Suppose women earn as much as men and pay the same investment costs as men. Table D12 shows the results. The fraction of women marrying between ages 23 and 29 would decrease from 38 percent to 36.89 percent. Of this 1.11 percent, 0.2 percent would choose to marry earlier and 0.91 percent would choose to marry later. The fraction of early brides would slightly increase because the fraction of women attending college would decrease from 38.9 percent to 38.3 percent and some of them would choose to marry early. Average spousal income of early brides would decrease, that of middle brides would increase by 0.68 percent, and that of late brides would increase by 0.37 percent. 
Table D12: Counterfactual 2. Equalized Labor-Market Opportunities

\begin{tabular}{||l|l|l|l|l||} 
moment & note & calibrated & counterfactual & percent change \\
$G_{\mathrm{w} 1}$ & fraction of early brides & 0.449534 & 0.451106 & 0.349743 \\
$G_{\mathrm{w} 2}$ & fraction of middle brides & 0.380081 & 0.368892 & -2.94383 \\
$G_{\mathrm{w} 3}$ & fraction of late brides & 0.170385 & 0.180002 & 5.6441 \\
$G_{w, \text { col }}$ & fraction of college women & 0.389479 & 0.382699 & -1.74082 \\
$y_{\mathrm{w} 1}$ & avg inc of early brides & 20510. & 43183.8 & 110.55 \\
$y_{\mathrm{w} 2}$ & avg inc of middle brides & 25169.9 & 53199.7 & 111.363 \\
$y_{\mathrm{w} 3}$ & avg inc of late brides & 24207.1 & 50888.1 & 110.219 \\
$x_{\mathrm{w} 1}$ & avg spousal inc of early brides & 47051.6 & 46851.4 & -0.425445 \\
$x_{\mathrm{w} 2}$ & avg spousal inc of middle brides & 55594.8 & 55970.4 & 0.675739 \\
$x_{\mathrm{w} 3}$ & avg spousal inc of late brides & 50699.8 & 50888.1 & 0.371288
\end{tabular}

Third, I consider equalization of investment opportunities. Namely, suppose the ability distribution of women would be just like that of men in the model. Table D13 shows the results. In equilibrium, the fraction of women going to college would decrease and the fraction of women choosing to marry later would also decrease. The average incomes would increase, however. Average spousal income of middle and late brides would increase by 1.85 and 3.66 percent, respectively. The fact that women's college enrollment would decrease is in line with the empirical finding that women's higher average non-cognitive skills result in a higher college enrollment for them. If women's ability distribution is fixed to be the same as men's, college enrollment would decrease.

Table D13: Counterfactual 3. Equalized Investment Opportunities

\begin{tabular}{||l|l|l|l|l||} 
moment & note & calibrated & counterfactual & percent change \\
$G_{\mathrm{w} 1}$ & fraction of early brides & 0.449534 & 0.450571 & 0.230603 \\
$G_{\mathrm{w} 2}$ & fraction of middle brides & 0.380081 & 0.386639 & 1.72554 \\
$G_{\mathrm{w} 3}$ & fraction of late brides & 0.170385 & 0.16279 & -4.45758 \\
$G_{w, \mathrm{col}}$ & fraction of college women & 0.389479 & 0.385009 & -1.14781 \\
$y_{\mathrm{w} 1}$ & avg inc of early brides & 20510. & 21497.3 & 4.8139 \\
$y_{\mathrm{w} 2}$ & avg inc of middle brides & 25169.9 & 27003.9 & 7.28675 \\
$y_{\mathrm{w} 3}$ & avg inc of late brides & 24207.1 & 25124.9 & 3.79132 \\
$x_{\mathrm{w} 1}$ & avg spousal inc of early brides & 47051.6 & 45589.5 & -3.1075 \\
$x_{\mathrm{w} 2}$ & avg spousal inc of middle brides & 55594.8 & 56621.3 & 1.84653 \\
$x_{\mathrm{w} 3}$ & avg spousal inc of late brides & 50699.8 & 52556.2 & 3.66142
\end{tabular}

\section{References in Appendix D}

Bruze, Gustaf, "Male and Female Marriage Returns to Schooling," International Economic Review, February 2015, 56 (1), 207-234.

Coles, Melvyn G. and Marco Francesconi, "Equilibrium Search and the Impact of Equal Opportunities for Women," June 2017. IZA DP No. 10827.

_ and _, "Equilibrium Search with Multiple Attributes and the Impact of Equal Opportunities for Women," Journal of Political Economy, 2018. 


\section{Online Appendix}

\section{E Figures with Total Income Instead of Labor Income}

Figure E1 shows the relationships between age at marriage and total income (instead of labor income). Figure E2 shows the total income differences between different age-at-marriage groups birth-year by birth-year. Figure E3 shows the various measures of average personal and spousal total income in mandated versus nonmandated states.

Figure E1: Stylized facts with total income

(a) Relationships between age at marriage and midlife total income for men and women

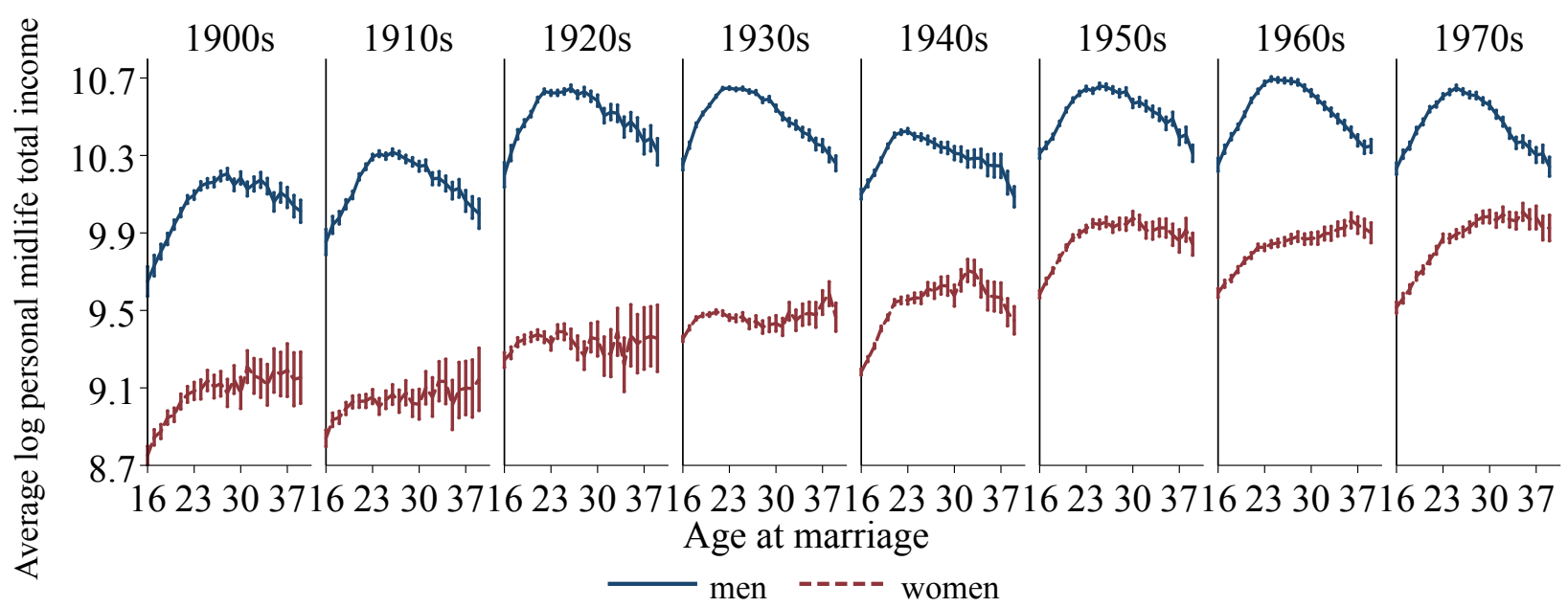

(b) Relationship between age at marriage and spousal total income for women

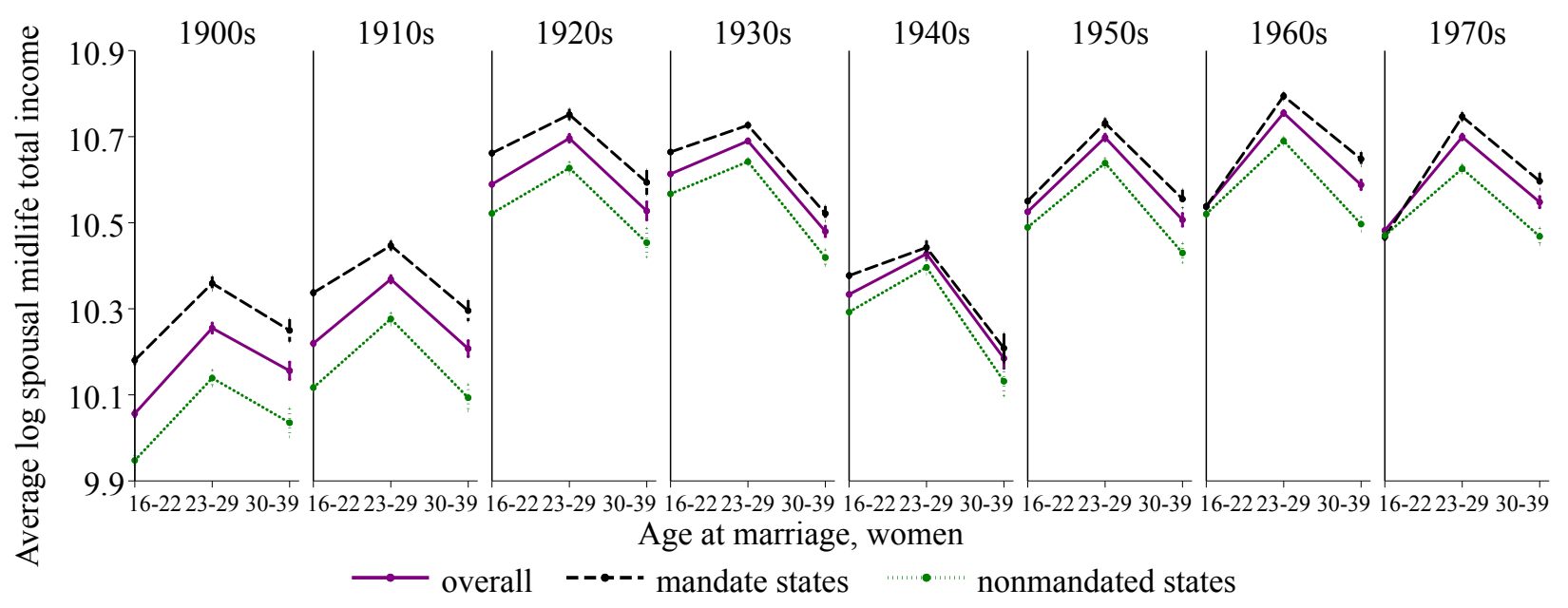


Figure E2: Average total income differences between age-at-marriage groups, by birth year (a) Average log midlife total income difference from middle grooms

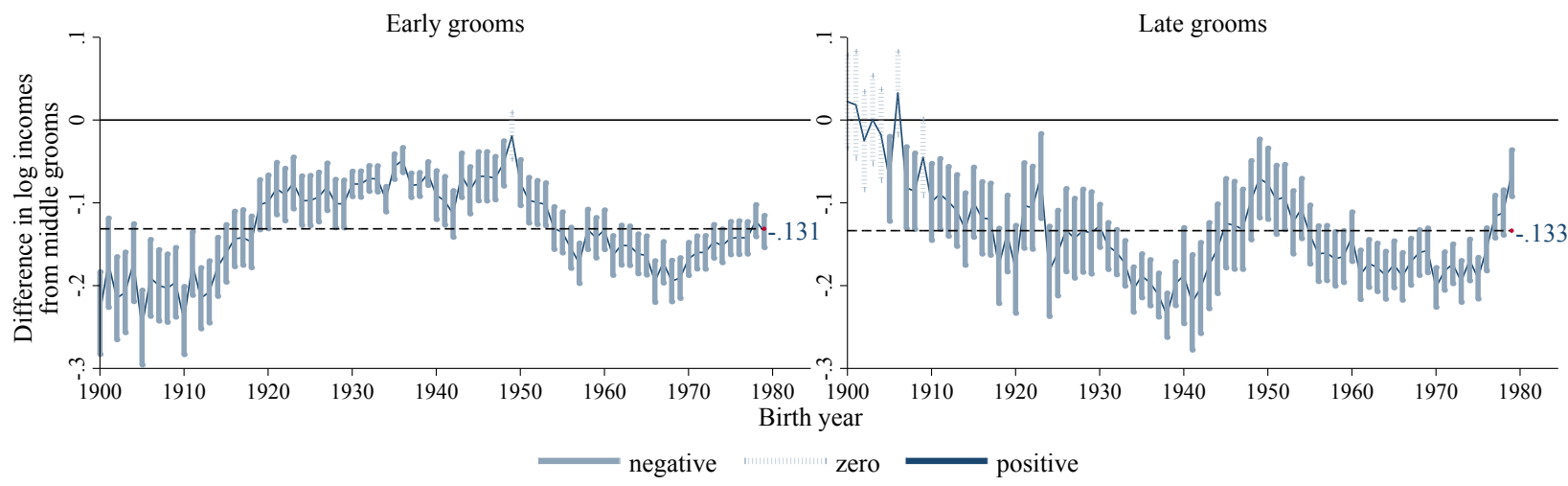

(b) Average log midlife total income difference from middle brides

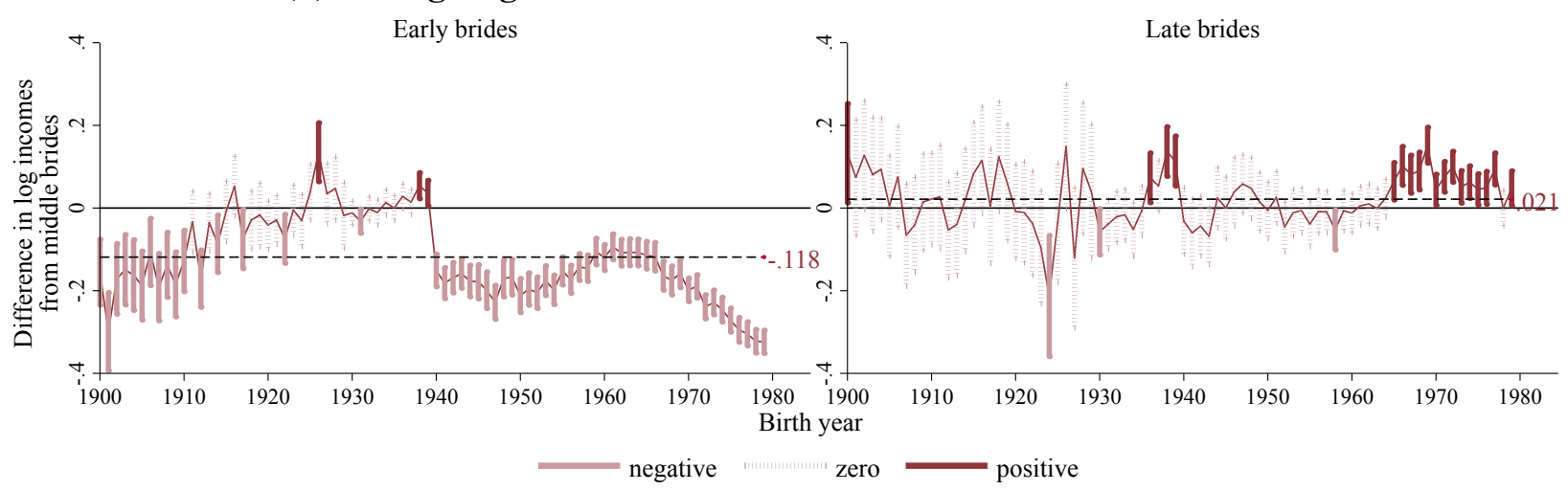

(c) Average log spousal total income difference from middle brides

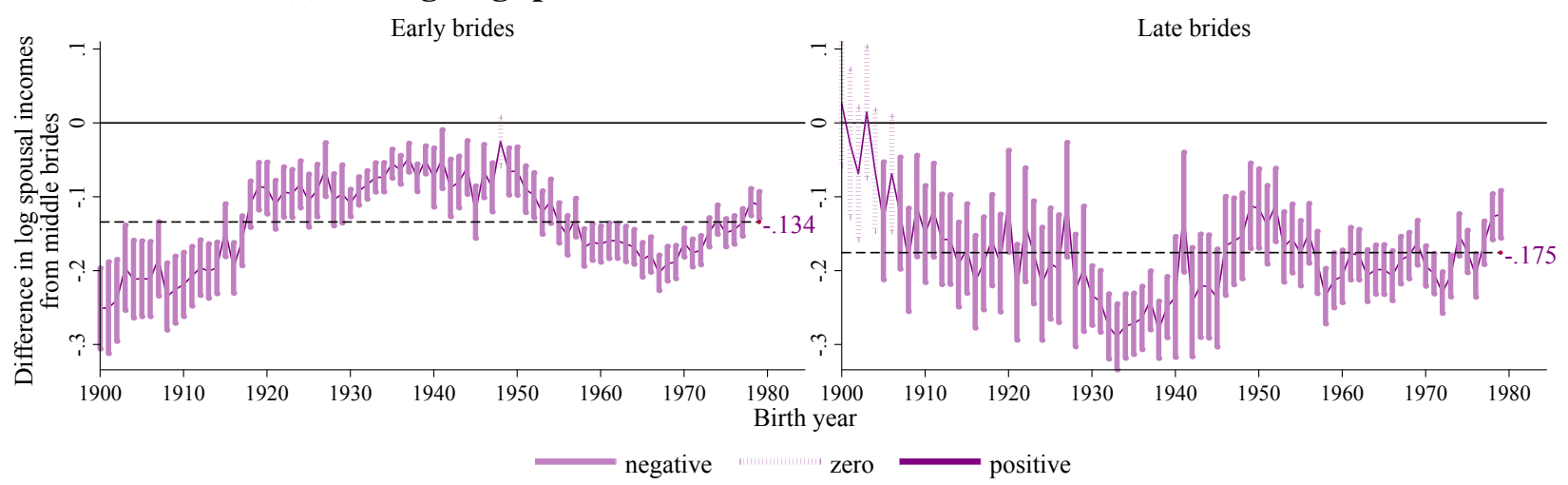

(d) Average spousal total income difference between early and late brides

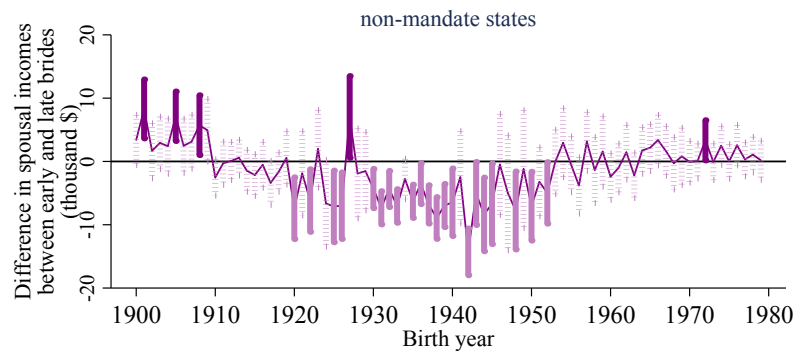

Average income of men with early brides significantly higher Average income of men with late brides significantly higher Average incomes of the two groups not significantly different

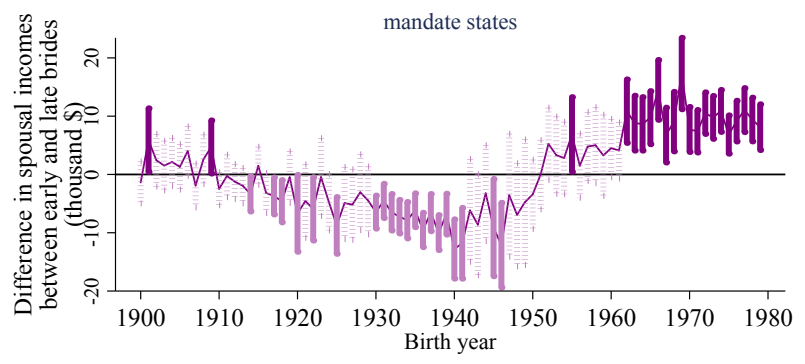

Average income of men with early brides significantly higher Average income of men with late brides significantly higher Average incomes of the two groups not significantly different 


\section{Figure E3: Total income and education in mandated versus nonmandated states}

(a) Spousal total income percentile rank by birth year

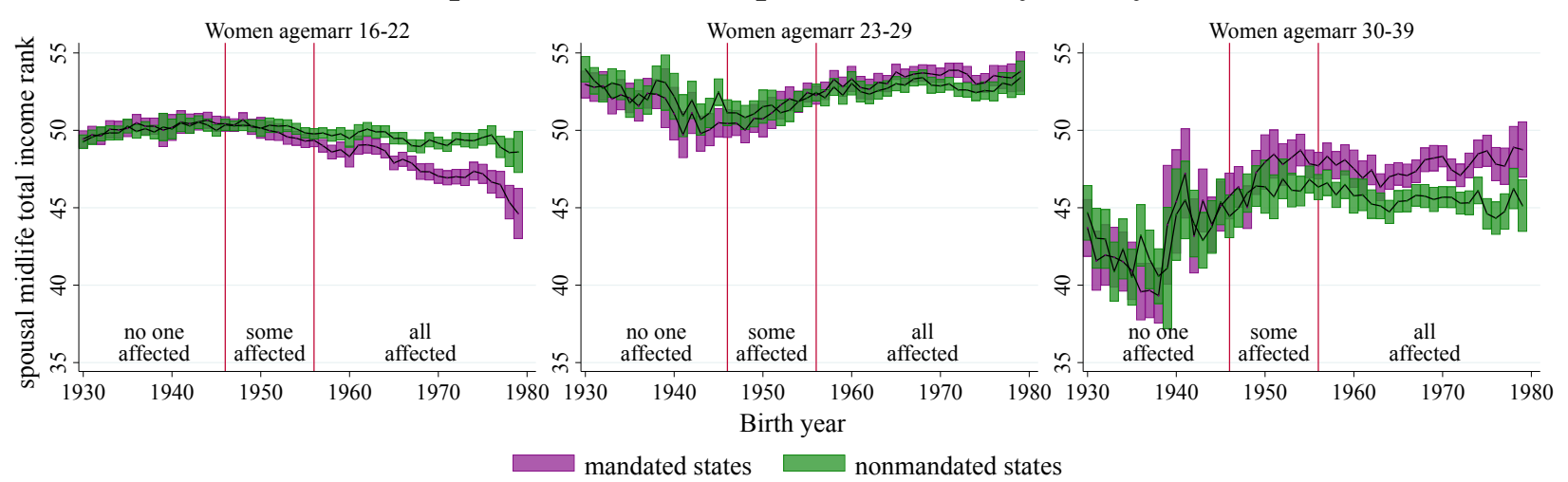

(b) Spousal total income z-score by birth year

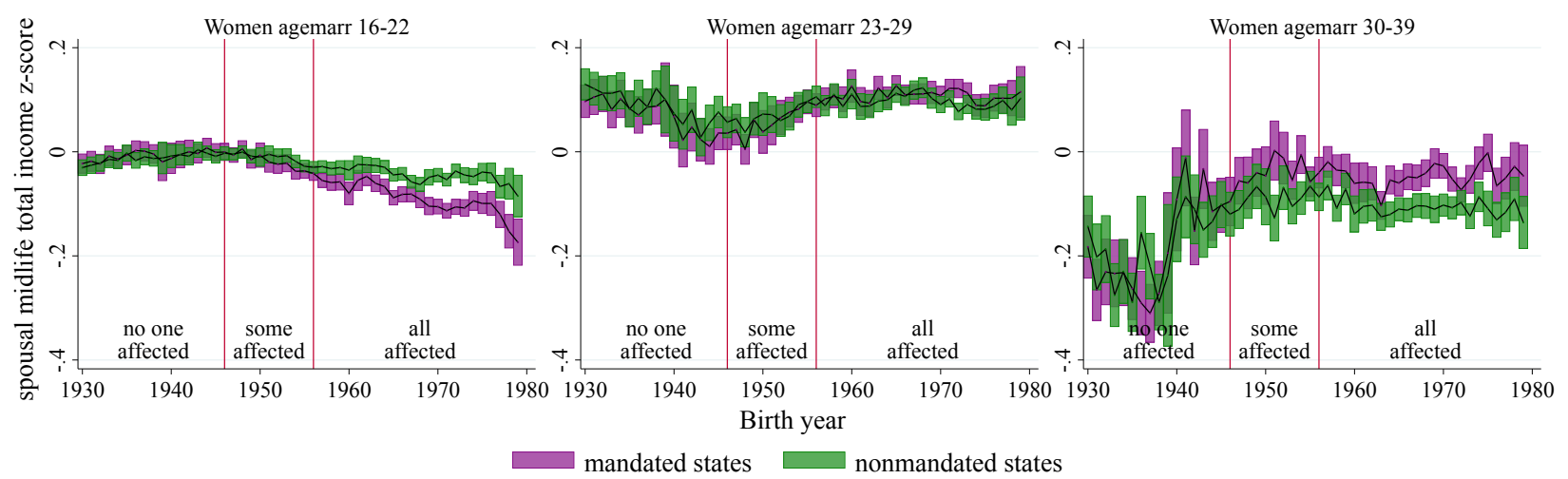

(c) Spousal total income by birth year

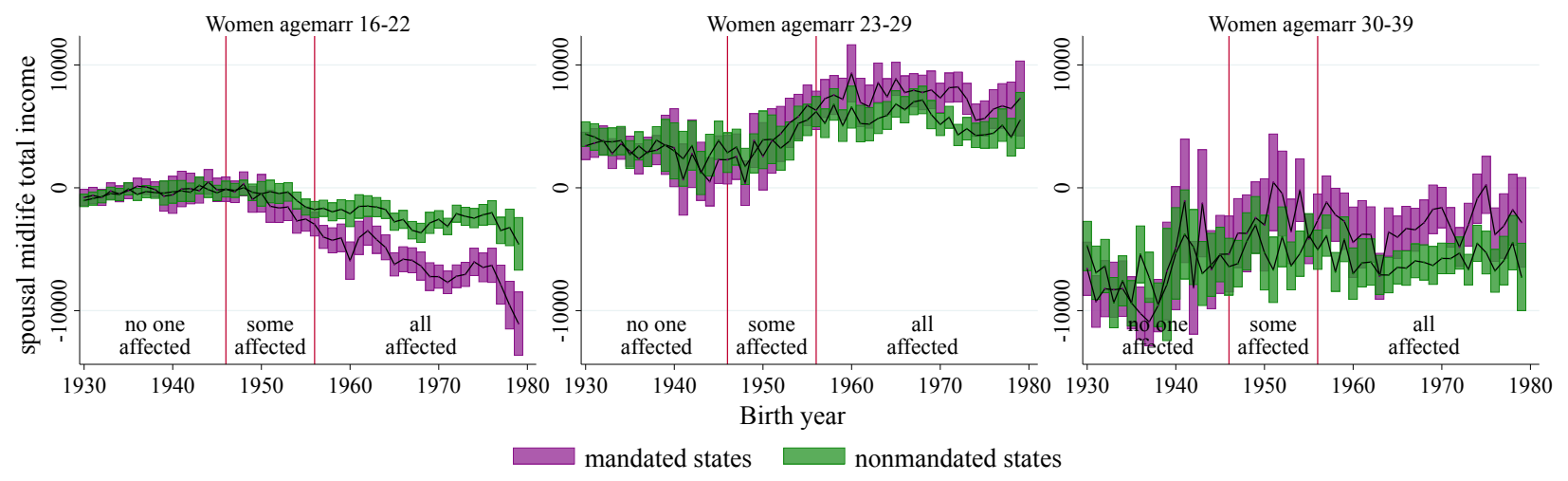

(d) Personal total income percentile rank by birth year

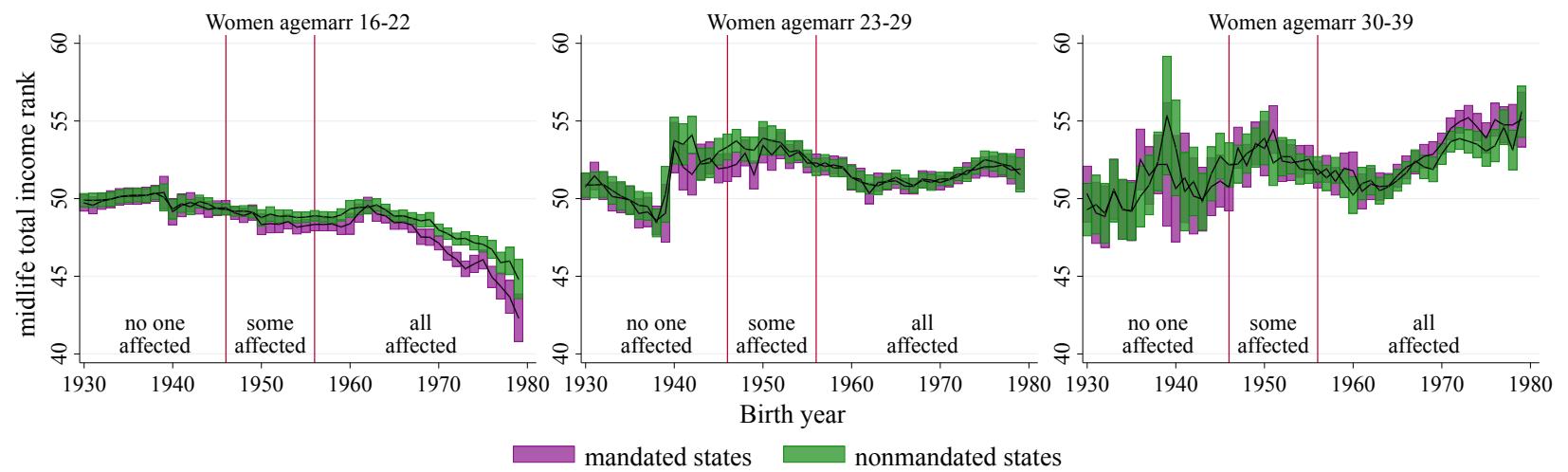

